This item was submitted to Loughborough's Research Repository by the author.

Items in Figshare are protected by copyright, with all rights reserved, unless otherwise indicated.

\title{
Powering future body sensor network systems: A review of power sources
}

PLEASE CITE THE PUBLISHED VERSION

https://doi.org/10.1016/j.bios.2020.112410

PUBLISHER

Elsevier

VERSION

AM (Accepted Manuscript)

PUBLISHER STATEMENT

This paper was accepted for publication in the journal Biosensors and Bioelectronics and the definitive published version is available at https://doi.org/10.1016/j.bios.2020.112410

\section{LICENCE}

CC BY-NC-ND 4.0

\section{REPOSITORY RECORD}

Wang, Y, H Wang, Jin Xuan, and DYC Leung. 2020. "Powering Future Body Sensor Network Systems: A Review of Power Sources". Loughborough University. https://hdl.handle.net/2134/12932808.v1. 


\title{
Powering future body sensor network systems: A review of power sources
}

Yifei Wang $^{\mathrm{a} *}$, Huizhi Wang ${ }^{\mathrm{b}}$, Jin Xuan $^{\mathrm{c}}$, Dennis Y.C. Leung ${ }^{\mathrm{a} *}$

${ }^{a}$ Department of Mechanical Engineering, the University of Hong Kong, Hong Kong, China

${ }^{b}$ Department of Mechanical Engineering, Imperial College London, London, United Kingdom

${ }^{\mathrm{c}}$ Department of Chemical Engineering, Loughborough University, Loughborough, United Kingdom

*Corresponding author: Dennis Y.C. Leung, Yifei Wang

Tel: (852) 39177911

Fax: (852) 28585415

Email: ycleung@hku.hk, wang1fei@connect.hku.hk

\begin{abstract}
Body sensor network is a promising medical technology to address the overwhelming global aging issue, which requires advanced micro power sources with high energy density, long lifetime, small form factor and good biocompatibility. Potential micro power technologies include batteries, fuel cells, energy harvesters and supercapacitors, each of which have their own merits and demerits when applied in the body sensor network. Batteries such as dry battery and Li ion battery are currently the most mature product which has been extensively employed in the body sensor network research, but the improvement of their energy density is relatively sluggish due to the cumbersome material storage. On the contrary, micro fuel cells can achieve much higher energy density because of their lightweight fuel and oxidant, which can be refueled instantly when applied in wearable sensors. For implanted devices, both abiotic and biotic fuel cells can utilize the dissolved glucose in the body fluid as the fuel. As for energy harvesters, they can receive energy from both the external environment such as solar and radiofrequency, and the human body itself such as body heat and motion. Finally, supercapacitor is an effective energy storage component especially for energy harvesters, which can achieve excellent cycle stability. In general, the selection of micro power sources for the body sensor network should consider the specific requirement from the specific sensor node, so that a body sensor network with hybrid power supply is much more reliable than that with single type of energy supply. With the continuous development of different power technologies, the body sensor network is expected to
\end{abstract}


be more lightweight, unobtrusive and reliable, leading to a low-cost and ubiquitous healthcare in the near future.

\section{Keywords}

Body sensor network; body area network; battery; fuel cell; energy harvester; supercapacitor

\section{Abbreviations}

BAN: body area network

BSN: body sensor network

ECG: electrocardiograph

EEG: electroencephalograph

EMG: electromyography

MAC: medium access control

MEMS: micro electromechanical system

OCV: open circuit voltage

PBS: phosphate buffered saline

PDMS: Polydimethylsiloxane

PENG: piezoelectric nanogenerator

PPG: photoplethysmography

PVDF: Polyvinylidene Fluoride

PyENG: pyroelectric nanogenerators

RF: radiofrequency

RFID: radiofrequency identification

TEG: thermoelectric generator

TENG: triboelectric nanogenerator

WBAN: wireless body area network

\section{Introduction}

Aging of population has become a more and more austere challenge to the development of human society, which is especially the case for developed countries or regions such as U.S.A, Japan and Europe. According to human demography, it is predicted that the world's population 
of the elderly aged 65 and over will be doubled from 375 million in 1990 to 761 million in 2025 (Ullah et al. 2012), which will even account for $15 \%$ of the global population by the middle of this century (Xing and Zhu 2009). This overwhelming aging trend will bring unprecedented pressure and challenge to the current manpower-based healthcare system, which is not only resource-limited but also high-cost. Along with the trend of aging, chronic disease is another great challenge to the existing healthcare service. Unlike acute disease, chronic disease requires long-term and continuous monitoring, analysis and treatment, which consumes a large portion of the limited medical resources. For instance, published report indicates that cardiovascular diseases are the largest cause of global death (about 30\%) (Latré et al. 2011), while the number of diabetics all around the world will climb to 360 million by 2030 (Patel and Wang 2010). Other chronic diseases such as hypertension, asthma, Alzheimer's disease, Parkinson's disease and renal failure will all need continuous monitoring and timely treatment (Latré et al. 2011). To tackle this upcoming predicament in the healthcare sector, a novel type of device-based healthcare technology has been proposed recently, namely the body sensor network (Yang and Yang 2006). This technology enables autonomous, ubiquitous and cost-efficient monitoring of health status for those in need, which will become an important supplement and great relief to the current centralized and manpower-based healthcare in hospitals using expensive and bulky medical facilities (Yan et al. 2010).

Body sensor network (BSN), also well known as body area network (BAN) or wireless body area network (WBAN), is a radiofrequency-based wireless network technology which interconnects multiple sensor and actuator nodes on, in and around the human body (Barakah and Ammad-uddin 2012). With the help of these miniaturized sensors and actuators, a BSN system can measure, analyze and communicate vital signs of the human body, including temperature, blood pressure, blood glucose, electrocardiograph (ECG), electroencephalograph (EEG), electromyography (EMG), and so on. This physiological data is next transmitted to a local processing unit such as cell phone, or to medical personnel through the ubiquitous network. BSN technology aims at bringing about a revolutionary change to the current healthcare system based on ambulances, hospitals, clinics and medical personnel (Johny and Anpalagan 2014), leading to a low-cost, ubiquitous yet unobtrusive healthcare service in the near future. Furthermore, BSN has an even wider application prospect other than attending elderlies and chronics, including disability nursing (paraplegia, visually impaired, hearing impaired), post- 
surgical care (Aziz et al. 2006), public safety (fire-fighters, policemen), emergency response (Gao et al. 2008), sports and entertainment, and so on.

As shown in Fig. 1(a), a BSN system is mainly composed of multiple sensors either attached on the body surface (e.g., ECG, EEG, EMG, pulse oximeter and motion sensors) or implanted inside the body (e.g., glucose sensor, endoscope capsule), multiple actuators to respond to the sensor information (e.g., drug delivery, neuro stimulator), a gateway (also known as body control unit, e.g., cell phone or personal digital assistant) to collect the data from these sensors and connect to the external database server, and the external medical system. A BSN generally consists 20-50 nodes, most of which are sensor nodes (Latré et al. 2011). Table-1 summaries typical type of sensors in a BSN system, including their function, power requirement and targeted lifetime. In addition, their specific locations on/in human body are illustrated in Fig. 1(b). Moreover, Fig. 1(c) shows the structure of a typical BSN node, which is mainly composed of the sensor/actuator hardware, power source, processor, memory and transceiver. It can collect vital physiological signal from human body, digitize it into electrical signal, and then transmit it to other devices. A BSN node generally consumes $1-100 \mu \mathrm{W}$ in standby mode, and up to $30 \mathrm{~mW}$ in fully active mode (Patel and Wang 2010). Compared with data collection and processing, the energy consumption of a BSN node is mainly attributed to its data transmission process to the external gateway, which is at least an order of magnitude higher than the former (Jovanov and Milenkovic 2011; Su and Zhang 2009; Xing and Zhu 2009).

Research and development of BSN system has benefited greatly from the rapid growth of various technologies such as biosensor, low-power integrated circuit and wireless communication. The core of BSN includes sensing and monitoring, power-efficient transmission protocols, energy supply, system architecture design, routing and security issues, and so on (Chin et al. 2012). Among them, energy supply is the prerequisite for the functionality, reliability and autonomy of BSN system. Although there are already many reviews on BSN technology, their content is quite general while the discussion on energy supply is very brief without details. On the other hand, specific review works on suitable power sources for BSN is very scarce in literature. Heller reviewed three types of implantable micro batteries including the $\mathrm{Zn}-\mathrm{AgCl}$ battery, the $\mathrm{Zn}-\mathrm{O}_{2}$ battery and the glucose- $\mathrm{O}_{2}$ fuel cell in 2006 (Heller 2006). Wei and Liu summarized three types of battery/fuel cell technologies and various wireless recharging strategies for implantable medical devices in 2008 (Wei and Liu 2008). Nevertheless, a 
comprehensive and updated review of recent research progress on various potential BSN power sources has not been conducted to the best of our knowledge. Therefore, this review aims at providing an introduction to the existing research works that are specifically focused on developing suitable power sources for BSN systems. The article structure is arranged as follow. First of all, we will compare the wearable sensors and implantable sensors in order to clarify their different requirements on the associated power supply units (Section 2). Next, we will review four mainstream micro power sources for BSN systems (Section 3), including batteries (Section 3.1), fuel cells (Section 3.2), energy harvesters (Section 3.3) and the supercapacitor (Section 3.4). Their advantages and disadvantages are discussed in detail. Furthermore, a special form of wearable energy, the textile-based power sources, is also introduced (Section 3.5). Finally, conclusions are made on the selection of suitable micro power system for BSN, and an outlook on their future perspective is presented.

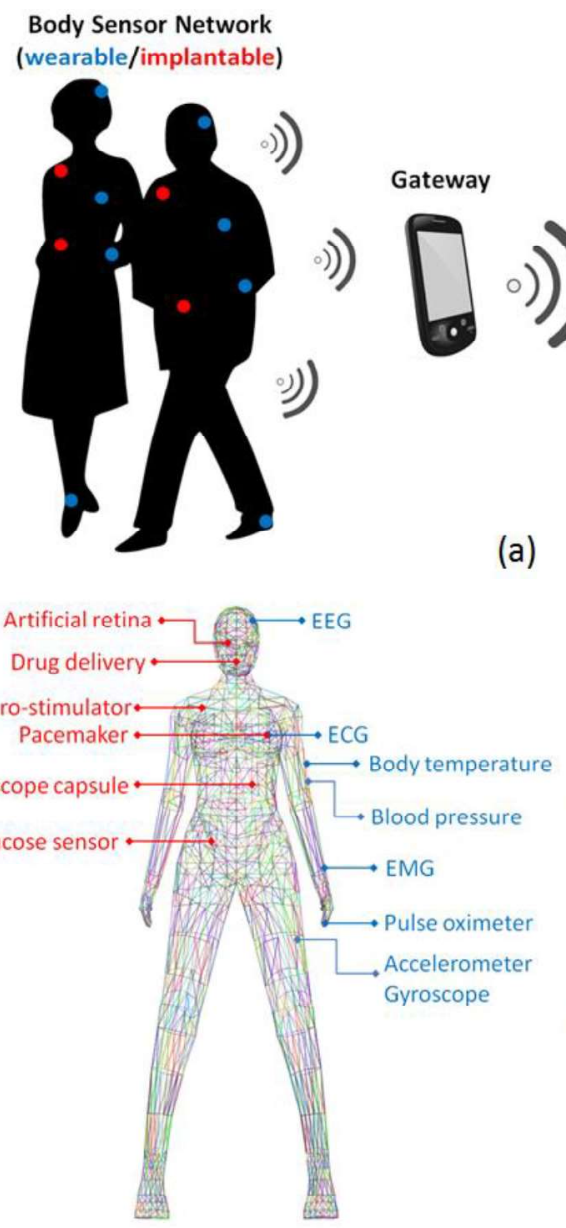

(b)
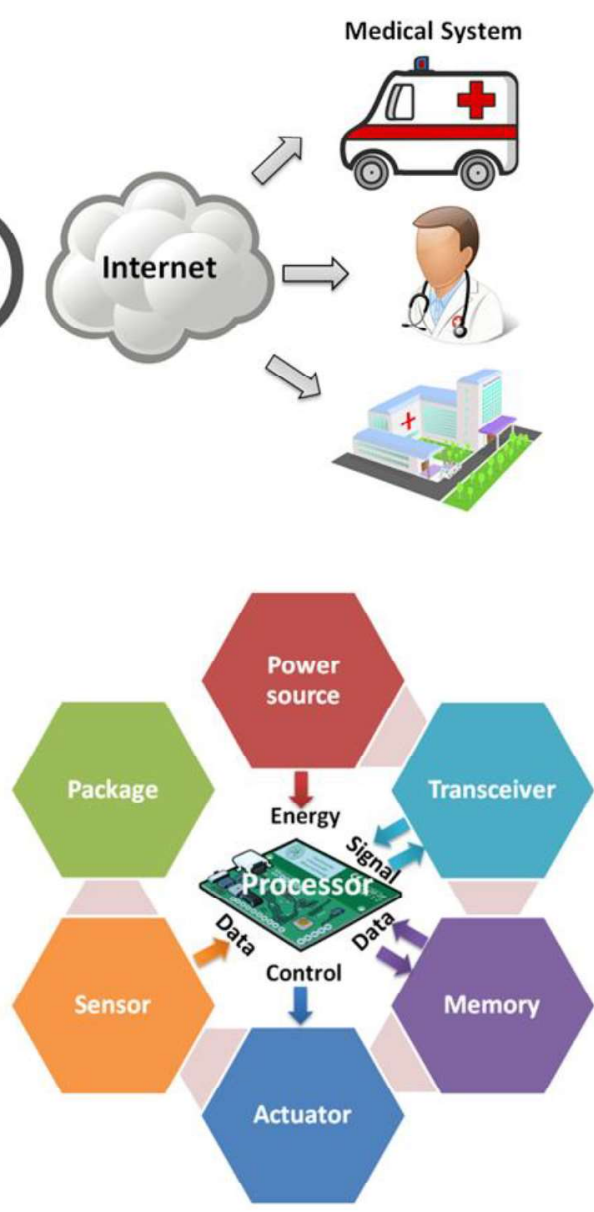

(c) 
Fig. 1 Schematic diagram of the body sensor network from system to single node: (a) A typical BSN system including end users, portable gateway, internet transmission and medical system; (b) Different types of sensor/actuator nodes in a BSN and their positions on/in human body; (c) Composition of a typical BSN node (free clip arts downloaded from openclipart.org).

Table 1 Typical type of sensors/actuators in a BSN system

\begin{tabular}{|c|c|c|c|c|}
\hline & Sensor type & Function & Power requirement & Lifetime \\
\hline \multirow{14}{*}{$\begin{array}{l}\text { Physiological } \\
\text { sensors }\end{array}$} & \multicolumn{4}{|c|}{ Wearable sensors/actuators } \\
\hline & ECG & $\begin{array}{l}\text { Monitoring the heart electrical } \\
\text { activity }\end{array}$ & Low & Weeks \\
\hline & EEG & $\begin{array}{l}\text { Monitoring the brain electrical } \\
\text { activity }\end{array}$ & Low & Weeks \\
\hline & EMG & $\begin{array}{l}\text { Monitoring the muscle } \\
\text { electrical activity }\end{array}$ & Low & Weeks \\
\hline & Pulse oximeter & $\begin{array}{l}\text { Monitoring } \mathrm{O}_{2} \text { concentration } \\
\text { in blood }\end{array}$ & Low & Weeks \\
\hline & Blood pressure sensor & Monitoring blood pressure & High & Weeks \\
\hline & $\begin{array}{l}\text { Body temperature } \\
\text { sensor }\end{array}$ & Monitoring body temperature & Low & Weeks \\
\hline & \multicolumn{4}{|c|}{ Implantable sensors/actuators } \\
\hline & Glucose sensor & $\begin{array}{l}\text { Monitoring glucose } \\
\text { concentration in blood }\end{array}$ & Extremely low & Years \\
\hline & Drug delivery & Deliver drugs to target area & Low & Years \\
\hline & $\begin{array}{l}\text { Cardiac defibrillator / } \\
\text { pacemaker }\end{array}$ & Correct cardiac arrhythmias & Low & Years \\
\hline & Neuro-stimulator & $\begin{array}{l}\text { Treatment of movement } \\
\text { disorders }\end{array}$ & Low & Years \\
\hline & Artificial retina & Vision recovery & Low & Years \\
\hline & Endoscope capsule & Visualization of digestive tract & Low & Hours \\
\hline \multirow{2}{*}{$\begin{array}{l}\text { Kinetic sensors } \\
\text { (wearable) }\end{array}$} & Accelerometer & \multirow{2}{*}{$\begin{array}{l}\text { Monitoring body posture and } \\
\text { orientation }\end{array}$} & Low & Weeks \\
\hline & Gyroscope & & Low & Weeks \\
\hline \multirow{3}{*}{$\begin{array}{l}\text { Ambient } \\
\text { sensors } \\
\text { (wearable) }\end{array}$} & Temperature sensor & $\begin{array}{l}\text { Monitoring ambient } \\
\text { temperature }\end{array}$ & Low & Weeks \\
\hline & Humidity sensor & Monitoring ambient humidity & Low & Weeks \\
\hline & Allergic sensor & $\begin{array}{l}\text { Monitoring allergic agent in } \\
\text { the air }\end{array}$ & Low & Weeks \\
\hline
\end{tabular}

\section{Wearable sensors vs. implantable sensors}

According to their specific locations, body sensors can be divided into two main categories, that is, wearable sensors on/near the human body, and implantable sensors inside the human body. Table-1 points out the specific sensors that belong to either wearable or implantable ones.

Table-2 further compares their features in several aspects. For wearable sensors, the sensor node can be designed into patch-shape or bandage-shape, which can be directly attached to the human skin to ensure an accurate sensing (Yan et al. 2010). However, this may cause skin 
irritation due to the long-term airtight contact. Alternatively, the sensor node can be integrated into clothes or accessories to realize more comfortable and convenient application, such as a wearable smart shirt (Lee and Chung 2009) or a smart watch (Gyselinckx et al. 2005). This will, however, affect the accuracy of the result due to the indirect contact and relative displacement between the sensor and the body. Nevertheless, to realize both of the two wearable BSN node designs, micro power sources with small form factor and high energy density are requisite for improving both the sensor reliability and user comfortness. Compared with wearable sensors, implantable sensors have much more stringent requirement on their biocompatibility and lifetime, since they are implanted inside body through surgical operation and cannot be replaced easily. Once implanted, biofouling will become an important issue since it may lead to inaccurate data acquisition or even total failure of the sensing device. Due to the accumulation of proteins, cells or other biomaterials on the sensor surface, the sensor will be gradually isolated from the tissue, losing its energy source such as glucose inside the body fluid (Chin et al. 2012). In 1960, the world's first surgical implantation of a cardiac pacemaker was accomplished (Cosnier et al. 2014). Afterwards, more and more implantable medical devices were developed, most of which were powered by lithium batteries. Nevertheless, in order to provide longer lifetime for future implanted devices, new micro power sources should be developed which can directly harvest energy from human body or ambient.

Table-2 Comparison between wearable and implantable sensors

\begin{tabular}{|c|c|c|}
\hline & Wearable sensors & Implanted sensors \\
\hline Volume/Weight & Larger/Heavier & Smaller/Lighter \\
\hline Power consumption & Relatively high & Relatively low \\
\hline Operation time & Several weeks & Several years \\
\hline Recharge ability & High & Low \\
\hline Biocompatibility & Low requirement & High requirement \\
\hline Examples & Patch-type sensor & Capsule-type sensor \\
& Watch-type sensor & \\
& T-shirt sensor & \\
\hline
\end{tabular}

Due to their different working environments, the potential power sources for wearable and implantable sensors are very different from each other. For instance, the conventional secondary batteries are currently applied widely in wearable sensors, but they are not suitable for powering implantable sensors due to the difficulty of recharge. This issue is slightly improved by the recent wireless recharge technology. Fuel cells can be applied in both wearable and implantable 
sensor node. However, it is requisite to employ fuels that are abundant in the human body fluid (such as glucose) for powering implantable sensors, while for wearable sensors the choice of fuel is much wider because of the convenient refueling ability. As for various energy harvesting technologies, their suitability is strongly determined by the energy source they depend on. For example, thermoelectric generator is more suitable for wearable sensors because of the relatively high temperature difference between body surface and the ambient. Radiofrequency energy transmission is especially suitable for powering implantable sensors because it can penetrate the human body without any damage to the user. Solar energy harvesting is obviously targeted for wearable sensors, which is much more advantageous in outdoor environment with sufficient sunshine. As for kinetic energy harvesters, they are also majorly designed for on-body applications because of the more frequent vibration, friction and pressure outside. Finally, supercapacitor can be applied in both wearable and implantable sensors as a short-term energy storage component, which is more appealing for implantable sensors because of its superior cycling lifetime compared with secondary batteries.

\section{Micro power sources for BSN}

Despite its great application prospect and economic value, the development of BSN is still in an early stage which is restricted by several aspects, such as sensor miniaturization, powerefficient data transmission, information security, and so on. Among them, system power supply is of key importance to its practical utilization. To increase the user comfortness, the multiple sensor nodes in BSN should be made as small and lightweight as possible, which inevitably restricts the size and weight of the affiliated power source. Benefited from recent advances in micro electromechanical system (MEMS), wireless communication and digital electronics, sensors and actuators can be made much smaller than before, which are in the range of 1-100 $\mu \mathrm{m}$ (Chen et al. 2011; Darwish and Hassanien 2011). In the meantime, the affiliated power source should provide sufficient energy to support the BSN for a long period of time with high fidelity, throughput and latency (Hanson et al. 2009). This dilemma has brought a great challenge to the current battery technology, whose energy density is increasing too slowly to satisfy the evergrowing energy demand from portable electronics (Oudenhoven et al. 2012). To tackle this problem, other innovative power sources are investigated for BSN, such as fuel cells, energy harvesters and supercapacitors, which present great application potential for the next-generation 
BSN products. In addition to these regular power sources, nuclear batteries utilizing radioactive decay can last for decades without recharging or replacement issues (Wei and Liu 2008). However, their current output is generally low, not to mention the relatively high cost and complicated disposal. Therefore, nuclear batteries are not included in this review.

\subsection{Battery}

Battery is currently the most popular and commercially available energy solution to BSN, which has been extensively employed for powering both wearable and implantable sensor nodes. In 2012, Oudenhoven et al. reviewed several micro battery technologies for wireless sensor network, including both primary batteries such as $\mathrm{Zn}-\mathrm{MnO}_{2}, \mathrm{Li}-\mathrm{MnO}_{2}$ and $\mathrm{Zn}$-air, and secondary batteries such as Ni-MH, Li-ion and $\mathrm{Li}_{2} \mathrm{O}_{2}$ (Oudenhoven et al. 2012). Nevertheless, the content is quite general and not specifically focused on BSN application. Because of its high technical and market maturity, specific research on the battery component in BSN is very scarce in literature, while most of the related works employ commercial batteries directly, such as primary dry battery and secondary $\mathrm{NiMH}$ or Li ion batteries. Nevertheless, due to its relatively low energy density, the size and weight of the battery component generally occupies the largest portion of the sensor node in most cases (Johnson et al. 2009). More importantly, the battery miniaturization will further decrease the energy density by more than $50 \%$ due to the increased ratio of non-active battery components such as package, sealing and electric contact (Oudenhoven et al. 2012). For instance, the commercial SHIMMER platform for developing wearable sensor node weighs $4.9 \mathrm{~g}$ without battery and $10.4 \mathrm{~g}$ with a $250 \mathrm{mAh} \mathrm{Li-polymer}$ battery, which is more than half of the overall weight (Ko et al. 2010). As a consequence, either a bulky sensor node or a limited sensor lifetime is adopted, both of which will impede the practical application of BSN. Considering the slow improvement of energy density for existing battery technologies in the past decades (a factor of 2-3 per decade (Oudenhoven et al. 2012)), the battery alone may not be competent for powering the BSN, unless innovative batteries with performance breakthrough are invented in the near future. In addition to this issue, the fabrication and recycle of batteries generally involve toxic/corrosive materials such as heavy metals and strong acid/alkaline electrolytes, which inevitably impair their bio-compatibility and environmental friendliness. Furthermore, batteries generally require a long period of time for 
recharging, which is not suitable for uninterrupted sensor monitoring. Recent R\&D on fast recharge of Li-ion batteries may help to alleviate this problem (Zaghib et al. 2011).

Table-3 summaries some of the commercial batteries that are commonly applied in BSN study. In general, primary batteries such as $\mathrm{Zn}-\mathrm{MnO}_{2}$ achieve lower voltage, specific energy and power output, but the low cost and negligible self-discharge are very competitive for the wearable BSN. The cylindrical and coin batteries are typical examples. On the contrary, secondary batteries such as Li-ion can achieve higher energy density and specific power, but the self-discharge rate is relatively high, not to mention their higher cost. Specifically, for the Li-ion battery, the polymer electrolyte is much safer than the ionic liquid electrolyte and more appropriate for developing flexible Li ion batteries for wearable electronics. Compared with these all-sealed batteries, the metal-air battery is a semi-open system which can breathe oxygen from ambient air, leading to the highest energy density. Among them, the $\mathrm{Zn}$-air battery is currently the most mature one, which has already been applied in hearing aids. The Zn-air battery can be both primary battery and secondary battery, whose energy density is as high as $1670 \mathrm{~W} \mathrm{~h} \mathrm{~L}^{-1}$. However, this technology is not mature yet with many technical issues, such as $\mathrm{Zn}$ corrosion and electrolyte stability.

Table-3 Common type of batteries applied in BSN study and their typical parameters

\begin{tabular}{|c|c|c|c|c|c|c|}
\hline Battery type & $\begin{array}{c}\text { Nominal voltage } \\
\text { (V) }\end{array}$ & $\begin{array}{c}\text { Specific } \\
\text { energy } \\
\left(\mathbf{W} \text { h } \mathbf{k g}^{-1}\right)\end{array}$ & $\begin{array}{c}\text { Energy } \\
\text { density } \\
\left(\mathbf{W} h L^{-1}\right)\end{array}$ & $\begin{array}{c}\text { Specific } \\
\text { power } \\
\left(\mathrm{W} \mathrm{kg}^{-1}\right)\end{array}$ & $\begin{array}{c}\text { Cycle } \\
\text { durability }\end{array}$ & $\begin{array}{c}\text { Self- } \\
\text { discharge } \\
\text { (per month) }\end{array}$ \\
\hline $\mathrm{Zn}-\mathrm{MnO}_{2}(\mathrm{P})$ & 1.5 & $85-190$ & $250-434$ & 50 & - & $0.17 \%$ \\
\hline $\mathrm{Li}^{-\mathrm{MnO}_{2}(\mathrm{P})}$ & 3 & $150-330$ & $300-710$ & $250-400$ & - & $1 \%$ \\
\hline Li-ion (R) & $3.2-3.85$ & $100-265$ & $250-693$ & $250-340$ & $500-1000$ & $5-10 \%$ \\
\hline Li polymer $(\mathrm{R})$ & 3.7 & $100-265$ & $250-693$ & $250-340$ & $500-1000$ & $5-10 \%$ \\
\hline Ni-MH (R) & 1.2 & $60-120$ & $140-300$ & $250-1000$ & 500 & $30 \%$ \\
\hline Zn-air (P/R)* & 1.5 & 442 & 1670 & 100 & - & $0.17 \%$ \\
\hline
\end{tabular}

*Not applied in BSN yet, but with high potential.

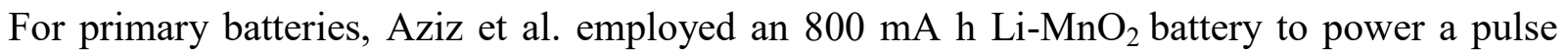
oximeter and two accelerometers for post-operative surgical patients, but the system lifetime was not evaluated (Aziz et al. 2006). Yuce et al. also powered their wearable BSN (temperature and pulse rate sensors) with a $600 \mathrm{~mA} \mathrm{~h} \mathrm{Li-} \mathrm{MnO}_{2}$ battery (Yuce et al. 2007). Due to the different power consumption rates, the pulse rate sensor could last for only 4.4 hours because of the high current of $126 \mathrm{~mA}$, while the temperature sensor can last for 12.9 hours. Lee et al. employed 
conventional dry batteries for their wearable ECG sensor and accelerometers (Lee et al. 2007). With two AA batteries in series $(2850 \mathrm{~mA} \mathrm{~h})$, the device could operate for 59 hours. With two AAA batteries in series (1250 mA h), the working time decreased to 24 hours. By using smaller coin batteries (600 $\mathrm{mA} \mathrm{h}$ ), the device could only work for less than 5 hours. Gao et al. and Lee et al. also used 2 AAA batteries for their BSN, one contains GPS, pulse oximeter, blood pressure, temperature and ECG sensors (Gao et al. 2008), and the other contains ECG sensor and accelerometers inside a T-shirt (Lee and Chung 2009). Considering the multiple sensors in their systems, the battery lifetime is believed to be quite challenging. In general, the cylindrical batteries are much more durable than coin ones, but the large weight and bulky volume is definitely not favored in future wearable BSN.

For secondary batteries, Ouchi et al. employed a Li ion battery for a wristwatch-shaped BSN with pulse meter, thermometer and galvanic skin reflex electrodes (Ouchi et al. 2002). The whole device weighs $70 \mathrm{~g}$ and the highest power consumption is $150 \mathrm{~mW}$. Barth et al. used a Li ion coin battery to power an accelerometer and two gyroscopes on the wrist (Barth et al. 2009). The battery size (30 mm diameter and $4.8 \mathrm{~mm}$ thickness) is much smaller than pouch cells or cylinder cells, but the capacity is also lower (300 mA h). Shnayder et al. replaced AA batteries with a tiny Li polymer battery (120 mA h) for wearable wireless sensors (Shnayder et al. 2005). The system weight is consequently reduced by half to $30.5 \mathrm{~g}$, but the durability is not exhibited. Fafoutis et al. also used a $100 \mathrm{~mA} \mathrm{~h} \mathrm{Li-polymer} \mathrm{battery} \mathrm{for} \mathrm{two} \mathrm{accelerometers} \mathrm{and} \mathrm{an} \mathrm{optional} \mathrm{gyroscope}$ (Fafoutis et al. 2017). With fully charge, their system can continuously operate for several months, which is mainly attributed to the low power consumption of their BSN. Compared with Li ion battery, the usage of NiMH battery is scarce in BSN study. Fariborzi et al. used a $150 \mathrm{~mA}$ h NiMH battery for powering a ECG sensor (Fariborzi et al. 2007). With an average current draw of $2.1 \mathrm{~mA}$, the battery can last for as long as 70 hours. In addition to the above-mentioned wearable sensors, an implanted BSN including a ECG sensor, a blood pressure sensor and a drug delivery actuator powered by a micro Li ion battery $(2.7 \mathrm{~mm}$ diameter, $13 \mathrm{~mm}$ thickness $)$ was developed by Fang et al. (Fang et al. 2011). Due to the small battery capacity of $10 \mathrm{~mW} \mathrm{~h}$, frequent wireless charging was required. In summary, the miniaturized secondary batteries are suitable for both wearable and implanted BSN systems, but the frequent battery recharge reduces not only the user comfort but also the system reliability. 
Compared with conventional rigid batteries, recently flexible batteries such as thin-film and fiber-shape cells have received a wide interest because of their great prospect in future wearable electronic market, including wearable BSN. As shown in Fig. 2, these flexible batteries include primary ones such as $\mathrm{Zn}-\mathrm{MnO}_{2}$ battery (Liu et al. 2019; Su et al. 2019; Wang et al. 2018), Zn-air (Li et al. 2018a; Liu et al. 2016; Park et al. 2015) and Al-air battery (Wang et al. 2020; Wang et al. 2019a; Wang et al. 2019c), and secondary batteries such as Li-ion (Deng et al. 2017; Leijonmarck et al. 2013; Liu et al. 2017), Zn-ion (Li et al. 2018b; Li et al. 2019; Zeng et al. 2019) and $\mathrm{Al}$ ion battery (Liang et al. 2019; Pan et al. 2019; Yu et al. 2019c). To improve the battery flexibility and safety level, either gel or polymer electrolyte is adopted, while the battery stability against various deformations such as bending, twisting and stretching have been characterized. With further development of their power output, energy density and mechanical robustness, these flexible batteries represent a promising energy solution to future wearable BSN, so that the corresponding combinational study is highly required. Due to the limited length of this article, interested readers are recommended to several recent reviews on different types of flexible batteries (Liu et al. 2018a; Peng et al. 2017; Tan et al. 2017; Tao et al. 2018; Yu et al. 2019b).

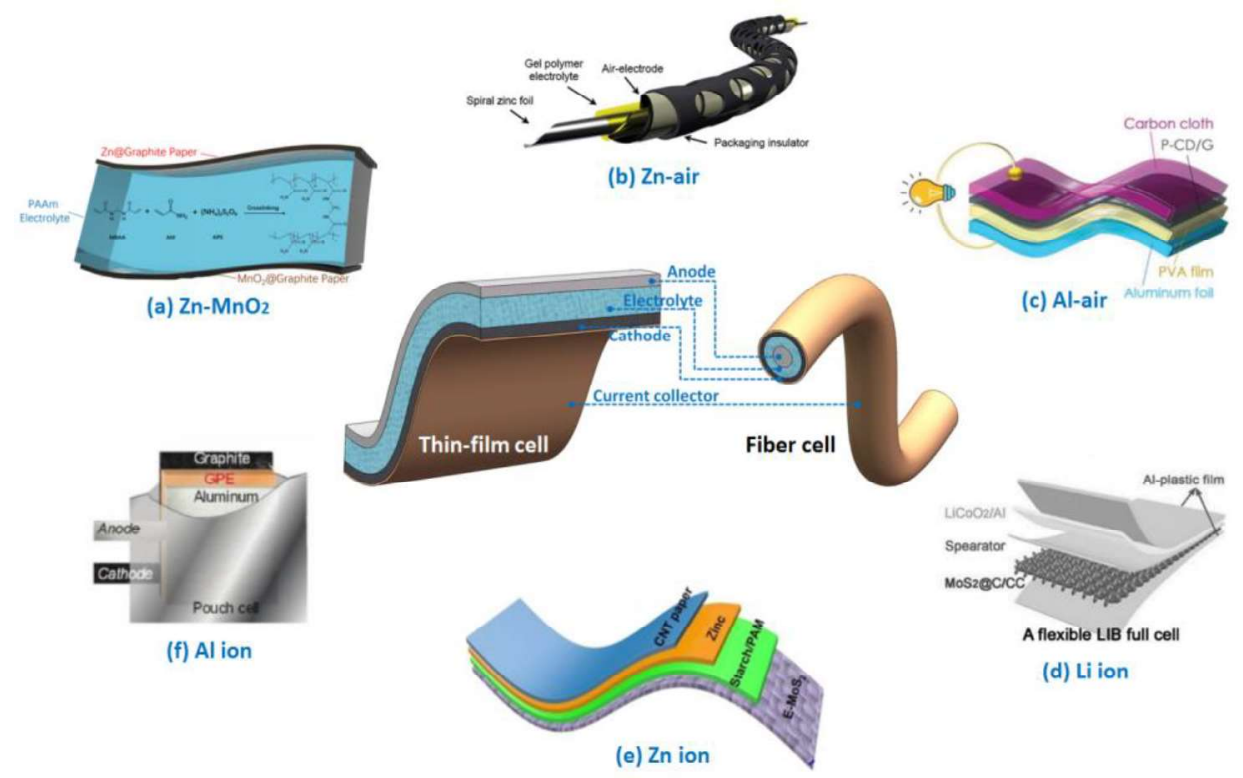

Fig. 2 Flexible thin-film and fiber-shape batteries with high potential for powering future wearable BSN: (a) $\mathrm{Zn}-\mathrm{MnO}_{2}$ battery (Wang et al. 2018) (reprinted with permission from American Chemical Society); (b) Zn-air battery (Park et al. 2015) (reprinted with permission from John Wiley \& Sons); (c) Al-air battery (Wang et al. 2020) (reprinted with permission from 
John Wiley \& Sons); (d) Li ion battery (Deng et al. 2017) (reprinted with permission from John Wiley \& Sons); (e) Zn ion battery (Li et al. 2019) (reprinted with permission from Elsevier); (f) $\mathrm{Al}$ ion battery (Yu et al. 2019c) (reprinted with permission from John Wiley \& Sons).

Despite the slow improvement of their energy density, the lifetime dilemma of batteries can be alleviated by suitable energy management strategies such as controlling the data transmission process or developing energy-saving medium access control (MAC) models (Aghera et al. 2010; Aghera et al. 2009; Otal et al. 2009; Zhang et al. 2010). In addition, novel data transmission technologies with lower energy consumption has been applied in BSN, such as low energy Bluetooth (Zhang et al. 2014b). Furthermore, most batteries generally have a capacity recovery effect during off-work mode. Therefore, it is very advantageous to utilize batteries in an intermittent discharge mode (Khan et al. 2012). All these strategies can help to improve the lifetime of the current battery-powered BSN system.

\subsection{Fuel cell}

Fuel cells are well known for their high energy density and uninterrupted operation. Similar to battery, a typical fuel cell is mainly composed of two electrodes sandwiching a thin-film electrolyte, but the reactants are not stored inside the cell. Instead, the fuel and oxidant are provided from outside the cell, so that the fuel cell can work continuously without material depletion (O'hayre et al. 2016). Alternatively, the fuel cell can be recharged by generating the reactants back from the products, namely, the unitized regenerative fuel cell (Wang et al. 2016b, 2017b). However, its round-trip energy efficiency is much lower than secondary batteries because of the higher reaction overpotential. Typical fuels include hydrogen, methanol, ethanol, formic acid and so on, while the most common oxidant is pure oxygen or air. Fuel cells can be applied in many areas, from megawatt power plants to kilowatt electric vehicles. As for portable electronics with lower rated power, micro fuel cells are highly feasible, which are currently under rapid development.

Micro fuel cells are especially suitable for powering BSN, including both wearable and implantable sensor nodes. For wearable sensors, the high energy density and instant refueling ability (e.g., by fuel cartridge replacement) make micro fuel cells a strong competitor against batteries, leading to long-term and uninterrupted sensor operation. Various hydrocarbon fuels 
such as methanol, ethanol and formic acid can be adopted as fuel; while for gaseous fuels such as hydrogen, gas storage and extract with high efficiency and safety need to be achieved first. As for implantable sensors, the fuel cartridge replacement is no longer available. Therefore, direct glucose fuel cell is the most suitable choice since glucose and oxygen are both available in the human body physiological fluid, ensuring a long lifetime without external replenishment (Cinquin et al. 2010). Some researchers regard the direct glucose fuel cell as an energy harvesting technique. However, in this review we still classify it in the fuel cell section for consistency purpose.

Based on the nature of electrode catalyst, fuel cells for BSN application can be classified into two main categories, namely, the abiotic fuel cell with noble metal catalyst, and the biofuel cell with bio-catalyst. Specifically, the biofuel cell can be further divided into enzymatic fuel cell and microbial fuel cell, which use enzyme and microorganism as electrode catalyst, respectively. In general, the noble metal catalyst has much better stability and lifetime, but the selectivity towards fuel oxidation and oxygen reduction reactions are very poor, so that the fuel and oxygen crossover needs to be inhibited to achieve high cell voltage and power. On the contrary, the enzyme and microorganism have very good selectivity, so that the biofuel cell has no worry about the crossover problem. However, the lifetime of enzyme is much more limited than noble metals, while the microorganism brings about safety concerns when it comes to implantable sensors. In literature, most studies focus on the implantable fuel cell including both abiotic and bio type, while the application in wearable medical devices is relatively scarce.

\subsubsection{Abiotic fuel cells (implantable)}

Till now, most abiotic fuel cells for BSN application are targeted for implantable sensors, which use glucose and oxygen dissolved in the body fluid for electricity generation. As early as 1960s, abiotic direct glucose fuel cell has already been explored as implantable power source for the cardiac pacemaker (Kerzenmacher et al. 2008b). However, later on relevant research works were suspended due to the invention of implantable lithium iodine battery in 1972 and the improvement of battery lifetime. Nevertheless, with the recent development of various implantable sensors and actuators, the abiotic fuel cell with high energy density, good biocompatibility and theoretically unlimited lifetime is getting great notice again, with many relevant research works conducted. Kerzenmacher et al. reviewed the implantable abiotic fuel 
cell fed on glucose in 2008 (Kerzenmacher et al. 2008b), while more recent research outcomes have been included in this section.

As summarized in Table-4, most implantable abiotic fuel cells use Pt as anode catalyst, which is mainly because of its high catalytic activity towards glucose oxidation. Theoretically, a glucose molecule can provide 24 free electrons along with complete oxidation. However, in real cases, the glucose molecule is partially oxidized to gluconic acid and releases two free electrons only as shown in Fig. 3 (Kloke et al. 2012). Other minor oxidation products include glucuronic, oxalic, glyoxylic and tartaric acids. As for the cathode, both Pt and carbon materials have been utilized for oxygen reduction. Between the anode and cathode, a layer of electric insulated material is necessary to separate the electrodes, of which either a polymer membrane (e.g., Nafion) or a porous inorganic membrane is used. Most of these works adopted in vitro study for fuel cell testing, in which the cell was immersed in a phosphate buffered saline (PBS) dissolved with $3 \mathrm{mmol} \mathrm{L}^{-1}$ glucose and 7\% oxygen saturation to mimic the body fluid. The peak power output is in the range of $1-10 \mu \mathrm{W} \mathrm{cm}$, which is mainly restricted by the low fuel and oxidant concentrations and the near neutral $\mathrm{pH}$ environment. Only a few researchers conducted in vivo studies in animals or plants. In 1970, Drake et al. inserted an abiotic fuel cell in an adult mongrel dog and demonstrated a continuous operation of 30 days (Drake et al. 1970). Recently, Sharma et al. also implanted their abiotic fuel cell into the right ventricle of a live Yorkshire pig (Sharma et al. 2011). The power density is as high as $10 \mu \mathrm{W} \mathrm{cm}{ }^{-2}$. However, the test lasted only 12 minutes. Holade et al. directly inserted their fuel cell electrodes into the orange pulp in order to utilize the glucose and fructose in the juice (Holade et al. 2015). The obtained open circuit voltage (OCV), maximum current density and peak power output were $0.36 \mathrm{~V}, 1.3 \mathrm{~mA} \mathrm{~cm}^{-2}$ and $182 \mu \mathrm{W}$, respectively. Nevertheless, the real application of implantable abiotic fuel cells inside human body still has a long way to go, before the biofouling and biocompatibility issue can be well solved.

One major problem of abiotic fuel cells for in-body operation is the selection of suitable anodic catalyst which can selectively oxidize glucose while stay passive to the oxygen reduction reaction. This is due to the fact that glucose and oxygen co-exist in the body fluid, causing inevitable crossover problem. Currently, Pt-based catalyst is commonly adopted in abiotic fuel cells due to its excellent catalytic activity and high biocompatibility. However, it has been reported that the Pt catalyst in fuel cell anode can be gradually poisoned by the amino acids and 
small organic molecules in tissue fluid, leading to poor long-term stability (Köhler et al. 2014). Therefore, it is necessary to develop suitable permselective membranes for fuel cell capsulation, in order to isolate these organic molecules from the electrode while allowing glucose and oxygen to pass through. On the other hand, employing non-noble catalysts instead of expensive Pt will make the abiotic fuel cells much more cost-effective for large-scale applications.

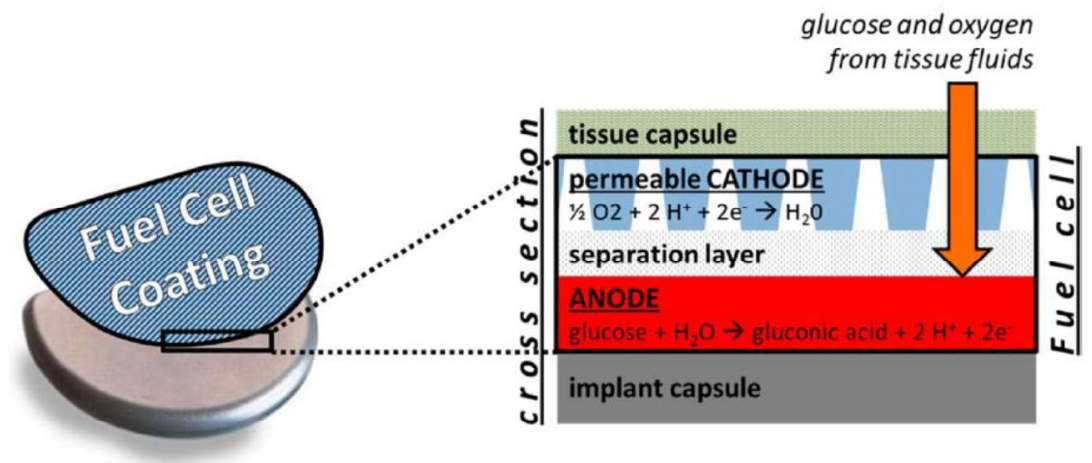

Fig. 3 Schematic diagram of the abiotic glucose fuel cell integrated on an implantable device (Kloke et al. 2012) (reprinted with permission from American Chemical Society)

Table-4 Summary of existing research works on implantable abiotic glucose fuel cells

\begin{tabular}{|c|c|c|c|c|c|}
\hline Reference & Anode & Electrolyte & Cathode & In vivo & Performance \\
\hline (Drake et al. 1970) & $\begin{array}{l}\text { Noble metal } \\
\text { alloy on Pt } \\
\text { screen }\end{array}$ & & $\begin{array}{l}\text { Pt black on } \mathrm{Pt} \\
\text { screen }\end{array}$ & Dog & $\begin{array}{l}2.2 \mu \mathrm{W} \mathrm{cm}^{-2} \\
\text { (30 days) }\end{array}$ \\
\hline (Stetten et al. 2006) & $\begin{array}{l}\mathrm{Pt}+\text { Activated } \\
\text { carbon }\end{array}$ & PVA-PAA membrane & $\begin{array}{l}\text { Activated } \\
\text { carbon }\end{array}$ & None & $\begin{array}{l}2 \mu \mathrm{W} \mathrm{cm}^{-2} \\
(7 \text { days })\end{array}$ \\
\hline $\begin{array}{l}\text { (Kerzenmacher et al. } \\
\text { 2008a) }\end{array}$ & $\begin{array}{l}\text { Pt-Bi alloy }+ \\
\text { Activated } \\
\text { carbon }\end{array}$ & $\begin{array}{l}\text { polyethersulfone filter } \\
\text { membrane }\end{array}$ & $\begin{array}{l}\text { Activated } \\
\text { carbon }\end{array}$ & None & $\begin{array}{l}\text { From } 3.3 \text { to } 1.0 \mu \mathrm{W} \\
\mathrm{cm}^{-2} \\
(224 \text { days })\end{array}$ \\
\hline $\begin{array}{l}\text { (Oncescu and } \\
\text { Erickson 2011) }\end{array}$ & Pt-Ni alloy & $\begin{array}{l}\text { phosphate buffered } \\
\text { saline }\end{array}$ & $\mathrm{Pt}$ & None & $2 \mu \mathrm{W} \mathrm{cm}^{-2}$ \\
\hline $\begin{array}{l}\text { (Kerzenmacher et al. } \\
\text { 2011) }\end{array}$ & Raney-Pt film & $\begin{array}{l}\text { phosphate buffered } \\
\text { saline }\end{array}$ & Raney-Pt film & None & $4.4 \mu \mathrm{W} \mathrm{cm}$ \\
\hline (Kloke et al. 2011) & Raney-Pt film & $\begin{array}{l}\text { phosphate buffered } \\
\text { saline }\end{array}$ & Raney-Pt film & None & $2.2 \mu \mathrm{W} \mathrm{cm}^{-2}$ \\
\hline (Sharma et al. 2011) & $\begin{array}{l}\text { Thin-film Pt } \\
\text { on Si substrate }\end{array}$ & Mesoporous silica & $\begin{array}{l}\text { Graphene on } \\
\text { SS mesh }\end{array}$ & Pig & $\begin{array}{l}10 \mu \mathrm{W} \mathrm{cm}{ }^{-2} \\
(12 \mathrm{~min})\end{array}$ \\
\hline (Rapoport et al. 2012) & Activated Pt & Nafion membrane & SWCNT & None & $3.4 \mu \mathrm{W} \mathrm{cm}$ \\
\hline (Kloke et al. 2012) & Pt-Au alloy & Filter membrane & Pt-Au alloy & None & $\begin{array}{l}5.1 \mu \mathrm{W} \mathrm{cm}{ }^{-2} \\
(90 \text { days })\end{array}$ \\
\hline (Köhler et al. 2014) & $\mathrm{Pt}$ & $\begin{array}{l}\text { Simulated tissue fluid } \\
\text { Simulated cerebrospinal } \\
\text { fluid }\end{array}$ & $\mathrm{Pt}$ & None & $\begin{array}{l}6.3 \mu \mathrm{W} \mathrm{cm}{ }^{-2} \\
\text { (19 hours or } 37 \\
\text { hours) }\end{array}$ \\
\hline (Holade et al. 2015) & $\begin{array}{l}\text { Au-Pt/CB on } \\
\text { bulky paper }\end{array}$ & Orange pulp & $\begin{array}{l}\mathrm{Pt} / \mathrm{CB} \text { on } \\
\text { carbon paper }\end{array}$ & Orange & $\begin{array}{l}182 \mu \mathrm{W} \\
\text { (7 hours) }\end{array}$ \\
\hline
\end{tabular}




\subsubsection{Biofuel cells (implantable)}

Biofuel cells for the implantable BSN, including both enzymatic fuel cells and microbial fuel cells, are well-known for their low fabrication cost, high performance at near-room temperature and neutral $\mathrm{pH}$, and selective catalysis to the mixed fuel and oxidant (Calabrese Barton et al. 2004). Early in 1976, Weidlich et al. already developed a biofuel cell which can output a power density of $4 \mu \mathrm{W} \mathrm{cm}^{-2}$ for over 150 days in animal experiment (Weidlich et al. 1976). Afterwards, continuous efforts have made in this area, which were reviewed by Cosnier et al. in 2014 (Cosnier et al. 2014). This section will include more recent works on biofuel cells, but only those related to implantable medical applications will be considered.

Table-5 summarizes existing research works on implantable biofuel cells, including both enzymatic and microbial fuel cells. The study on enzymatic fuel cells is very popular in recent years. Most of them use glucose oxidase for anode reaction and bilirubin oxidase or laccase for cathode reaction, which are generally grown on carbon support such as carbon fiber (Mano et al. 2003), graphite (Coman et al. 2010) and buckypaper (Halámková et al. 2012). In addition, other types of sugar such as fructose (Niitsu et al. 2015) and trehalose (Rasmussen et al. 2012) were also investigated considering the different implanting host. As for the electrolyte, some in vivo studies directly inserted electrodes into the host body so the body fluid serves as the fuel cell electrolyte, while other in vitro studies used the real or simulated body fluid as electrolyte, such as serum (Coman et al. 2010), blood (Ó Conghaile et al. 2016) and transdermal extract (Du Toit et al. 2016). For the in vivo studies, various hosts have been employed, such as grape (Mano et al. 2003), insect (Rasmussen et al. 2012), snail (Halámková et al. 2012) and rat (Cinquin et al. 2010) as shown in Fig. 4(a-d). However, till now no human test was found yet, indicating that this technology is still not mature enough with many potential health hazards. The power density varies from 4 to $350 \mu \mathrm{W} \mathrm{cm}{ }^{-2}$, which is generally higher than abiotic fuel cells. However, there is a lack of their durability study, with the longest test of 2 weeks achieved by Halámková et al. (Halámková et al. 2012). As for the microbial fuel cell, the relevant study is much less. Justin et al. employed the human white blood cells for glucose oxidation, but the current density output is very low, only 1.4-2.7 $\mu \mathrm{A} \mathrm{cm}$ (Justin et al. 2004). Han et al. and Dong et al. studied the application of microbial fuel cells for implantable medical devices in the human colon (Dong et al. 2013; Han et al. 2010). Simulated intestinal fluid was used as electrolyte, and the power 
density is 7.33 and $1.17 \mu \mathrm{W} \mathrm{cm}{ }^{-2}$, respectively. Similarly, no in vivo study in human body was found.

Despite their relatively high power output, there are specific concerns on these two implantable biofuel cell technologies. For the enzymatic fuel cell, the lifetime and stability of the enzymes inside its electrodes are of great concern, which greatly hinder their operation ability and lifetime. As for the microbial fuel cell, safety issue is the most significant obstacle considering the potential risk of micro-organism infection (Kerzenmacher et al. 2008b). Furthermore, the sterilization of both biofuel cells is very complex and problematic before implantation, which is much easier for abiotic fuel cells (e.g., by steam) (Kloke et al. 2012). Furthermore, the biofouling problem caused by tissue accumulation on fuel cell surface (Fig. 4(e)) will gradually deteriorate the performance of all implantable fuel cells, which prevent the glucose and oxygen from penetrating into the fuel cell electrodes.

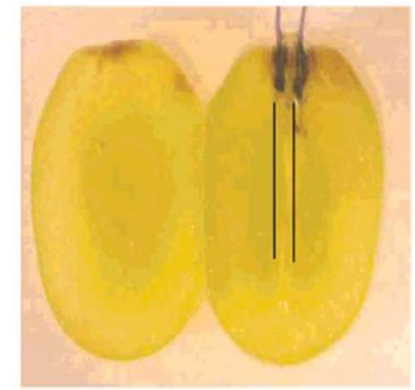

(a)

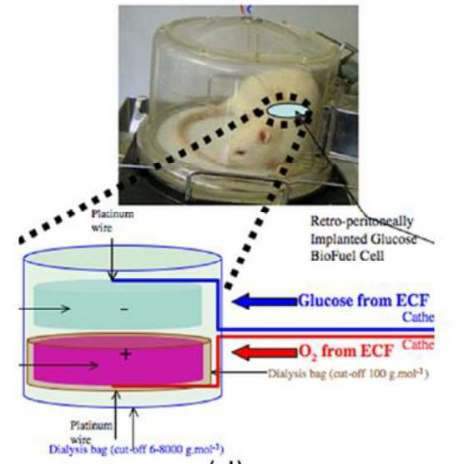

(d)

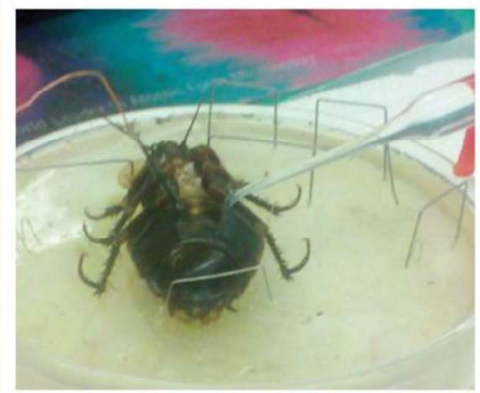

(b)

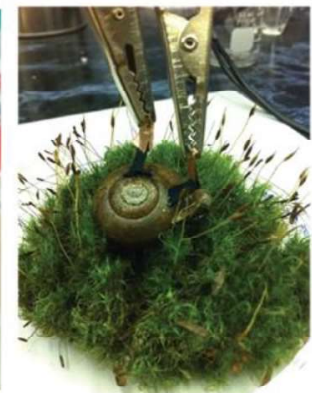

(c)

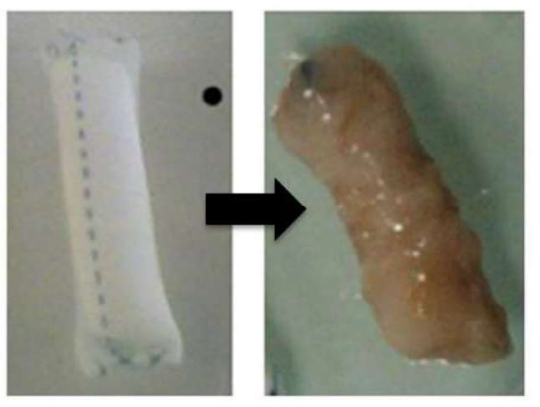

(e)

Fig. 4 Implantable biofuel cells with in vivo test: (a) Compartmentless cell in a grape (Mano et al. 2003) (reprinted with permission from American Chemical Society); (b) Compartmentless cell in an insect (Rasmussen et al. 2012) (reprinted with permission from American Chemical Society); (c) Compartmentless cell in a snail (Halámková et al. 2012) (reprinted with permission from 
American Chemical Society); (d) Dialysis bag cell in a rat and (e) Biofouling of the implanted biofuel cell (Cinquin et al. 2010) (reprinted from open access article).

Table-5 Summary of existing research works on implantable biofuel cells

\begin{tabular}{|c|c|c|c|c|c|}
\hline Reference & Anode & Electrolyte & Cathode & In vivo & Performance \\
\hline \multicolumn{6}{|c|}{ Enzymatic fuel cell } \\
\hline $\begin{array}{l}\text { (Mano et al. } \\
\text { 2003) }\end{array}$ & $\begin{array}{l}\text { Glucose oxidase on } \\
\text { carbon fiber }\end{array}$ & Body tissue & $\begin{array}{l}\text { Bilirubin oxidase on } \\
\text { carbon fiber }\end{array}$ & Grape & $2.4 \mu \mathrm{W}$ at $0.52 \mathrm{~V}$ \\
\hline $\begin{array}{l}\text { (Coman et al. } \\
\text { 2010) }\end{array}$ & $\begin{array}{l}\text { cellobiose } \\
\text { dehydrogenase on } \\
\text { graphite }\end{array}$ & Serum & $\begin{array}{l}\text { Bilirubin oxidase on } \\
\text { graphite }\end{array}$ & None & $\begin{array}{l}4 \mu \mathrm{W} \mathrm{cm} \mathrm{cm}^{-2} \text { at } 0.19 \\
\mathrm{~V}\end{array}$ \\
\hline $\begin{array}{l}\text { (Cinquin et al. } \\
\text { 2010) }\end{array}$ & $\begin{array}{l}\text { glucose oxidase and } \\
\text { ubiquinone on } \\
\text { graphite disc }\end{array}$ & Body tissue & $\begin{array}{l}\text { Polyphenol oxidase } \\
\text { and quinone on } \\
\text { graphite disc }\end{array}$ & Rat & $\begin{array}{l}6.5 \mu \mathrm{W} \text { at } 0.13 \mathrm{~V} \\
(\sim 3 \text { hours })\end{array}$ \\
\hline $\begin{array}{l}\text { (Miyake et al. } \\
\text { 2011) }\end{array}$ & $\begin{array}{l}\text { Glucose } \\
\text { dehydrogenase on } \\
\text { plastic needle }\end{array}$ & Body tissue & $\begin{array}{l}\text { Bilirubin oxidase on } \\
\text { carbon paper }\end{array}$ & Rabbit & $0.42 \mu \mathrm{W}$ at $0.56 \mathrm{~V}$ \\
\hline $\begin{array}{l}\text { (Rasmussen et al. } \\
\text { 2012) }\end{array}$ & $\begin{array}{l}\text { Trehalase and } \\
\text { glucose oxidase on } \\
\text { polymeric backbone }\end{array}$ & Body tissue & $\begin{array}{l}\text { Bilirubin oxidase on } \\
\text { polymeric backbone }\end{array}$ & Insect & $\begin{array}{l}55 \mu \mathrm{W} \mathrm{cm}^{-2} \text { at } 0.2 \\
\mathrm{~V} \\
(2.5 \text { hours })\end{array}$ \\
\hline $\begin{array}{l}\text { (Halámková et al. } \\
\text { 2012) }\end{array}$ & $\begin{array}{l}\text { glucose } \\
\text { dehydrogenase on } \\
\text { buckypaper }\end{array}$ & Body tissue & $\begin{array}{l}\text { oxygen-reducing } \\
\text { laccase on } \\
\text { buckypaper }\end{array}$ & Snail & $\begin{array}{l}30 \mu \mathrm{W} \mathrm{cm}{ }^{-2} \\
(2 \text { weeks) }\end{array}$ \\
\hline $\begin{array}{l}\text { (Southcott et al. } \\
\text { 2013) }\end{array}$ & $\begin{array}{l}\text { glucose } \\
\text { dehydrogenase on } \\
\text { buckypaper }\end{array}$ & Serum & $\begin{array}{l}\text { oxygen-reducing } \\
\text { laccase on } \\
\text { buckypaper }\end{array}$ & None & $\sim 0.6 \mathrm{~mW}$ at $0.3 \mathrm{~V}$ \\
\hline $\begin{array}{l}\text { (Niitsu et al. } \\
2015 \text { ) }\end{array}$ & $\begin{array}{l}\text { Fructose } \\
\text { dehydrogenese on } \\
\text { carbon fabric }\end{array}$ & $\begin{array}{l}\text { Fructose } \\
\text { solution }\end{array}$ & $\begin{array}{l}\text { Bilirubin oxidase on } \\
\text { carbon fabric }\end{array}$ & None & $350 \mu \mathrm{W} \mathrm{cm}{ }^{-2}$ \\
\hline $\begin{array}{l}\text { (Ó Conghaile et } \\
\text { al. 2016) }\end{array}$ & $\begin{array}{l}\text { Pyranose } \\
\text { dehydrogenase on } \\
\text { graphite electrode }\end{array}$ & Human blood & $\begin{array}{l}\text { Bilirubin oxidase on } \\
\text { Au electrode }\end{array}$ & None & $73 \mu \mathrm{W} \mathrm{cm}{ }^{-2}$ \\
\hline $\begin{array}{l}\text { (Du Toit et al. } \\
\text { 2016) }\end{array}$ & $\begin{array}{l}\text { Glucose oxidase on } \\
\text { Au electrode }\end{array}$ & $\begin{array}{l}\text { Transdermal } \\
\text { extract }\end{array}$ & $\begin{array}{l}\text { Laccase on } \mathrm{Au} \\
\text { electrode }\end{array}$ & None & $0.004 \mu \mathrm{W}$ \\
\hline \multicolumn{6}{|c|}{ Microbial fuel cell } \\
\hline $\begin{array}{l}\text { (Justin et al. } \\
2004)\end{array}$ & $\begin{array}{l}\text { Human white blood } \\
\text { cells + Graphite }\end{array}$ & Nafion-117 & Graphite & None & $1.4-2.7 \mu \mathrm{A} \mathrm{cm}^{-2}$ \\
\hline (Han et al. 2010) & $\begin{array}{l}\text { Activated carbon } \\
\text { cloth }\end{array}$ & $\begin{array}{l}\text { Simulated } \\
\text { intestinal } \\
\text { fluid }\end{array}$ & Pt on carbon paper & None & $7.33 \mu \mathrm{W} \mathrm{cm}{ }^{-2}$ \\
\hline (Dong et al. 2013) & Carbon cloth & $\begin{array}{l}\text { Simulated } \\
\text { colonic fluid }\end{array}$ & Pt on carbon paper & None & $1.17 \mu \mathrm{W} \mathrm{cm}^{-2}$ \\
\hline
\end{tabular}

\subsubsection{Wearable fuel cells}

In addition to direct glucose fuel cells for the implantable BSN, micro fuel cells with other types of fuel are also promising for the wearable BSN. In literature, great efforts have been made on miniaturized fuel cell systems for portable applications, of which the passive direct methanol fuel cell is especially promising because of its high energy density and simple structure (Yao et 
al. 2006). In addition, to cater for various wearable electronics, flexible fuel cell based on either plastic materials (Chang et al. 2013) or cellulose paper (Wang et al. 2019b) is also under rapid development, which is a strong competitor to flexible batteries. Nevertheless, only a few of them applied the fuel cell in biomedical applications. Adlhart et al. designed a hydrogen fuel cell with replaceable metal hydride cartridge, which can provide several hundred watt-hours of electric power to medical devices such as total artificial hearts and left ventricular assist devices (Adlhart et al. 1997). Nevertheless, the $50 \mathrm{~L}$ hydride cartridge weighing $115 \mathrm{~g}$ is too cumbersome for the potential user. Sim et al. proposed a micro direct methanol fuel cell for powering medical devices (Sim et al. 2001). However, as they mentioned in the article, methanol itself is fatal to the human body and associated with tremendous health risk. Therefore, the harmless ethanol fuel is more appropriate for such applications. Aravamudhan et al. designed an orientationindependent, self-priming micro direct ethanol fuel cell for wearable or implantable medical applications (Aravamudhan et al. 2005). The cell can generate an OCV of $260 \mathrm{mV}$ and a peak power density of $8.1 \mathrm{~mW} \mathrm{~cm}^{-2}$ with only $5 \mu \mathrm{L}$ ethanol fuel. Nevertheless, no application of micro fuel cells in the wearable BSN has been found yet, which is a promising research field in future.

\subsection{Energy harvester}

For batteries and fuel cells (except for implantable fuel cells fed on body fluid), either electrical recharge or mechanical refuel is essential to keep them operating continuously for a long lifetime, which inevitably decreases the user comfort level and system reliability. On the contrary, the energy harvesting technology, also known as energy scavenging, does not need to be recharged or refueled regularly. Instead, it can obtain energy continuously from either the ambient environment (solar, wind, radiofrequency, and so on) or the human body itself (body temperature, respiration, body movement, and so on). This makes the BSN completely autonomous without worrying about the potential power breakdown, leading to a much longer lifetime and reduced maintenance cost. This is especially the case for implanted medical devices such as the cardiac pacemaker, which is extremely difficult to recharge or replace. Despite its promising prospect, currently the power output of energy harvesting is generally very limited, which can deliver only a small amount of energy to the BSN (Latré et al. 2011). Therefore, it is quite challenging to employ energy harvester alone for powering the sensor node, which still needs other energy storage component. The relevant research is quite abundant in recent years, 
including several related review papers with different focuses (Akhtar and Rehmani 2017; Olivo et al. 2011; Romero et al. 2009), while more updated research outcomes will be introduced in this section.

\subsubsection{Thermoelectric energy harvesting}

According to the Seebeck effect, when there is a temperature difference across two dissimilar materials, charge carriers will diffuse from the hot side to the cold side (electrons for n-type semiconductor and holes for p-type semiconductor), leading to a thermocouple with a useful electric voltage as shown in Fig. 5(a). Since the voltage output of one thermocouple is limited, normally a few $\mu \mathrm{V}$, thousands of them will be connected electrically in series and thermally in parallel, leading to a thermoelectric generator (TEG) which can obtain voltage as high as $\mathrm{mV}$ level (Fig. 5(b)). The normal human body temperature is $36.5-37.5^{\circ} \mathrm{C}$, which is generally higher than the ambient temperature due to continuous metabolism. Therefore, a micro TEG can be utilized to transfer this thermal energy into electric energy, which is especially suitable for powering wearable sensors autonomously. In fact, micro TEG has long been employed as an energy source for wristwatches (e.g., Seiko watch) (Kishi et al. 1999). The human body can produce heat energy equivalent to electric energy with a power density of $20 \mathrm{~mW} \mathrm{~cm} \mathrm{c}^{-2}$ (Johny and Anpalagan 2014), which is sufficient for most of the body sensors. However, the current TEGs can only harvest about $30 \mu \mathrm{W} \mathrm{cm}{ }^{-2}$ due to their low efficiency (Vullers et al. 2009). To solve this issue, novel thermoelectric nanomaterials with high heat to electricity conversion efficiency needs to be developed. In addition, the system design such as the array of thermocouples also needs optimization, which is strongly determined by the MEMS technology.

Table-6 summarizes the research works applying micro TEG to body sensors, including ECG, EMG, EEG, pulse oximeter, fall detection and temperature sensors. Till now, most of these studies favor to place the micro TEG on the wrist, while only a few of them placed it elsewhere such as in clothes or even implanted in human body. Among the different types of TEGs, the BiTe and Si-Ge based TEG were the most popular choice, probably because of their high technology maturity and energy conversion efficiency. As for the size, the projected area is

normally less than $4 \times 4 \mathrm{~cm}^{2}$ which is close to the size of a wrist watch, while great efforts have been paid to reduce the thickness in order to make the device less obtrusive. Utilizing the limited temperature difference between human body and the ambient, these micro TEGs generally 
achieve voltage output of dozens of or hundreds of $\mathrm{mV}$, which can be further pumped up to several V by a DC/DC convertor (Kappel et al. 2012). As for the power output, both low value of $0.3 \mathrm{nW}$ and high value of $3 \mathrm{~mW}$ have been reported, but the most common level is hundreds of $\mu \mathrm{W}$. To improve the limited power output, an energy storage unit is necessary in the power system, such as a secondary battery or a supercapacitor. Most of the micro TEGs in BSN are focused on wearable sensors utilizing the temperature difference between body surface and ambient environment, while the study on implantable TEG is very scarce, which aims to utilize the temperature difference between body tissue inside and skin surface. Yang et al. proved the feasibility of this idea by both numerical simulation and in vitro/vivo experiments (Yang et al. 2007). However, the temperature difference and consequently the power output were much lower than the wearable cases.

In addition to the TEG that harvests energy from the temperature difference, the pyroelectric generator is another type of thermoelectric energy harvester which can obtain energy from the variation of temperature. By employing a pyroelectric material, either heating or cooling can change its electric polarization inside and generate a temporary voltage, which will diminish when the temperature stabilizes. Specifically, when nanostructured materials are used, the pyroelectric nanogenerators (PyENG) are obtained. Yang et al. employed the $\mathrm{ZnO}$ nanowire arrays as pyroelectric material sandwiched by an Ag foil and a ITO foil, and the energy conversion efficiency from heat to electricity was $0.05-0.08 \mathrm{~V} \mathrm{~m}^{2} \mathrm{~W}^{-1}$ (Yang et al. 2012a). They also developed a PyENG based on lead zirconate titanate film (Yang et al. 2012b). For a temperature change of $45 \mathrm{~K}$ at a rate of $0.2 \mathrm{~K} \mathrm{~s}^{-1}$, an open circuit voltage of $22 \mathrm{~V}$ and a maximum power density of $0.215 \mathrm{~mW} \mathrm{~cm}^{-3}$ could be generated, which is promising for powering wireless sensors. Nevertheless, due to the stable temperature of human body, the PyENG requiring repetitive heating and cooling is not as efficient as the TEG for power generation, except in some specific conditions such as in a respirator (Xue et al. 2017). Instead, it is much more suitable as self-powered temperature sensor as shown in Fig. 5(c), which can help to reduce the overall energy consumption of BSN (Yang et al. 2012c). 


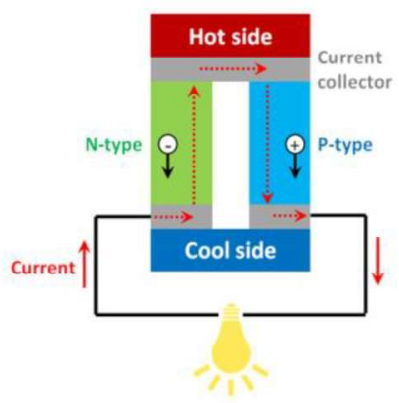

(a)

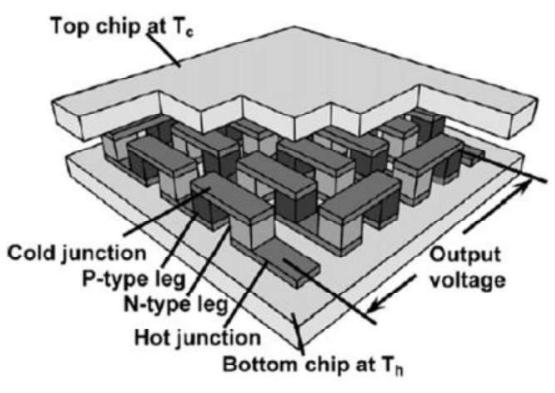

(b)

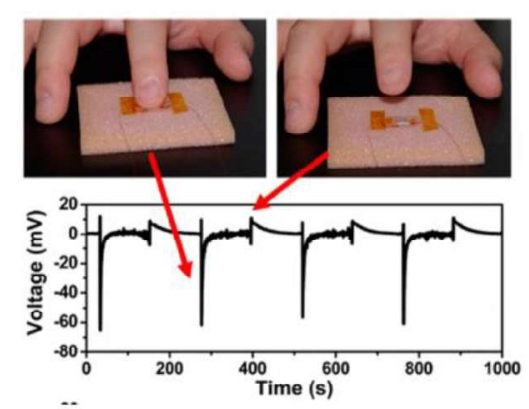

(c)

Fig. 5 Thermoelectric energy harvesting for BSN application: (a) Schematic diagram of a thermocouple; (b) Composition of a TEG with multiple thermocouples (Wang et al. 2009) (reprinted with permission from Elsevier); (c) A self-powered temperature sensor based on pyroelectric nanogenerator (Yang et al. 2012c) (reprinted with permission from American Chemical Society).

Table-6 Summary of micro TEGs for BSN application

\begin{tabular}{|c|c|c|c|c|c|c|}
\hline Reference & Sensor & Position & Material & Size & Voltage & Power \\
\hline $\begin{array}{l}\text { (Gyselinckx et al. } \\
2005 \text { ) }\end{array}$ & EEG & wrist & SiGe & $\begin{array}{l}4.5 \times 3 \times 0.8 \\
\mathrm{~mm}^{3}\end{array}$ & $1.7-3.5 \mathrm{~V}$ & $4 \mu \mathrm{W}$ \\
\hline $\begin{array}{l}\text { (Leonov et al. } \\
2005 \text { ) }\end{array}$ & & wrist & BiTe & $\begin{array}{l}3 \times 3 \times 1 \\
\mathrm{~cm}^{3}\end{array}$ & $1-1.5 \mathrm{~V}$ & $100 \mu \mathrm{W}$ \\
\hline (Torfs et al. 2006) & Pulse oximeter & wrist & BiTe & & $1.2-2 \mathrm{~V}$ & $100-200 \mu \mathrm{W}$ \\
\hline (Wang et al. 2007) & & wrist & $\begin{array}{l}\text { Poly- } \\
\text { SiGe }\end{array}$ & & $1 \mathrm{~V}$ & $1-2 \mu \mathrm{W}$ \\
\hline $\begin{array}{l}\text { (Leonov et al. } \\
\text { 2007) }\end{array}$ & & wrist & BiTe & & & $\begin{array}{l}250 \mu \mathrm{W} \\
20 \mu \mathrm{W} \mathrm{cm}{ }^{-2}\end{array}$ \\
\hline (Wang et al. 2009) & & wrist & $\begin{array}{l}\text { Poly- } \\
\text { SiGe }\end{array}$ & & $\begin{array}{l}0.15 \mathrm{~V} \\
12.5 \\
\mathrm{~V} /\left(\mathrm{K}^{2} \mathrm{~cm}^{2}\right)\end{array}$ & $\begin{array}{l}0.3 \mathrm{nW} \\
0.026 \mu \mathrm{W} /\left(\mathrm{K}^{2} \mathrm{~cm}^{2}\right)\end{array}$ \\
\hline $\begin{array}{l}\text { (Leonov et al. } \\
2009 \text { ) }\end{array}$ & ECG & clothes & & $\begin{array}{l}3 \times 4 \times 0.65 \\
\mathrm{~cm}^{3}\end{array}$ & $1 \mathrm{~V}$ & $0.8-3 \mathrm{~mW}$ \\
\hline (Hoang et al. 2009) & Fall Detection & & & & & $40-520 \mu \mathrm{W}$ \\
\hline (Zhang et al. 2013) & $\begin{array}{l}\text { ECG, EMG, } \\
\text { EEG }\end{array}$ & & $\mathrm{BiTe}$ & $4 \times 4 \mathrm{~cm}^{2}$ & $\begin{array}{l}30 \mathrm{mV} \\
(1.35 \mathrm{~V})\end{array}$ & $60-200 \mu \mathrm{W}$ \\
\hline (Kappel et al. 2013) & Temperature & & & $\begin{array}{l}0.5 \times 0.2 \\
\mathrm{~mm}^{2}\end{array}$ & $\begin{array}{l}250 \mathrm{mV} / \mathrm{K} \\
(1.2 \mathrm{~V})\end{array}$ & \\
\hline (Voss et al. 2014) & & $\begin{array}{l}\text { Upper } \\
\text { arm/ wrist }\end{array}$ & & & & $\begin{array}{l}0.238-1.65 \mathrm{~mW} \\
\text { (wrist) }\end{array}$ \\
\hline $\begin{array}{l}\text { (Kanan and } \\
\text { Bensalem 2016) }\end{array}$ & Temperature & wrist & BiTe & $4 \mathrm{x} 4 \mathrm{~cm}^{2}$ & $\begin{array}{l}50 \mathrm{mV} \\
(3 \mathrm{~V})\end{array}$ & $50 \mu \mathrm{W}$ to $15 \mathrm{~mW}$ \\
\hline
\end{tabular}

\subsubsection{Kinetic energy harvesting}


In addition to thermal energy, the kinetic activity of human body also generates mechanical energy every day, which can be utilized to power the BSN if it can be efficiently converted to electricity. To achieve this goal, various kinetic energy harvesters such as electromagnetic generator, piezoelectric generator and triboelectric generator have been investigated in Fig. 6(a). The electromagnetic generator is mainly composed of a magnet and a coil, which can generate electricity by electromagnetic induction when there is a relative displacement between them. In the case of wearable applications, the linear vibration movement is much more common than the rotation movement, while the latter is generally employed in large stationary generators (De Pasquale 2013). The piezoelectric generator utilizes the piezoelectric effect of certain materials to generate electricity when mechanical stress is applied (Fig. 6(b)), which can not only harvest energy from repetitive movements such as respiration, heartbeat, blood circulation and walking, but also be used as a self-powered body sensor. As for the triboelectric generator as shown in Fig. 6(c), it can utilize the static electricity generated by two different materials when there is a sliding or contact/separation movement between them. Similarly, this technology is also highly promising for developing self-powered body sensors. Compared with thermoelectric energy harvesting, the kinetic energy harvesters can provide much higher voltage of tens of volts with low-frequency body motions.

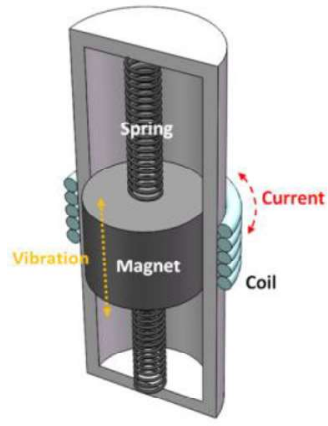

(a)

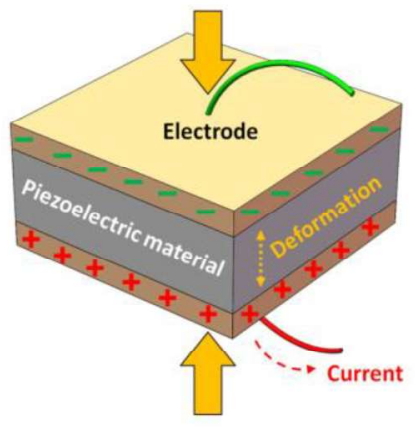

(b)

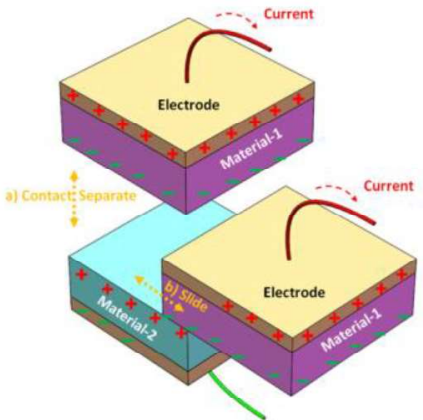

(c)

Fig. 6 Different types of kinetic energy harvesters for BSN application: (a) Electromagnetic generator; (b) Piezoelectric generator; (c) Triboelectric generator.

In literature, the application of kinetic energy harvesters in BSN is quite scarce. Olivo et al. employed an electromagnetic motor to harvest kinetic energy from human movements (Olivo et al. 2010). By using a supercapacitor to collect the harvested charge and an extra boosting circuit, 
their energy system can power the sensor node up to seven times faster than that with only a single supercapacitor. Orecchini et al. embedded a piezoelectric pushbutton in a shoe in order to scavenge the energy from human walking (Orecchini et al. 2011). With each step, $850 \mu \mathrm{J}$ energy could be harvested and stored in a capacitor, which was then used to power a RFID tag for human positioning, tracking and sensing. Huang et al. developed a triboelectric generator using two triboelectric layers in a mass-spring system (Huang et al. 2016). With a low motion frequency of 1-10 Hz, a voltage output of $20 \mathrm{~V}$ could be generated without external signal conditioning circuits. In addition to these conventional designs, recently the piezoelectric nanogenerator and triboelectric nanogenerator were also proposed by utilizing nanostructured materials, which are specifically reviewed in following sections considering their fast development and great potential for BSN application.

\section{Piezoelectric nanogenerator}

Piezoelectric nanogenerator (PENG) based on a $\mathrm{ZnO}$ nanowire array was first proposed in 2006 (Wang and Song 2006). Afterwards, more and more efforts have been made focusing on two main aspects, namely, improving its power output and energy efficiency, and employing it as self-powered sensors. As for its application in BSN, both PENG-based power sources and PENG-based body sensors have been developed, which is not only wearable but also implantable as shown in Fig. 7(a-c).

As shown in Fig. 7(a), Li et al. developed a PENG based on single $\mathrm{ZnO}$ nanowire, which was implanted on the diaphragm and heart of a live rat in order to harvest the mechanical energy from its respiration and heartbeat, respectively ( $\mathrm{Li}$ et al. 2010). This single wire generator could provide an OCV of $50 \mathrm{mV}$ and a short-circuit current of $0.5 \mathrm{nA}$. Hwang et al. reported a flexible PENG based on single crystalline $\mathrm{Pb}\left(\mathrm{Mg}_{1 / 3} \mathrm{Nb}_{2 / 3}\right) \mathrm{O}_{3}-\mathrm{PbTiO}_{3}$, which could be used as a selfpowered cardiac pacemaker (Hwang et al. 2014). The PENG thin film generated a voltage of 8.2 $\mathrm{V}$ and a current output of $145 \mu \mathrm{A}$ through repetitive bending, which was successfully demonstrated as pacemaker in a live rat. Chou et al. dispersed the piezoelectric particles $\left(\mathrm{PbZr}_{0.52} \mathrm{Ti}_{0.48} \mathrm{O}_{3}\right)$ and Ag-coated glass microspheres into a silicon rubber matrix, and used them to fabricate a stretchable PENG (Chou et al. 2018). The OCV and current output could reach 20 $\mathrm{V}$ and $0.55 \mu \mathrm{A}$, respectively. Hu et al. proposed a self-powered BSN system using PENG as a power source (Hu et al. 2011). It can work wirelessly and autonomously with long-distance data 
transmission ability $(5-10 \mathrm{~m})$. The PENG was made of a five-layer free cantilever beam, which could provide a voltage of $10 \mathrm{~V}$ and a current output of $0.6 \mu \mathrm{A}$. In general, the current PENG provides relatively small current output, which restricts its application to low-power sensors only. Alternatively, the continuously generated electricity can be stored in a supercapacitor first, which is suitable for sensors with long standby period and low-frequency mission.

The PENG can also be used as self-powered sensors for testing various body movements, such as heartbeat, pulse and gesture. $\mathrm{Wu}$ et al. employed a cellular polypropylene piezoelectret as a flexible PENG, which was used to detect physiological signals such as coughing and arterial pulse (Wu et al. 2015a). Chen et al. developed a stretchable and transparent PENG as shown in Fig. 7(b), which used sprayed Ag nanowire as electrodes and a nanocomposite of $\mathrm{BaTiO}_{3}$ and PDMS as piezoelectric layer (Chen et al. 2017a). When attached conformally to the human body, this device could monitor various physiological signals such as eye movement, speaking and artery pulse. Maity and Mandal developed an all-organic PENG by employing the electro-spun PVDF nanofiber as piezoelectric layer and PEDOT-deposited PVDF nanofiber as electrodes (Maity and Mandal 2018). The PENG sensor showed a high sensitivity towards human movements such as walking and foot strikes, which could also be used as self-powered vibration sensor. Yan et al. presented an ultrathin $(80 \mu \mathrm{m})$ PENG-based pressure sensor as shown in Fig. 7(c), which was framed by caging the piezoelectric nanoparticles inside the 3D cellular electret mimicking the human epidermis (Yan et al. 2018). The self-powered sensor could be used for heartbeat measurement, eyeball motion detection and tactile imaging. By replacing the conventional energy-consuming body sensors, the PENG-based sensors can help to reduce the energy consumption of the whole BSN system.

More details about the PENG-based energy harvesters and self-powered sensors can be found in a more specific review paper (Hu and Wang 2015). 


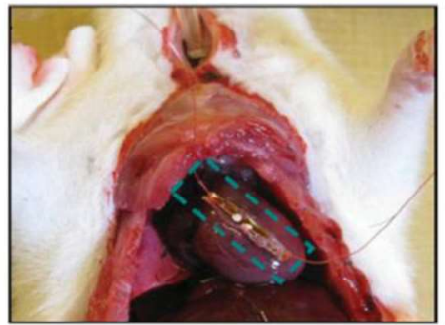

(a)

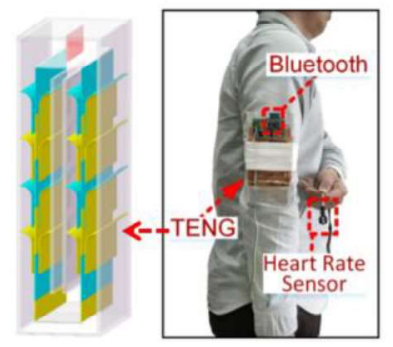

(d)

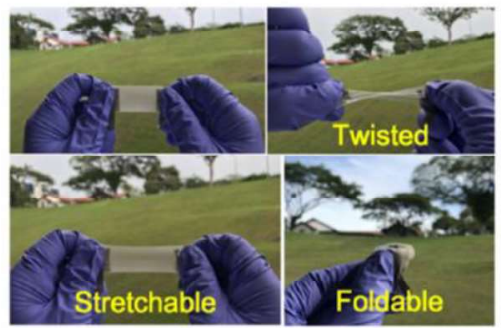

(b)

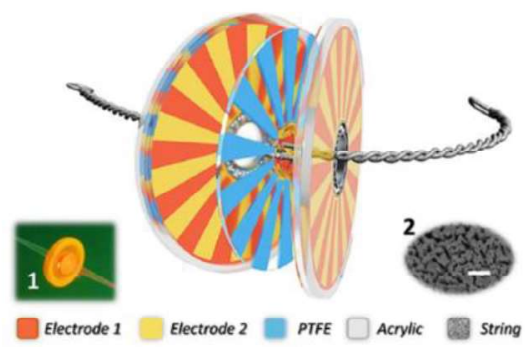

(e)

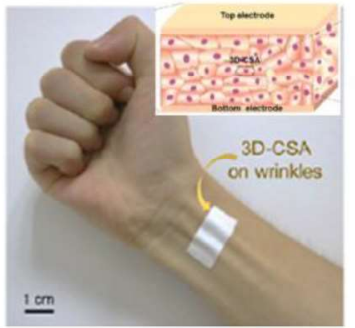

(c)

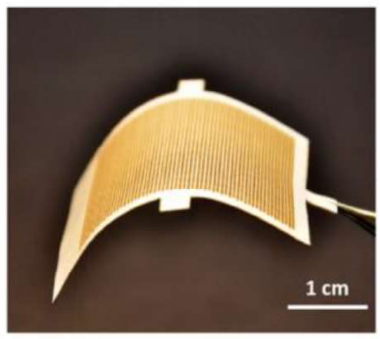

(f)

Fig. 7 PENGs and TENGs for BSN application: (a) A single-wire PENG implanted on the heart surface of a live rat (Li et al. 2010) (reprinted with permission from John Wiley \& Sons); (b) A transparent and stretchable PENG (Chen et al. 2017a) (reprinted with permission from American Chemical Society); (c) An ultrathin PENG as self-powered sensor on skin surface (Yan et al. 2018) (reprinted with permission from American Chemical Society); (d) A 3D TENG harvesting the linear vibration energy and powering a heart rate sensor (Lin et al. 2017) (reprinted with permission from American Chemical Society); (e) A rotational TENG harvesting the rotation energy by an active pulling (Tang et al. 2018) (reprinted with permission from Elsevier); (f) A flexible TENG fabricated on paper (Fan et al. 2015) (reprinted with permission from American Chemical Society).

\section{Triboelectric nanogenerator}

Triboelectric nanogenerator (TENG) can harvest various forms of mechanical energy, from large-scale wind energy on rooftop (Zhang et al. 2016b) and wave energy in ocean (Chen et al. 2015b), to small-scale body energies such as walking and heartbeat, which also has a wide range of working temperature from 77 to $320 \mathrm{~K}$ (Su et al. 2015). Great efforts have been made since its first appearance in 2012 (Fan et al. 2012), which is especially suitable for powering on-body biosensors considering its low fabrication cost and high cycling robustness (Chen and Wang 2017; Lin et al. 2016; Zhu et al. 2015). 
In the beginning, 3D TENGs based on linear vibration were developed, which can be mounted either on human body or on various accessories such as backpack (Yang et al. 2013b) and shoe insole (Hou et al. 2013; Zhu et al. 2013a). Yang et al. developed a 3D TENG utilizing both the vertical contact/separation and in-plane sliding movements, which can achieve power density as high as $145 \mu \mathrm{W} \mathrm{cm}$ cm $^{-2}$ (Yang et al. 2014b). They also designed a triple-cantilever based TENG using $\mathrm{ZnO}$ nanowire arrays on the surface of beryllium-copper alloy foil (Yang et al. 2013a). The OCV was up to $101 \mathrm{~V}$ and the power density was $25.2 \mu \mathrm{W} \mathrm{cm} \mathrm{cm}^{-2}$. Chen et al. designed a harmonic-resonator-based TENG which could harvest tiny vibration with amplitude less than 3 $\mathrm{mm}$ (Chen et al. 2013). A high OCV of $287.4 \mathrm{~V}$ and a power density of $72.6 \mu \mathrm{W} \mathrm{cm} \mathrm{cm}^{-2}$ were achieved. Zhu et al. utilized the fully-contacted, sliding electrification process to develop TENG, which also used the grating of linear rows on sliding surface to maximize the power output (Zhu et al. 2013b). Their TENG could harvest various forms of sliding energy, such as rotation, rolling and linear piston motion. Zhang et al. designed a spherical TENG which was composed of an outer transparent shell, an inner PFA ball and an aluminum electrode (Zhang et al. 2014a). This device could deliver an OCV of $57 \mathrm{~V}$ and a power output of $128 \mu \mathrm{W}$. To further improve the output current and power, Yang et al. developed a 3D stacked integrated TENG system with multilayers of single TENG cells (Yang et al. 2014c). With improved surface area and superior synchronization, a high current output of $1.14 \mathrm{~mA}$ was achieved, together with a power density as high as $10.46 \mathrm{~mW} \mathrm{~cm}^{-2}$. Jing et al. developed a case-encapsulated TENG to harvest energy from reciprocating sliding (Jing et al. 2014). With multiple sets of grating electrodes, a power density of $136 \mu \mathrm{W} \mathrm{cm}{ }^{-2}$ could be achieved at a sliding rate of $1 \mathrm{~m} \mathrm{~s}^{-1}$. As shown in Fig. 7(d), Lin et al. developed a downy-structure TENG for powering a heart rate sensor (Lin et al. 2017). When mounted on the upper arm, the device could obtain a maximum power of $2.28 \mathrm{~mW}$ from walking with a conversion efficiency of 57.9\%. They also developed a TENG-based heart rate sensor on the wrist and combined it with the TENG power unit. With rational design, the TENG can also harvest acoustic energy (Yang et al. 2014a). However, the power density of $6 \mu \mathrm{W} \mathrm{cm}^{-2}$ was relatively low compared with the above-mentioned TENGs with direct vibration.

In addition to the vibration energy, TENG can also be used to harvest the rotation energy. Zhu et al. proposed a radial-arrayed TENG which was mainly composed of a copper rotator and a composite stator (Zhu et al. 2014a). When the external movement triggered the rotation, a high power output of $1.5 \mathrm{~W}$ could be delivered with an efficiency of $24 \%$, corresponding to a power 


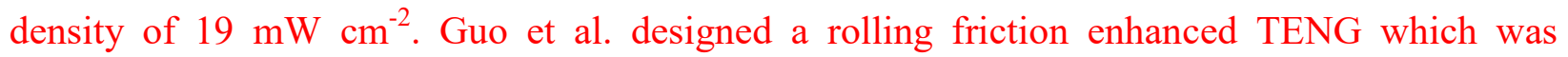
composed of a rotator, a stator and an aluminum rod on the outer surface (Guo et al. 2015). With a rotation rate of $1000 \mathrm{r} \mathrm{min}^{-1}$, this TENG could generate a power output of $25 \mu \mathrm{W} \mathrm{cm}{ }^{-2}$. Chen et al. presented an automatic-transition TENG which could utilize the rotation energy effectively with the help of two magnets (Chen et al. 2015a). With $6.5 \mathrm{~m} \mathrm{~s}^{-1}$ wind blow or $5.5 \mathrm{~L} \mathrm{~min}^{-1}$ water flow, this harvester could charge a capacitor to $120 \mathrm{~V}$ within $60 \mathrm{~s}$. Kuang et al. proposed a 2D rotary TENG which could harvest energy effectively from human body motions, such as foot pedaling, arm swinging and foot pressure (Kuang et al. 2015). At $500 \mathrm{r} \mathrm{min}^{-1}$, a voltage of $200 \mathrm{~V}$ and a current output of $0.75 \mathrm{~mA}$ were generated. In addition to passive activities such as respiration and walking, Tang et al. reported a whirligig-shape TENG powered by active pulling by the user as shown in Fig. 7(e) (Tang et al. 2018). With one pulling, a charge capacity of 310 $\mu \mathrm{C}$ and a power output of $40.18 \mathrm{~mW}$ can be obtained, while the peak voltage and current could reach $153 \mathrm{~V}$ and $317 \mu \mathrm{A}$, respectively. Nevertheless, the rotation movement is not as common as the vibration movement in human body, which is also difficult to achieve high device flexibility for on-body applications.

To better accommodate wearable applications, flexible TENGs have been developed recently. Yang et al. fabricated a human skin-based TENG which utilized the contact/separation between the human skin and a PDMS film with micro-pyramid surface structure (Yang et al. 2013e). The OCV was as high as $1000 \mathrm{~V}$ and the power density could reach $50 \mu \mathrm{W} \mathrm{cm}{ }^{-2}$. By employing a thin-film Kapton as substrate, Bai et al. demonstrated a flexible multilayered TENG with a weight of $7 \mathrm{~g}$ (Bai et al. 2013). With a power output of $9.8 \mathrm{~mW} \mathrm{~cm}^{-2}$, this flexible TENG could be integrated into clothes or attached onto human body directly. Zhu et al. developed a thin-film TENG with micro grating (0.6 g weight and $60 \mathrm{~cm}^{2}$ area), which was also highly flexible and shape-adaptive (Zhu et al. 2014b). With a sliding velocity of $10 \mathrm{~m} \mathrm{~s}^{-1}$, it could deliver an average power output as high as $3 \mathrm{~W}\left(50 \mathrm{~mW} \mathrm{~cm}^{-2}\right)$. Fan et al. used paper as a soft substrate and developed a paper-based flexible TENG as shown in Fig. 7(f), which was only $125 \mu \mathrm{m}$ thick (Fan et al. 2015). It could harvest the acoustic energy with a maximum power density of 12.1 $\mu \mathrm{W} \mathrm{cm} \mathrm{cm}^{-2}$. Liu et al. developed a stretchable and deformable TENG using thermally triggered shape memory polymer as substrate material, which could exhibit an OCV of $220 \mathrm{~V}$ and a power density of $28.2 \mu \mathrm{W} \mathrm{cm} \mathrm{cm}^{-2}$ (Liu et al. 2018b). Furthermore, the flexible TENG can be implanted to harvest energy from inside the body. Zheng et al. implanted their TENG under the left chest skin 
of a living rat to harvest energy from its periodic breathing, which generated an average voltage of $3.73 \mathrm{~V}$ and a current of $0.14 \mu \mathrm{A}$ (Zheng et al. 2014). The harvested energy was then successfully used to power a pacemaker. To sum up, the thin-film and flexible PENG represents a promising energy solution to both wearable and implanted BSNs, provided that its power and current density can be further improved in near future.

In addition to energy harvesting, the TENG can also be used as self-powered body sensors, which is primarily targeted for pressure change detection (Wang et al. 2015; Zhang et al. 2017). Bai et al. developed a membrane-based TENG sensor which could sense the variation of surface triboelectric charges induced by the change in air pressure (Bai et al. 2014). The as-fabricated device could sense the footstep, respiration and heartbeat with high resolution. Inspired by human eardrum, Yang et al. developed a PENG-based bionic membrane sensor which achieved a superior sensitivity of $51 \mathrm{mV} \mathrm{Pa}^{-1}$ and a fast response time less than $6 \mathrm{~ms}$ (Yang et al. 2015). It was demonstrated for cardiovascular system characterization as well as voice recognition. Lin et al. designed a large-scale and washable smart textile based on TENG sensor array, which was fabricated by conductive fibers and elastomeric materials with a wave structure (Lin et al. 2018). Integrated with data processing and wireless transmission functions, such a sensing textile could be used for real-time sleep monitoring and sleep quality evaluation. Meng et al. fabricated a flexible self-powered pressure sensor by the weaving method, which was extremely stable for up to 40000 motion cycles (Meng et al. 2019). The flexible sensor could be used for blood pressure measurement and continuous diagnosis of cardiovascular disease. Xia et al. also developed a flexible PENG-based sensor for temperature monitoring, which was composed of PVDF, PTFE and $\mathrm{Cu}$ foil electrode (Xia et al. 2018). The detection range was $10-90{ }^{\circ} \mathrm{C}$ and the response time was as short as $0.01 \mathrm{~s}$. In addition to these, the TENG-based sensors can also be used for location tracking (Su et al. 2014), human-machine interfacing (Yang et al. 2014d) and angle measurement (Wu et al. 2015b) by rational design, which will further improve the function of BSN without extra power consumption.

\subsubsection{Radiofrequency energy harvesting}

Benefited from their ubiquitous existence in urban and suburban areas, radiofrequency (RF) transmissions from telecommunication networks is an abundant source for energy harvesting in a BSN system, such as outdoor mobile base station, TV station, radio station and indoor Wi-Fi as 
shown in Fig. 8(a) (Barroca et al. 2012). With the help of a rectifying antenna (rectenna), the RF energy in the ambient can be converted to direct current and stored in batteries/supercapacitors. Table-7 summarizes recent studies using RF energy harvesting to power BSN. The general harvestable power is dozens of $\mu \mathrm{W}$, and the distance between the sensor and RF source can reach as long as $10 \mathrm{~m}$. Nevertheless, due to the relatively large size of antenna, the power density is not as good as other energy harvesting technologies, which is only $0.01-0.1 \mu \mathrm{W} \mathrm{cm}{ }^{-2}$ (Borges et al. 2015).

Mandal et al. developed a wearable tag including a custom integrated circuit, an antenna for RF energy harvesting, and various biosensors for monitoring electrical heart signals, blood oxygen saturation and body temperature (Mandal et al. 2010). With a RF source of $800 \mathrm{~mW}$ at a distance of $3.1 \mathrm{~m}$, an output power of $15 \mu \mathrm{W}$ could be obtained. If the RF source power was further increased to $4 \mathrm{~W}$, the distance could be further extended to $7 \mathrm{~m}$. Barroca et al. examined a series of outdoor RF energy sources for BSN energy harvesting (Barroca et al. 2012). It was found that more energy can be obtained from radio broadcast stations (79-96 MHz), emergency broadcast stations (391 MHz), television broadcast stations (750 to $759 \mathrm{MHz}$ ), GSM 900 broadcast stations (935 to $960 \mathrm{MHz}$ ), GSM 1800 broadcast stations (1854 to $1870 \mathrm{MHz}$ ) and UMTS broadcast stations (2115-2160 MHz). With the distance between sensor node and RF source shortened from $11 \mathrm{~m}$ to $1.5 \mathrm{~m}$, the scavenged power could be improved from $1 \mu \mathrm{W}$ to $1.9 \mathrm{~mW}$. Xia et al. also developed a BSN powered by far-field RF energy harvesting (Xia et al. 2014). To increase the energy harvesting sensitivity, a rectifier with on-chip maximum efficiency tracking loop is employed. The RF-powered BSN could function normally at a distance of $3 \mathrm{~m}$ for a base-station power of $20 \mathrm{dBm}$ (that is, $100 \mathrm{~mW}$ ), and $9 \mathrm{~m}$ for $30 \mathrm{dBm}$ (that is, $1 \mathrm{~W}$ ).

To harvest more energy from far-field RF sources, multi-band rectenna is more advantageous than its single-band counterpart, which can utilize RF sources with a broader frequency range. Barreca et al. developed a dual-band printed antenna to harvest RF energy from both GSM 900 and GSM 1800, which was implemented within clothes for wearable applications (Barroca et al. 2013). When the distance was less than $9 \mathrm{~m}$, the harvestable power was more than $100 \mu \mathrm{W}$. Liu et al. further developed a triple-band RF energy harvester which could utilize GSM-900, GSM1800 and UMTS-2100 (Liu et al. 2014). Compared with the sum of three separate single-band harvesters, the triple-band harvester could achieve a conversion efficiency of $31.2 \%$, which was 1.59 times of the former case. Yang et al. also developed a triple-band RF energy harvester 
which covered GSM-900, UMTS-2100 and TD-LTE (Yang et al. 2018). High RF to DC conversion efficiencies of 59\%, 49\% and $48 \%$ could be achieved, respectively.

In addition to far-field RF sources, near-field RF sources on body, such as wearable devices and cell phones, can also be utilized to transmit RF power to the sensor node nearby as shown in Fig. 8(b). Yan et al. used patch-type sensor to monitor the ECG signal, which could receive RF energy from a chest band with $4 \times 12$ inductor arrays (Yan et al. 2010). With a RF of $13.56 \mathrm{MHz}$, the sensor nodes harvested the energy via their adaptive threshold rectifier, which could generate a power of $20 \mu \mathrm{W}$ with a conversion efficiency of $54.9 \%$. Cheng et al. developed a nearthreshold, multi-node BSN powered by RF energy harvesting (Cheng et al. 2012). A smartphone was employed as a base station to send broadcasts at $434.16 \mathrm{MHz}$, which functioned well at over $1.4 \mathrm{~m}$ distance between the smart-phone and the sensors.

Furthermore, the existing radiofrequency identification (RFID) technology can also be applied in the healthcare industry (Amendola et al. 2014). A RFID system is mainly composed of multiple passive (without power unit) or active (with power unit) tags, together with a reader which can generate an electrical magnetic field for powering the passive tags. By adding functions such as sensing and computation to the tags, the RFID technology can be evolved from logistics application to the healthcare sector. More importantly, the passive tags need no external power sources and can be wirelessly powered by the reader, eliminating the battery issues such as insufficient energy density and troublesome recharge or replacement. However, one of the main disadvantages of a RFID-based healthcare is its limited coverage region, that is, $15 \mathrm{~m}$ with passive tags and $25 \mathrm{~m}$ with active tags (Catarinucci et al. 2015). Therefore, its application has been restricted to near-field functions such as patient identification and monitoring in hospitals or sanatoriums.

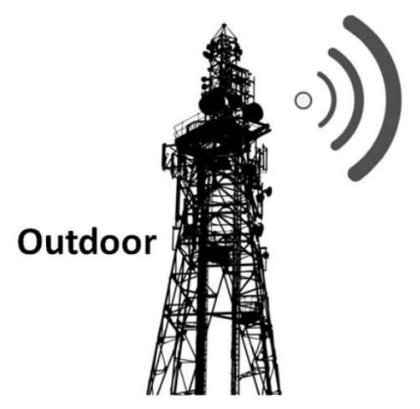

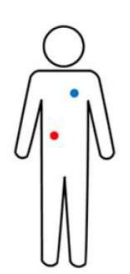

(a)
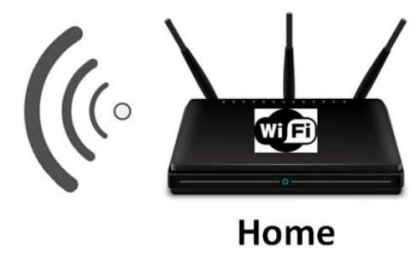

Home

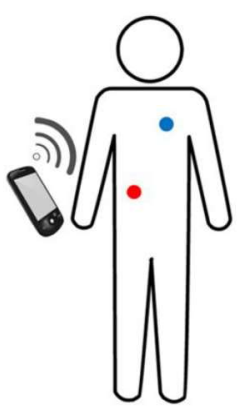

(b) 
Fig. 8 RF energy harvesting technology for powering BSN: (a) Schematic diagram of the farfield RF energy harvesting from both outdoor base station and indoor Wi-Fi; (b) Schematic diagram of the near-field energy harvesting from portable electronic devices. (free clip arts downloaded from openclipart.org)

Table-7 Summary of RF energy harvesting for BSN application

\begin{tabular}{|c|c|c|c|c|c|c|c|}
\hline Reference & Sensor type & Node size & Power* & $\begin{array}{l}\begin{array}{l}\text { Energy } \\
\text { efficiency }\end{array} \\
\end{array}$ & Distance & $\begin{array}{l}\text { RF source } \\
\text { power* }\end{array}$ & $\begin{array}{l}\text { RF source } \\
\text { frequency }\end{array}$ \\
\hline \multirow{2}{*}{$\begin{array}{l}\text { (Mandal et al. } \\
2010 \text { ) }\end{array}$} & \multirow{2}{*}{$\begin{array}{l}\text { Phono- } \\
\text { cardiogram }\end{array}$} & & \multirow{2}{*}{$15 \mu \mathrm{W}$} & & $3.1 \mathrm{~m}$ & $800 \mathrm{~mW}$ & \multirow[t]{2}{*}{$800 \mathrm{MHz}$} \\
\hline & & & & & $7 \mathrm{~m}$ & $4 \mathrm{~W}$ & \\
\hline $\begin{array}{l}\text { (Yan et al. } \\
2010)\end{array}$ & ECG & $\begin{array}{l}3 \mathrm{~cm} \times 3 \mathrm{~cm} \\
\text { (antenna) }\end{array}$ & $20 \mu \mathrm{W}$ & $54.9 \%$ & & & $\begin{array}{l}13.56 \\
\mathrm{MHz}\end{array}$ \\
\hline $\begin{array}{l}\text { (Cheng et al. } \\
2012 \text { ) }\end{array}$ & $\begin{array}{l}\text { ECG, EEG, } \\
\text { EMG, } \\
\text { Temperature }\end{array}$ & & $25 \mu \mathrm{W}$ & $16 \%$ & $1.4 \mathrm{~m}$ & $1 \mathrm{~W}$ & $\begin{array}{l}434.16 \\
\mathrm{MHz}\end{array}$ \\
\hline $\begin{array}{l}\text { (Barroca et al. } \\
\text { 2012) }\end{array}$ & & & $1-1925 \mu \mathrm{W}$ & & $\begin{array}{l}1.52- \\
10.97 \mathrm{~m}\end{array}$ & & $\begin{array}{l}79-2160 \\
\mathrm{MHz}\end{array}$ \\
\hline \multirow{2}{*}{$\begin{array}{l}\text { (Xia et al. } \\
2014)\end{array}$} & \multirow[t]{2}{*}{ Temperature } & & \multirow[t]{2}{*}{$10 \mu \mathrm{W}$} & & $3 \mathrm{~m}$ & $100 \mathrm{~mW}$ & \multirow{2}{*}{$\begin{array}{l}904.5 \\
\mathrm{MHz}\end{array}$} \\
\hline & & & & & $9 \mathrm{~m}$ & $1 \mathrm{~W}$ & \\
\hline $\begin{array}{l}\text { (Barroca et al. } \\
\text { 2013) }\end{array}$ & & $12 \mathrm{~cm} \times 8 \mathrm{~cm}$ & $>100 \mu \mathrm{W}$ & & $<9 \mathrm{~m}$ & $3 \mathrm{~W}$ & $\begin{array}{l}900 \mathrm{MHz} \\
1800 \mathrm{MHz}\end{array}$ \\
\hline $\begin{array}{l}\text { (Liu et al. } \\
2014 \text { ) }\end{array}$ & & $11 \mathrm{~cm}$ length & $10 \mu \mathrm{W}$ & $31.2 \%$ & & & $\begin{array}{l}900 \mathrm{MHz} \\
1800 \mathrm{MHz} \\
2100 \mathrm{MHz}\end{array}$ \\
\hline $\begin{array}{l}\text { (Yang et al. } \\
2018 \text { ) }\end{array}$ & Temperature & $\begin{array}{l}6.6 \mathrm{~cm} \mathrm{x} \mathrm{7cm} \\
\text { (antenna) }\end{array}$ & & $\begin{array}{l}59 \% \\
49 \% \\
48 \%\end{array}$ & & $100 \mu \mathrm{W}$ & $\begin{array}{l}900 \mathrm{MHz} \\
2025 \mathrm{MHz} \\
2360 \mathrm{MHz}\end{array}$ \\
\hline
\end{tabular}

* Power unit of $\mathrm{dBm}$ has been converted to $\mathrm{W}$ for universal comparison

\subsubsection{Solar energy harvesting}

Solar energy is one of the most abundant energy sources that can be utilized to power wearable BSN, which is generally harvested by solar cells. Among them, the second-generation thin-film solar cells are much more popular than the first-generation crystalline silicon solar cells because of their high flexibility, light weight and low cost. To date, commercial solar cells can generate up to $100 \mathrm{~mW} \mathrm{~cm}^{-2}$ of electric power under bright sunlight (10,000-100,000 lux), which is sufficient for most body sensors (Toh et al. 2014). Nevertheless, at indoor environment (320$500 \mathrm{lux}$ ), which is more common for BSN application, the harvestable power is much reduced to less than $1 \mathrm{~mW} \mathrm{~cm}^{-2}$ (Vieira et al. 2003). Therefore, large area of solar panel is generally required, which inevitably decreases the user comfort level. Toh et al. employed a flexible photovoltaic panel $(7.2 \mathrm{~cm} \times 6 \mathrm{~cm})$ to harvest solar energy for their temperature sensor node 
(Toh et al. 2014). A power management circuit was also integrated to maximize the harvested electrical power. Operated in an indoor environment of $320 \mathrm{lux}$, an output power of $56 \mu \mathrm{W}$ was achievable, which could power a wearable sensor node for more than 15 hours. Liberale et al. used a thin-film, flexible and stretchable photovoltaic cell to power a wearable sensor node (Liberale et al. 2014). With 500 lux of indoor light, the cell could provide a current of $0.1 \mathrm{~mA}$ at $2.5 \mathrm{~V}$, corresponding to a power output of $250 \mu \mathrm{W}$. Voss et al. compared the performance of three different solar cells with different areas at either the upper arm or the wrist (Voss et al. 2014). In general, the power output was proportional to the cell area, which was also highly sensitive to the indoor light conditions. For instance, the $37 \mathrm{~mm}$ x $114 \mathrm{~mm}$ solar cell provided as high as $43 \mathrm{~mW}$ when facing the window, while it was only $0.83 \mathrm{~mW}$ with fluorescent only.

To reduce the system volume, sensors can be integrated on the back of solar panel. Wu et al. developed a wearable BSN using a flexible solar panel $(7.2 \mathrm{~cm} \times 6 \mathrm{~cm})$ as substrate for an accelerometer, a temperature sensor and a photoplethysmography (PPG) sensor as shown in Fig. 9(a) (Wu et al. 2017). With 30-60 min of outdoor charging, the system could autonomously operate for 24 hours and meet the average power requirement of $1.76 \mathrm{~mW}$. The flexible solar panel can also be conveniently integrated into clothes, so that the user comfortness will not be compromised too much. Dionisi et al. developed a BSN on a T-shirt, which can monitor respiration rate, heart rate and body movement (Dionisi et al. 2016). A $27 \mathrm{~cm} \mathrm{x} 17.5 \mathrm{~cm}$ flexible solar panel on the T-shirt chest was utilized to power the whole system with a power consumption of $17 \mathrm{~mW}$. By comparison with physiological data obtained from commercial instruments, the accuracy of the BSN-based health monitoring was well verified. The solar cell can also work as a supplement for the secondary battery in BSN, so that the battery lifetime can be extended. Tran and Chung employed a flexible solar panel $(19 \mathrm{~cm} \mathrm{x} 4 \mathrm{~cm})$ to prolong the lifetime of a $500 \mathrm{~mA} \mathrm{~h}$ rechargeable battery for ECG sensor and PPG sensor, which consumed $12.5 \mathrm{~mA}$ at $3.3 \mathrm{~V}$ (Tran and Chung 2016). Under an irradiance of $2.9 \mathrm{~mW} \mathrm{~cm}^{-2}$, the lifetime of the BSN was prolonged by $950 \%$. However, the increment of the system volume and weight should also be carefully considered.

In addition to commercial thin-film solar cells available in the market, current research on the third-generation solar cells will also strongly support the development of solar-powered body sensors, such as organic solar cells, dye-sensitized solar cells and perovskite solar cells. These novel types of solar cells are potentially more cost-efficient and environmental-friendly than 
silicon-based solar cells. Nevertheless, long-term stability and energy conversion efficiency remain two great challenges at the moment, which requires further optimization in both cell structure and material. Among them, ultrathin organic solar cell with a total thickness less than $10 \mu \mathrm{m}$ is especially promising for wearable applications, which has much improved flexibility, reduced weight and good conformability for electronics on clothes or skin. Recently, Park et al. integrated a $3 \mu \mathrm{m}$-thick double-grating-patterned organic solar cell (Fig. 9(b)) with an organic electrochemical transistor as self-powered cardiac sensor (Park et al. 2018). The solar cell energy efficiency and the power density could reach $10.5 \%$ and $11.46 \mathrm{~W} \mathrm{~g}^{-1}$, respectively, while the self-powered sensor was successfully demonstrated on both human finger and rat heart surface. Huang et al. also developed a $3 \mu \mathrm{m}$-thick organic solar cell by using a fullerene/non-fullerene mixed acceptor, which could achieve an energy efficiency of 13\% (Huang et al. 2020). The solar cell was very robust when facing mechanical deformation, retaining $97 \%$ of the energy efficiency after 1000 bending cycles. Furthermore, Kimura et al. fabricated a $2.6 \mu \mathrm{m}$-thick organic solar cell using a $1.3 \mu \mathrm{m}$-thick transparent polyimide substrate, which achieved an energy efficiency of 9\% (Kimura et al. 2019). After 3 hours in the maximum power point tracking test, an efficiency of $90 \%$ was maintained, indicating its improved operational stability compared with those on rigid glass substrates. More information on ultrathin solar cells can be found in two recent review works (Fukuda et al. 2020; Yu et al. 2019a).

To sum up, flexible solar cell is a promising candidate for wearable BSN, but its relatively large area has impeded its practical application. To alleviate this issue, either a smart design of the solar cell (e.g., solar harvesting clothes) or a cooperation with other power sources (e.g., secondary batteries) can be adopted. The latter option is also good for the overall system reliability, considering the varying light conditions all day long. 

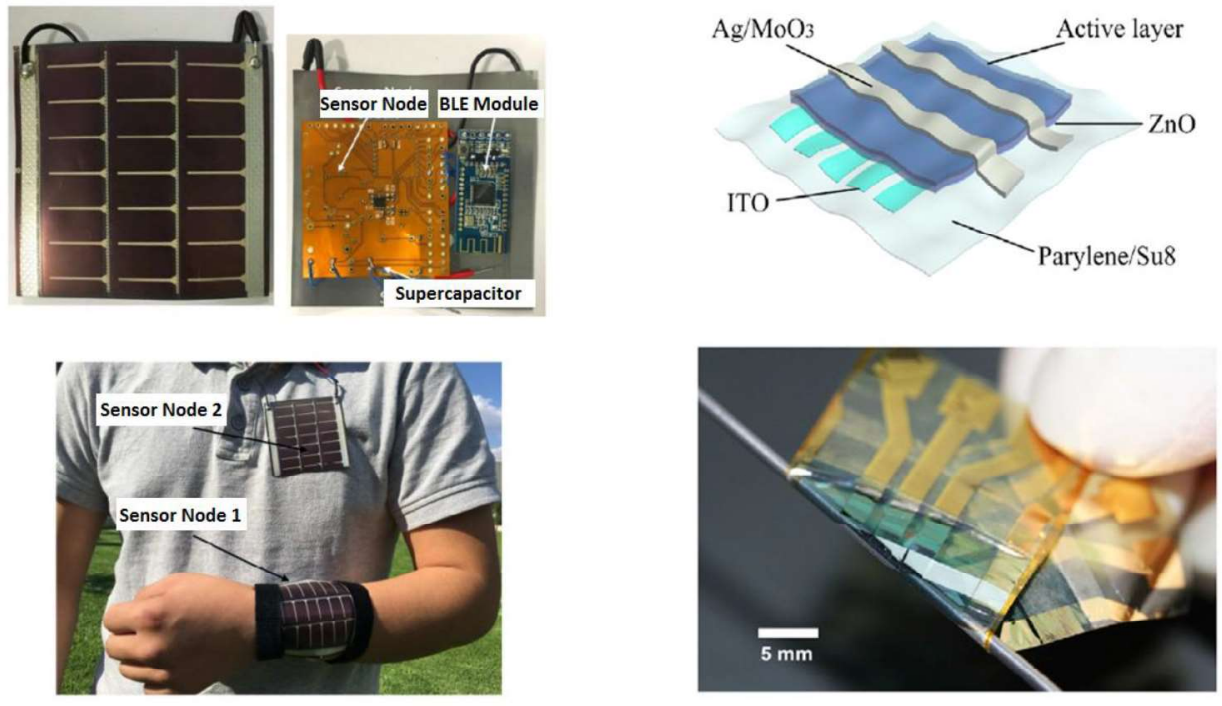

(a)

(b)

Fig. 9 Wearable sensor nodes with flexible solar energy harvester: (a) Second-generation thinfilm solar cell based on amorphous silicon (Wu et al. 2017) (reprinted from open access article); (b) Third-generation organic solar cell with ultra-small thickness (Huang et al. 2020) (reprinted with permission from Elsevier).

\subsubsection{Hybrid energy harvesting}

A single energy harvesting type is not robust to autonomous systems, which can be affected by many factors such as environmental conditions and body status. On the other hand, a hybrid energy harvesting system is much more stable and reliable, which can generate and store more energy at diversified conditions. In literature, hybrid energy harvesting has already been explored for different applications, such as energy rooftop (solar-triboelectric) (Zheng et al. 2015), traffic control (electromagnetic-triboelectric) (Zhang et al. 2016a) and safety helmet (Jin et al. 2016). As for BSN, two strategies for hybrid energy harvesting are investigated: one is a hybrid system including independent energy harvesters, and the other is a hybrid cell integrating different energy harvesting mechanisms.

In the former case, different energy harvesters are directly utilized in the same BSN. Leonov et al. employed a TEG (14 modules) and two PV cells to power their ECG sensor, which were all mounted on a shirt (Leonov et al. 2009). The TEG provided a power of $0.8-1 \mathrm{~mW}$ at sedentary status and up to $3 \mathrm{~mW}$ at walking status, while the PV cells generated $150-200 \mu \mathrm{W}$ at indoor environment. Wang et al. also utilized the TEG and PV cells to power their BSN (Wang et al. 
2011). The TEG was mainly responsible for powering sensing component, while the PV cells were used to power the signal processing and wireless communication circuits. An overall power consumption of $0.23 \mu \mathrm{W}$ was achieved in their study. Magno et al. developed a smart watch which was equipped with an ultra-low power camera, a microphone, an accelerometer, and a temperature sensor (Magno et al. 2016). In addition to a $40 \mathrm{~mA} \mathrm{~h}$ Li-polymer battery, 8 solar cells and 7 TEGs were integrated to the wrist band in order to harvest energy from ambient light and human body temperature. The solar cells could provide $550 \mu \mathrm{W}$ at indoor environment while the TEGs could deliver $98 \mu \mathrm{W}$ with $3{ }^{\circ} \mathrm{C}$ temperature difference.

The above strategy is convenient and effective, but will inevitably increase the system redundancy. Alternatively, different energy harvesting technologies can be integrated into a single device, which can be even flexible and stretchable with proper material and structure design. As shown in Fig. 10, various combinations have been proposed in literature, such as the kinetic-kinetic, thermal-kinetic, solar-kinetic (Yoon et al. 2015) and electrochemical-kinetic hybrid energy harvesting (Yang et al. 2013c). Among them, the kinetic-kinetic and thermalkinetic combinations are more frequently studied.

To improve the energy harvesting efficiency from body movements, piezoelectric, triboelectric and electromagnetic generators can be integrated into a single cell. Chen et al. developed a flexible PENG-TENG based on electrospun nanofiber mat as shown in Fig. 10(a), which could be attached conformally on human skin to harvest touch energies (Chen et al. 2017b). The peak power density was 84 and $0.11 \mu \mathrm{W} \mathrm{cm}$ from the triboelectric and piezoelectric parts, respectively. Song et al. also fabricated a flexible PENG-TENG using the electrospun PVDF-CNT-BaTiO 3 fabric as piezoelectric layer and the PDMS-CNT-graphite film as triboelectric layer (Song et al. 2018). The peak voltage was $161.66 \mathrm{~V}$ and the maximum power density was $222 \mu \mathrm{W} \mathrm{cm}{ }^{-2}$. When electromagnetic generator is further introduced, the thin-film structure is no longer feasible. Hamid and Yuce developed a 3D piezoelectric-electromagnetic cell for powering wearable sensors (Hamid and Yuce 2017). As shown in Fig. 10(b), a magnet inside a shell winded with coils could generate electromagnetic energy during body motion; meanwhile it also hit the piezoelectric transducers to generate piezoelectric energy, providing significantly higher power output than the individual energy harvesters. Yan et al. also developed a piezoelectric-electromagnetic cell for powering the wearable BSN (Yan et al. 2020). With a specific design, the low-frequency linear movement from human body was converted to high- 
frequency rotation first, which was then utilized to generate sufficient energy for a temperature sensor and a humidity sensor. Furthermore, He et al. developed a piezoelectric-triboelectricelectromagnetic ternary cell based on a magnetic levitation structure (He et al. 2018). As shown in Fig. 10(c), two electromagnetic generators, two piezoelectric generators and one triboelectric generator were integrated inside the same chamber, which could generate power of $74.4 \mathrm{~mW}$, $227 \mathrm{~mW}$ and $78.4 \mu \mathrm{W}$, respectively, under a vibration of $20 \mathrm{~Hz}$.

The thermal energy and kinetic energy can also be harvested at the same time. As shown in Fig. 10(d), Lee et al. integrated a $\mathrm{ZnO}$ nanowire-based PENG on the top of a BiTe-based TEG to produce a flexible hybrid cell (Lee et al. 2013). When connected in series, the hybrid cell provided a voltage of $0.12 \mathrm{~V}$ and a current of $90 \mathrm{nA}$, which was exactly the sum of current outputs from the TEG and the PENG alone. Yang et al. integrated a polymer film-based TENG on the top of a BiTe-based TEG (Yang et al. 2013d). The harvested energy was stored in a Li-ion battery first, which was then used for water splitting with a $\mathrm{H}_{2}$ generation rate of $4 \mathrm{e}^{-4} \mathrm{~mL} \mathrm{~s}^{-1}$. In general, the TEG provides high current output while the PENG/TENG provides high voltage output, and the key is to avoid disturbing the heat dissipation of the TEG beneath. In addition to TEG, the PyENG can also be integrated with kinetic energy harvesters. Lee et al. fabricated a stretchable PyENG-PENG hybrid cell based on P(VDF-TrFE) polymer, PDMS-CNT composite and graphene nano-sheets as shown in Fig. 10(e) (Lee et al. 2014). The total voltage generated when facing both compression and temperature variation was $1.4 \mathrm{~V}$, and the performance was stable even after a number of stretch-release cycles. Zi et al. developed a PyENG-PENG-TENG ternary cell with a multi-layer stack structure ( $\mathrm{Zi}$ et al. 2015). With a sliding frequency of 4.41 $\mathrm{Hz}$, the TENG produced an OCV as high as $1132.6 \mathrm{~V}$ and a current of $145 \mu \mathrm{A} \mathrm{cm} \mathrm{cm}^{-2}$, while the PyENG and PENG could harvest energy from friction-induced heat and normal force, respectively. As a consequence, the charge rate for a capacitor was doubled compared with TENG alone. Wang et al. employed a PVDF nanowires-PDMS composite film as a triboelectric layer and a polarized PVDF film as both the piezoelectric and pyroelectric layer, leading to a highly transparent and flexible ternary cell (Wang et al. 2016a). Compared with single component operation, the hybrid harvester exhibited much better charging ability. Sun et al. also reported a flexible and transparent ternary cell including PENG, TENG and PyENG, which was realized by using a leaf venation-like silver nanowire electrode (Sun et al. 2018). The voltage output was up to $55 \mathrm{~V}$ and $86 \mathrm{~V}$ for the mechanical and thermal part, respectively, which could 
also be attached on human skin for body signal monitoring. In conclusion, integrated cell with hybrid energy harvesting technique not only provides higher power output but also improves its energy robustness, with a minimum cost of system redundancy.

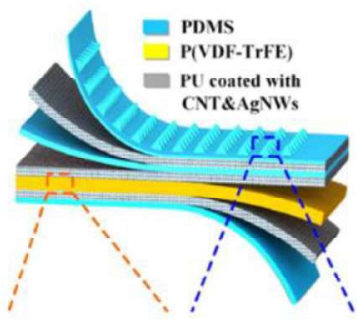

(a)

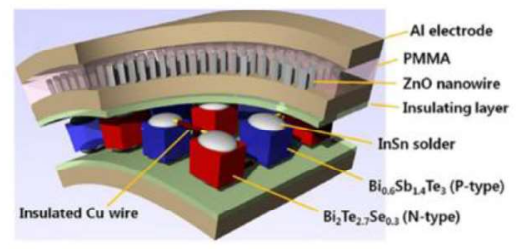

(d)

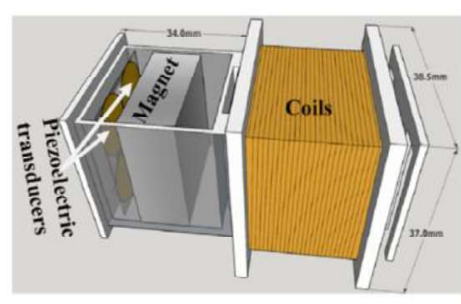

(b)

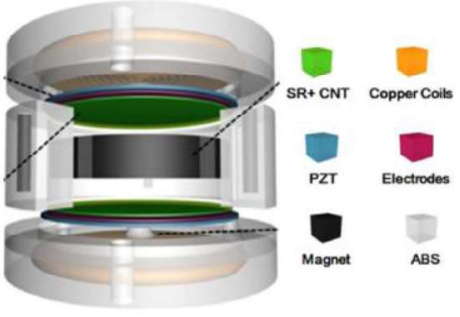

(c)

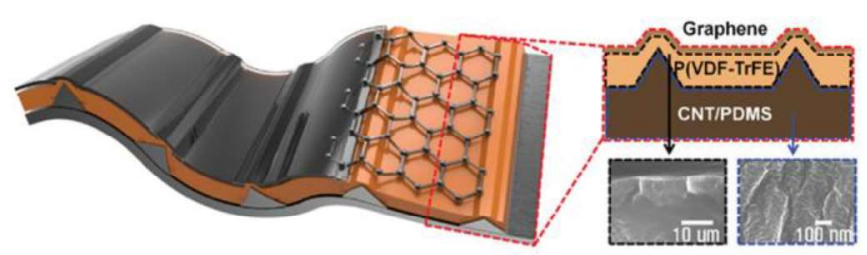

(e)

Fig. 10 Different energy harvesting technologies integrated into a single cell: (a) A flexible PENG-TENG hybrid cell (Chen et al. 2017b) (reprinted with permission from Elsevier); (b) A 3D piezoelectric-electromagnetic hybrid cell (Hamid and Yuce 2017) (reprinted with permission from Elsevier); (c) A piezoelectric-triboelectric-electromagnetic ternary cell based on a magnetic levitation structure (He et al. 2018) (reprinted with permission from Elsevier); (d) A flexible PENG-TEG hybrid cell (Lee et al. 2013) (reprinted with permission from Elsevier); (e) A stretchable PyENG-PENG hybrid cell (Lee et al. 2014) (reprinted with permission from John Wiley \& Sons).

\subsection{Supercapacitor}

As shown in Fig. 11(a), a supercapacitor is mainly composed of two porous electrodes separated by an ion-conductive membrane, among which there are electrolytes connecting the two electrodes ionically. When an external voltage is applied, ions inside the electrolyte will be separated (cations to the negative electrode while anions to the positive electrode), so that two electrostatic double-layers can be formed on the two electrodes, respectively. In addition to this double-layer capacitance, electrochemical reactions may also occur at the electrode surface, 
generating an extra pseudo capacitance for the supercapacitor. Benefited from the extremely small thickness of the double layer (nm scale) and the much increased surface area of porous electrodes, the capacitance of a supercapacitor can reach $\mathrm{F}$ scale, which is much higher than conventional capacitors (González et al. 2016).

Compared with secondary batteries, supercapacitors can have much longer lifetime in terms of charge-discharge cycling, which can be used for 10-15 years. They can also be charged and discharged at much higher rates, leading to fast recharge ability in a few seconds. These advantages make them very appealing for powering the BSN, especially the implanted sensors. Nevertheless, the energy density of current supercapacitors is generally lower (1-10 $\left.\mathrm{Wh} \mathrm{kg}^{-1}\right)$ than batteries, which is therefore not suitable for long-term continuous operation. Also, their selfdischarge is much severer (e.g., 50\% capacity loss in 30-40 days), requiring more frequent recharge than batteries. Another important issue of supercapacitors is the necessary regulation of their voltage output. This is because the output voltage of a supercapacitor is proportional to the charge storage in it, which will degrade linearly without regulation. Furthermore, the cost of current supercapacitors is much higher than batteries.

Despite their merits and demerits, supercapacitors have already been utilized in BSN systems, which are generally coupled with energy harvesting. Torfs et al. combined a supercapacitor with a TEG for powering a pulse oximeter in the form of a watch (Torfs et al. 2006). At ambient temperature, an electric power of $100 \mu \mathrm{W}$ could be provided. Olivo et al. used a supercapacitor as charge storage for an electromagnetic micro motor (Olivo et al. 2010). A charge pump was further integrated with the supercapacitor in order to reduce the start-up time for powering the sensor node. Yamada et al. developed a swallowable biosensor which could obtain the $\mathrm{pH}$ value in stomach and internal body temperature (Yamada et al. 2004). Several supercapacitors were utilized as power source and charged wirelessly by induced voltage from outside the human body. Mercier and Chandrakasan also charged the supercapacitors in multiple sensor nodes wirelessly by a local base station battery, minimizing the energy storage requirement of the node itself (Mercier and Chandrakasan 2010). A power transfer efficiency as high as 95\% was achievable. As for solar energy harvesting, Toh et al. employed a $100 \mathrm{mF}$ supercapacitor to store electric energy from a flexible PV panel (Toh et al. 2014). Liberale et al. also integrated a $10 \mathrm{mF}$ supercapacitor with their thin-film PV cell, which was mounted on wrist (Liberale et al. 2014). In addition to conventional cylindrical and rigid supercapacitors, recently flexible supercapacitors 
with either thin-film or fiber-shape structure have also been developed for both wearable and implanted applications. For instance, Moon et al. demonstrated a transparent and stretchable thin-film supercapacitor as shown in Fig. 11(b) by using Ag/Au/Polypyrrole core-shell nanowire networks as electrode and $\mathrm{PVA}_{-} \mathrm{H}_{3} \mathrm{PO}_{4}$ gel as electrolyte (Moon et al. 2017). The as-fabricated supercapacitor exhibited great performance stability and mechanical robustness against repetitive bending or stretching. Sim et al. developed a fiber-shaped supercapacitor using PEDOT:PSS/ferritin-coated biscrolled fiber as electrode, which can be used inside human body for powering various implanted medical devices (Sim et al. 2018). This design is especially suitable for wound suture, which was successfully demonstrated in a mouse as shown in Fig. 10(c). For more information about the flexible supercapacitors, readers are recommended to several specific review papers (Alipoori et al. 2020; Hui et al. 2019; Palchoudhury et al. 2019).

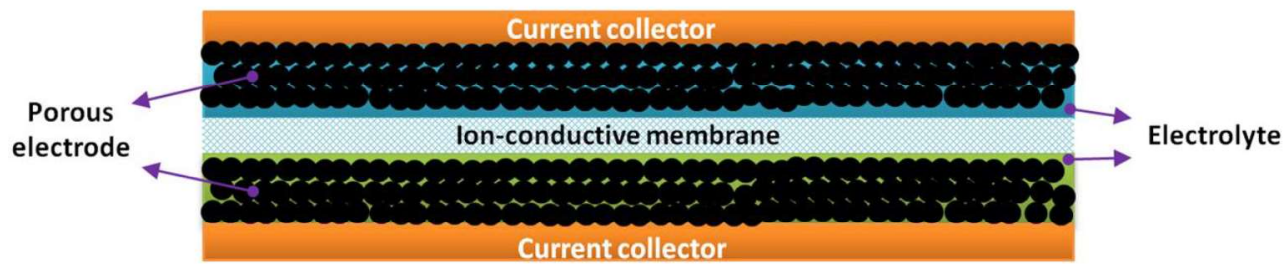

(a)

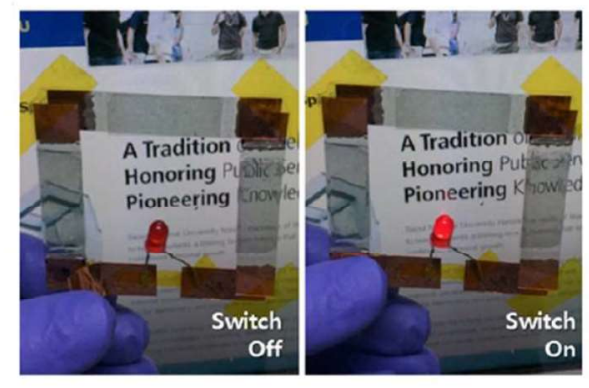

(b)

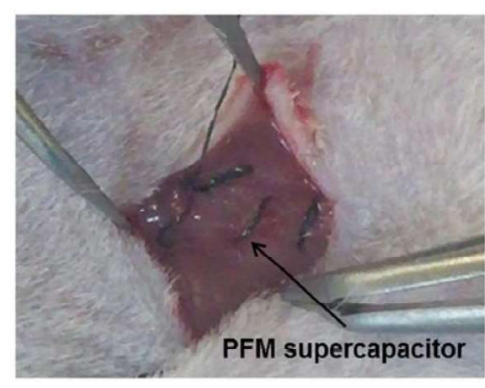

(c)

Fig. 11 Application of supercapacitors in BSN: (a) Schematic diagram of a supercapacitor; (b) A thin-film supercapacitor with high flexibility and transparency (Moon et al. 2017) (reprinted from open access article); (c) A fiber-shaped supercapacitor for implantable sensors (Sim et al. 2018) (reprinted with permission from Elsevier).

\subsection{Textile-based power sources}

In order to make them flexible, lightweight and unobtrusive, conventional 3D block-shaped cell is gradually replaced by $2 \mathrm{D}$ thin-film cell as mentioned above. In addition to this, the 1D 
fiber-shaped cell is also highly promising for wearable applications, which can be woven into textiles that are similar to conventional clothes in appearance (that is, smart textile). In this manner, not only the effective cell area is greatly enlarged but also the user comfortness is guaranteed. Till now, various textile-based power sources have been proposed in literature, including the textile-based batteries, energy harvesters and supercapacitors. As for the fuel cell, relevant research is not found, probably due to its complex auxiliary system for mass, heat and water management that are difficult to be made in fiber shape. Furthermore, hybrid textile energy systems integrating two to three types of them were also developed accordingly.

For the textile-based battery, various chemical types have been explored already, such as primary Zn-C (Yu et al. 2013), Al-air (Xu et al. 2016), and secondary Li ion (Wang et al. 2017a), Li-air (Zhang et al. 2016d), Zn-air (Xu et al. 2015), Zn-NiCo (Huang et al. 2017), and so on. In general, fiber battery is fabricated by twisting two fiber electrodes coated with gel/polymer electrolyte into an insulating tube as shown in Fig. 12(a). Alternatively, a concentric multi-layer structure as shown in Fig. 2 can be employed. Nowadays, the fiber battery can be woven into clothes either working as independent power supplier or serving as energy storage for other fiber energy harvesters in the same textile. Among all the candidates, currently the Li ion fiber battery exhibits the highest application potential (Zhang et al. 2016e).

With higher cycling stability, textile-based supercapacitor is another promising candidate for in-clothes energy storage as shown in Fig. 12(b). Similar to the fiber battery, either a twisted electrode structure or a concentric cell design is employed for the fiber supercapacitor, with acid/alkaline gel electrolyte separating in between (Chen et al. 2020a; Yu et al. 2015). When woven into clothes, the shortcomings of fiber supercapacitor include lower energy density and faster self-discharge, which may be, however, less problematic if continuous energy harvesting is provided at the same time.

Before significant breakthrough of their power density and energy efficiency, energy harvesters with relatively large surface area seem inevitable, so that textile-based energy harvesting might be an effective solution to minimize the conflict between the performance and user comfortness. In literature, both the textile-based PENG and TENG for kinetic energy harvesting and the textile-based PV cell for solar energy harvesting have been developed. For the textile-based PENG, a piezoelectric fiber is generally woven together with conventional thread and electrode wire as shown in Fig. 12(c), while electricity is generated when pressure is induced 
from body movements. Zhang et al. developed a textile-based PENG based on $\mathrm{BaTiO}_{3}$-polymer fiber, but the current output of $24 \mathrm{nA}$ was relatively limited (Zhang et al. 2015). For the textilebased TENG, two triboelectric fibers based on different materials are generally used and woven into textile as shown in Fig. 12(d), while the electricity can be generated from either the deformation of the textile or the contact/separation between it and external objects. Zhou et al. developed a textile-based TENG using nylon fabric and polyester fabric, and the current output reached 1.2 and $2.5 \mu \mathrm{A}$ under the deformation mode and contact/separation mode, respectively (Zhou et al. 2014). In addition to energy harvesting, textile-based PENG and TENG can also be used as self-powered body sensors for sleep monitoring (Lin et al. 2018), pulse measurement (Meng et al. 2020), respiration sensing (Zhou et al. 2020), and so on. As for the textile-based PV cell, a fiber photoanode is generally woven with a fiber counter electrode as shown in Fig. 12(e), which can produce electricity continuously under solar irradiation. With $100 \mathrm{~mW} \mathrm{~cm} \mathrm{cutdoor}^{-2}$ sunlight, an OCV of $4.6 \mathrm{~V}$ and a short-circuit current density as high as $7.8 \mathrm{~mA} \mathrm{~cm}$ chere $^{-2}$ wer. demonstrated by Zhang et al., which was capable of charging a $2 \mathrm{mF}$ capacitor to $3 \mathrm{~V}$ in $60 \mathrm{~s}$ (Zhang et al. 2016c).

By weaving the fiber battery, energy harvester and supercapacitor together into the same textile, smart clothes with energy harvesting and storage functions can be obtained for future autonomous wearable electronics. As shown in Fig. 12(f), $\mathrm{Pu}$ et al. integrated a fiber supercapacitor based on rGO-Ni-yarn and a fiber TENG based on woven Ni-polyester strap and parylene-Ni-polyester strap ( $\mathrm{Pu}$ et al. 2016). When vibrated at $10 \mathrm{~Hz}$, the supercapacitor could be charged to $2.1 \mathrm{~V}$ in $913 \mathrm{~s}$, which next provided a current output of $1 \mu \mathrm{A}$ for $808 \mathrm{~s}$. Dong et al. also combined fiber TENG with fiber supercapacitor by a weft-knitting technique (Dong et al. 2017). When the energy textile was tapped by hand, it could power a calculator or a temperaturehumidity meter. Chen et al. combined a fiber solar cell with fiber TENG by weaving them together as an energy harvesting fabric (Chen et al. 2016). With one piece of such fabric (4cm $x$ $5 \mathrm{~cm}$ ) under sunlight and with mechanical excitation, a $2 \mathrm{mF}$ capacitor could be charged to $2 \mathrm{~V}$ within 1 min. The fabric was also demonstrated to power an electric watch and recharge a cellphone. Chai et al. wove the fiber electrodes of a dye-sensitized solar cell together with fiber supercapacitor, producing a PV-SC energy textile as shown in Fig. 12(g) (Chai et al. 2016). The sample could be charged to $1.2 \mathrm{~V}$ in $17 \mathrm{~s}$ under sun light, which output a current of $0.1 \mathrm{~mA}$ for $78 \mathrm{~s}$. Wen et al. further combined the dye-sensitized fiber solar cell, fiber TENG and fiber 
supercapacitor together, and attached the hybrid energy textile to a T-shirt (Wen et al. 2016). The solar cell provided an OCV of $0.74 \mathrm{~V}$ and a current density of $11.92 \mathrm{~mA} \mathrm{~cm}^{-2}$ while the TENG delivered a maximum current of $0.91 \mu \mathrm{A}$, which were both collected by the supercapacitor (1.9 $\mathrm{mF} \mathrm{cm}{ }^{-1}$ ) for further usage. Instead of supercapacitor, Zhang et al. wove the $\mathrm{Zn}-\mathrm{MnO}_{2}$ fiber battery with the dye sensitized fiber solar cell (Fig. 12(h)) to obtain a photo-rechargeable fabric with higher energy density and lower self-discharge (Zhang et al. 2020). When charged under 1sun condition for $1 \mathrm{~min}$, the energy fabric could be discharged at $0.1 \mathrm{~mA}$ for $10 \mathrm{~min}$, which could also be stored for more than 60 days without significant loss. The energy fabric was further demonstrated in a wearable BSN including a temperature sensor, a body-motion sensor and a humidity sensor.

To sum up, the textile-based power sources and the associated "energy clothes" represent a promising direction for future wearable $\mathrm{BSN}$, which requires continuous research and development to further improve their power output, energy density, energy efficiency, mechanical robustness and safety level. More importantly, the textile-based power solution has a great potential to achieve the separation of the sensor node with the energy supply unit. Instead, the minimized sensor node can be mounted on clothes directly near the power supply port. In this manner, both minimized sensor size and improve energy storage can be achieved, ensuring an unobtrusive and durable healthcare monitoring. Nevertheless, the sensor sensitivity and accuracy in this situation need to be carefully characterized considering the negative effect from the cloth separation and power unit interference. For more details about the textile-based power sources, several related review works are recommended (Chen et al. 2020b; Sun et al. 2017; Zhai et al. 2016). 


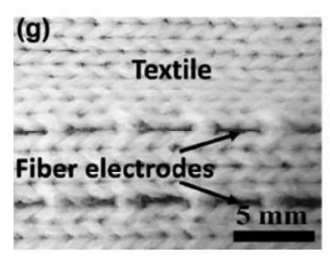

(a)

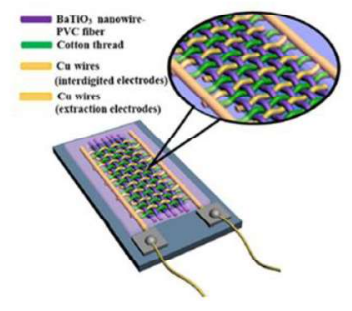

(c)

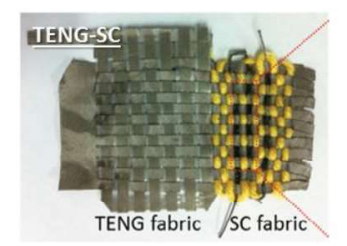

(f)
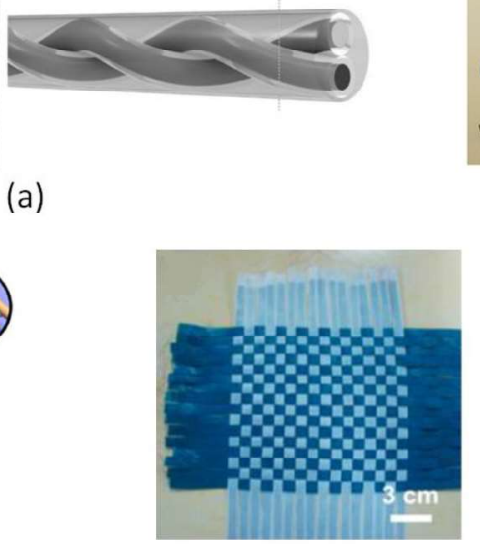

(d)

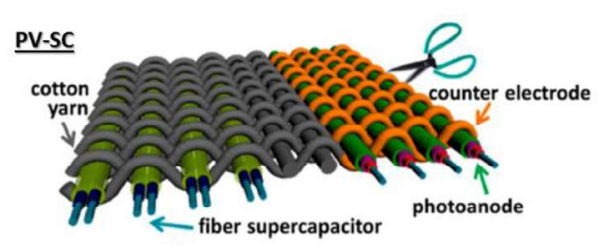

(g)

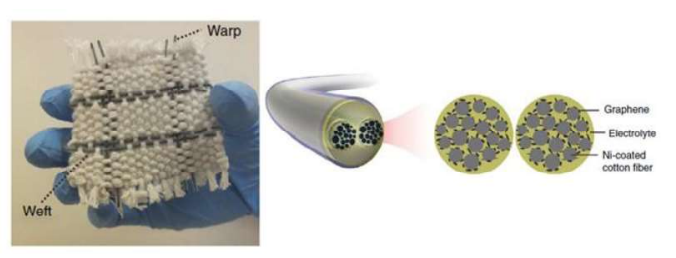

(b)

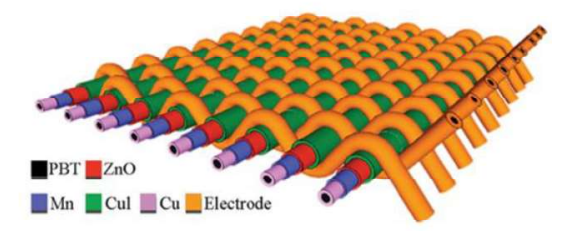

(e)

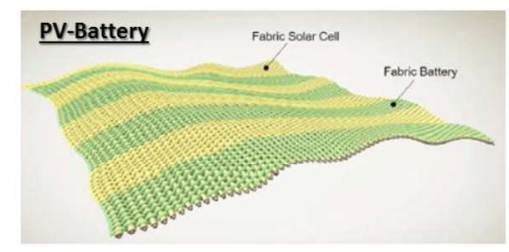

(h)

Fig. 12 Different types of textile-based power sources for powering BSN: (a) Textile-based Li ion battery and the fiber-shape single cell (Wang et al. 2017a) (reprinted with permission from John Wiley and Sons); (b) Textile-based supercapacitor and the fiber-shape single cell (Liu et al. 2015) (reprinted from open access article); (c) Textile-based PENG (Zhang et al. 2015) (reprinted with permission from Elsevier); (d) Textile-based TENG (Zhou et al. 2014) (reprinted with permission from American Chemical Society); (e) Textile-based solar cell (Zhang et al. 2016c) (reprinted with permission from John Wiley and Sons); (f) Textile-based hybrid TENGsupercapacitor $(\mathrm{Pu}$ et al. 2016) (reprinted with permission from John Wiley and Sons); (g) Textile-based hybrid solar cell-supercapacitor (Chai et al. 2016) (reprinted with permission from American Chemical Society); (h) Textile-based hybrid solar cell-battery (Zhang et al. 2020) (reprinted with permission from Elsevier).

\section{Conclusions and Future Perspectives}

In this work, four main types of micro power sources for BSN systems have been reviewed, including batteries, fuel cells, energy harvesters and supercapacitors. The batteries and fuel cells can serve independently in the sensor node, while the energy harvesters need an auxiliary energy 
storage unit such as a supercapacitor. Each of them has its own advantages and disadvantages when applied in BSN systems, which especially relate to the type of sensor node.

Batteries have long been applied in portable electronics because of their high technical maturity and market share. Till now, most BSN studies use commercial dry battery and Li ion battery directly, which provide not only sufficient power to various body sensors but also longterm energy storage. However, the unsatisfactory energy density and long recharging time greatly hinder their application in future BSN products. This is especially the case for implanted sensors, which should also consider safety issues associated with the hazardous battery materials. To solve these issues, green battery technologies such as metal-air batteries and non-Li ion batteries are currently under rapid development, focusing on improving the energy density, fabrication cost, pollution level as well as safety issues. Nevertheless, improving the current flexible Li ion battery is still the most practical solution to BSN products, which has already been applied in the wearable electronic market.

To achieve a breakthrough in energy density, micro fuel cells appear to be a more suitable candidate than batteries. In addition, they can be refueled instantly by fuel cartridge replacement, which is suitable for the wearable BSN. As for implanted sensors, direct glucose fuel cell is a promising candidate which can harvest the dissolved glucose and oxygen in human body fluid. Nevertheless, the current fuel cell technology is not mature in several aspects, including high cost, complex system and insufficient stability. The employment of Pt catalyst and polymer membrane electrolyte makes fuel cell much more expensive than batteries. Also, the requirement of reactant delivery and water management in fuel cells lead to less convenience for portable applications. Finally, the long-term stability issue originated from the poisoning of catalyst, dehydration of membrane and biofouling when implanted greatly restricts their long-term operation ability. These issues need to be addressed before the combination of micro fuel cells and BSN can come to practical application.

Unlike batteries and fuel cells, energy harvesters can generate electricity continuously from ambient or human body itself, which is believed to be the final solution to the absolute BSN autonomy. In literature, various energy harvesters have been integrated with body sensors, such as thermoelectric, kinetic, radiofrequency and solar cells. Among them, the thermoelectric, kinetic and solar energy harvesters produce more electricity in wearable sensors, while the radiofrequency energy harvest is especially suitable for implanted sensors. As for power output, 
currently the solar cell achieves the highest power density while the radiofrequency harvester obtains the lowest. Nevertheless, the values are still unsatisfactory compared with batteries or fuel cells, leading to cumbersome sensor node with less user comfortness. To solve this issue, more efforts are required to improve their energy conversion efficiency significantly, which is not likely to happen in the near term. Alternatively, a textile-based energy harvesting is highly feasible at the present stage.

As for the supercapacitor, it is mainly targeted for short-term energy storage, which is generally not used independently in the sensor node. Compared with batteries, one of its greatest properties is the superior cycle stability, which is especially suitable for implanted sensors. However, the low energy density and high self-discharge rate greatly impair its energy storage ability, so a continuous power input from energy harvesting is necessary to ensure BSN reliability. In the market, commercial supercapacitors are available for direct application in BSN system, together with a decreasing cost forecasted for the coming decades. Nevertheless, to better accommodate the wearable BSN, flexible supercapacitors with either thin-film or fiber structures need to be improved.

From the above comparison, it can be concluded that a BSN with hybrid energy supply may be a more realistic and reliable solution than that with single-type power source. For instance, batteries are more suitable for sensor nodes with high power requirement and intermittent mission profile. Fuel cells are more suitable for sensor nodes with long-term and continuous operation. As for energy harvesters and supercapacitor, their combination is suitable for sensor nodes with low power requirement and great difficulty in recharging or refueling. On the other hand, when considering the different technical maturity of these power technologies, a gradual evolution of BSN power system is more realistic, starting from the battery-dominant BSN to the final autonomous BSN with energy harvesters. Therefore, it is necessary to pay efforts to all these micro power technologies, such as improving energy density and cycle stability for batteries, fabrication cost and long-term durability for fuel cells, and energy conversion efficiency for energy harvesters. To sum up, a lightweight, everlasting, reliable and biocompatible micro power system is an indispensable guarantee to the successful implementation of BSN, which will contribute greatly to a low-cost and ubiquitous medical future for humankind. 


\section{Acknowledgements}

The authors would like to acknowledge the CRCG grant of the University of Hong Kong (201711160009) and the SZSTI of Shenzhen Municipal Government (JCYJ20170818141758464) to provide funding support to this project. 


\section{References}

Adlhart, O.J., Rohonyi, P., Modroukas, D., Driller, J., 1997. A small portable proton exchange membrane fuel cell and hydrogen generator for medical applications. ASAIO journal (American Society for Artificial Internal Organs: 1992) 43(3), 214-219.

Aghera, P., Krishnaswamy, D., Fang, D., Coskun, A., Rosing, T., 2010. DynAHeal: Dynamic energy efficient task assignment for wireless healthcare systems. Proceedings of the Conference on Design, Automation and Test in Europe, pp. 1661-1664. European Design and Automation Association.

Aghera, P., Tajana, S.R., Fang, D., Patrick, K., 2009. Energy management in wireless healthcare systems. Proceedings of the 2009 International Conference on Information Processing in Sensor Networks, pp. 363-364. IEEE Computer Society.

Akhtar, F., Rehmani, M.H., 2017. Energy harvesting for self-sustainable wireless body area networks. IT Professional 19(2), 32-40.

Alipoori, S., Mazinani, S., Aboutalebi, S.H., Sharif, F., 2020. Review of PVA-based gel polymer electrolytes in flexible solid-state supercapacitors: Opportunities and challenges. Journal of Energy Storage 27, 101072.

Amendola, S., Lodato, R., Manzari, S., Occhiuzzi, C., Marrocco, G., 2014. RFID technology for loT-based personal healthcare in smart spaces. IEEE Internet of things journal 1(2), 144-152.

Aravamudhan, S., Rahman, A.R.A., Bhansali, S., 2005. Porous silicon based orientation independent, selfpriming micro direct ethanol fuel cell. Sensors and Actuators A: Physical 123, 497-504.

Aziz, O., Lo, B., King, R., Darzi, A., Yang, G.-Z., 2006. Pervasive body sensor network: an approach to monitoring the post-operative surgical patient. Wearable and Implantable Body Sensor Networks, 2006. BSN 2006. International Workshop on, pp. 4 pp.-18. IEEE.

Bai, P., Zhu, G., Jing, Q., Yang, J., Chen, J., Su, Y., Ma, J., Zhang, G., Wang, Z.L., 2014. Membrane - based self - powered triboelectric sensors for pressure change detection and its uses in security surveillance and healthcare monitoring. Advanced Functional Materials 24(37), 5807-5813.

Bai, P., Zhu, G., Lin, Z.-H., Jing, Q., Chen, J., Zhang, G., Ma, J., Wang, Z.L., 2013. Integrated multilayered triboelectric nanogenerator for harvesting biomechanical energy from human motions. ACS nano 7(4), 3713-3719.

Barakah, D.M., Ammad-uddin, M., 2012. A survey of challenges and applications of wireless body area network (WBAN) and role of a virtual doctor server in existing architecture. Intelligent Systems, Modelling and Simulation (ISMS), 2012 Third International Conference on, pp. 214-219. IEEE.

Barroca, N., Ferro, J.M., Borges, L.M., Tavares, J., Velez, F.J., 2012. Electromagnetic energy harvesting for wireless body area networks with cognitive radio capabilities. Proc. of URSI Seminar of the Portuguese Committee.

Barroca, N., Saraiva, H.M., Gouveia, P.T., Tavares, J., Borges, L.M., Velez, F.J., Loss, C., Salvado, R., Pinho, P., Gonçalves, R., 2013. Antennas and circuits for ambient RF energy harvesting in wireless body area networks. 2013 IEEE 24th annual international symposium on personal, indoor, and mobile radio communications (PIMRC), pp. 532-537. IEEE.

Barth, A.T., Hanson, M.A., Powell Jr, H.C., Lach, J., 2009. TEMPO 3.1: A body area sensor network platform for continuous movement assessment. Wearable and Implantable Body Sensor Networks, 2009. BSN 2009. Sixth International Workshop on, pp. 71-76. IEEE.

Borges, L.M., Chávez-Santiago, R., Barroca, N., Velez, F.J., Balasingham, I., 2015. Radio-frequency energy harvesting for wearable sensors. Healthcare technology letters 2(1), 22-27.

Calabrese Barton, S., Gallaway, J., Atanassov, P., 2004. Enzymatic biofuel cells for implantable and microscale devices. Chemical reviews 104(10), 4867-4886.

Catarinucci, L., De Donno, D., Mainetti, L., Palano, L., Patrono, L., Stefanizzi, M.L., Tarricone, L., 2015. An loT-aware architecture for smart healthcare systems. IEEE Internet of Things Journal 2(6), 515-526. 
Chai, Z., Zhang, N., Sun, P., Huang, Y., Zhao, C., Fan, H.J., Fan, X., Mai, W., 2016. Tailorable and wearable textile devices for solar energy harvesting and simultaneous storage. ACS nano 10(10), 9201-9207.

Chang, I., Park, T., Lee, J., Lee, M.H., Ko, S.H., Cha, S.W., 2013. Bendable polymer electrolyte fuel cell using highly flexible Ag nanowire percolation network current collectors. Journal of Materials Chemistry A 1(30), 8541-8546.

Chen, D., Jiang, K., Huang, T., Shen, G., 2020a. Recent advances in fiber supercapacitors: materials, device configurations, and applications. Advanced Materials 32(5), 1901806.

Chen, G., Li, Y., Bick, M., Chen, J., 2020b. Smart textiles for electricity generation. Chemical Reviews 120(8), 3668-3720.

Chen, J., Huang, Y., Zhang, N., Zou, H., Liu, R., Tao, C., Fan, X., Wang, Z.L., 2016. Micro-cable structured textile for simultaneously harvesting solar and mechanical energy. Nature Energy 1(10), 1-8.

Chen, J., Wang, Z.L., 2017. Reviving Vibration Energy Harvesting and Self-Powered Sensing by a Triboelectric Nanogenerator. Joule 1(3), 480-521.

Chen, J., Yang, J., Guo, H., Li, Z., Zheng, L., Su, Y., Wen, Z., Fan, X., Wang, Z.L., 2015a. Automatic mode transition enabled robust triboelectric nanogenerators. ACS nano 9(12), 12334-12343.

Chen, J., Yang, J., Li, Z., Fan, X., Zi, Y., Jing, Q., Guo, H., Wen, Z., Pradel, K.C., Niu, S., 2015b. Networks of triboelectric nanogenerators for harvesting water wave energy: a potential approach toward blue energy. ACS nano 9(3), 3324-3331.

Chen, J., Zhu, G., Yang, W., Jing, Q., Bai, P., Yang, Y., Hou, T.C., Wang, Z.L., 2013. Harmonic - resonator based triboelectric nanogenerator as a sustainable power source and a self - powered active vibration sensor. Advanced materials 25(42), 6094-6099.

Chen, M., Gonzalez, S., Vasilakos, A., Cao, H., Leung, V.C., 2011. Body area networks: A survey. Mobile networks and applications 16(2), 171-193.

Chen, X., Parida, K., Wang, J., Xiong, J., Lin, M.-F., Shao, J., Lee, P.S., 2017a. A stretchable and transparent nanocomposite nanogenerator for self-powered physiological monitoring. ACS applied materials \& interfaces 9(48), 42200-42209.

Chen, X., Song, Y., Su, Z., Chen, H., Cheng, X., Zhang, J., Han, M., Zhang, H., 2017b. Flexible fiber-based hybrid nanogenerator for biomechanical energy harvesting and physiological monitoring. Nano Energy 38, 43-50.

Cheng, J., Xia, L., Ma, C., Lian, Y., Xu, X., Yue, C.P., Hong, Z., Chiang, P.Y., 2012. A near-threshold, multinode, wireless body area sensor network powered by RF energy harvesting. Custom Integrated Circuits Conference (CICC), 2012 IEEE, pp. 1-4. IEEE.

Chin, C.A., Crosby, G.V., Ghosh, T., Murimi, R., 2012. Advances and challenges of wireless body area networks for healthcare applications. Computing, Networking and Communications (ICNC), 2012 International Conference on, pp. 99-103. IEEE.

Chou, X., Zhu, J., Qian, S., Niu, X., Qian, J., Hou, X., Mu, J., Geng, W., Cho, J., He, J., 2018. All-in-one fillerelastomer-based high-performance stretchable piezoelectric nanogenerator for kinetic energy harvesting and self-powered motion monitoring. Nano Energy 53, 550-558.

Cinquin, P., Gondran, C., Giroud, F., Mazabrard, S., Pellissier, A., Boucher, F., Alcaraz, J.-P., Gorgy, K., Lenouvel, F., Mathé, S., 2010. A glucose biofuel cell implanted in rats. PloS one 5(5), e10476.

Coman, V., Ludwig, R., Harreither, W., Haltrich, D., Gorton, L., Ruzgas, T., Shleev, S., 2010. A Direct Electron Transfer - Based Glucose/Oxygen Biofuel Cell Operating in Human Serum. Fuel cells 10(1), 9-16. Cosnier, S., Le Goff, A., Holzinger, M., 2014. Towards glucose biofuel cells implanted in human body for powering artificial organs. Electrochemistry Communications 38, 19-23.

Darwish, A., Hassanien, A.E., 2011. Wearable and implantable wireless sensor network solutions for healthcare monitoring. Sensors 11(6), 5561-5595.

De Pasquale, G., 2013. Energy harvesters for powering wireless systems. Handbook of MEMS for wireless and mobile applications, pp. 345-400. Elsevier. 
Deng, Z., Jiang, H., Hu, Y., Liu, Y., Zhang, L., Liu, H., Li, C., 2017. 3D ordered macroporous MoS2@ C nanostructure for flexible Li - ion batteries. Advanced Materials 29(10), 1603020.

Dionisi, A., Marioli, D., Sardini, E., Serpelloni, M., 2016. Autonomous wearable system for vital signs measurement with energy-harvesting module. IEEE Transactions on Instrumentation and Measurement 65(6), 1423-1434.

Dong, K., Jia, B., Yu, C., Dong, W., Du, F., Liu, H., 2013. Microbial fuel cell as power supply for implantable medical devices: A novel configuration design for simulating colonic environment. Biosensors and Bioelectronics 41, 916-919.

Dong, K., Wang, Y.-C., Deng, J., Dai, Y., Zhang, S.L., Zou, H., Gu, B., Sun, B., Wang, Z.L., 2017. A highly stretchable and washable all-yarn-based self-charging knitting power textile composed of fiber triboelectric nanogenerators and supercapacitors. Acs Nano 11(9), 9490-9499.

Drake, R., Kusserow, B., Messinger, S., Matsuda, S., 1970. A tissue implantable fuel cell power supply. ASAIO Journal 16(1), 199-205.

Du Toit, H., Rashidi, R., Ferdani, D.W., Delgado-Charro, M.B., Sangan, C.M., Di Lorenzo, M., 2016. Generating power from transdermal extracts using a multi-electrode miniature enzymatic fuel cell. Biosensors and Bioelectronics 78, 411-417.

Fafoutis, X., Vafeas, A., Janko, B., Sherratt, R.S., Pope, J., Elsts, A., Mellios, E., Hilton, G., Oikonomou, G., Piechocki, R., 2017. Designing wearable sensing platforms for healthcare in a residential environment. EAI Endorsed Transactions on Pervasive Health and Technology 3(12).

Fan, F.-R., Tian, Z.-Q., Wang, Z.L., 2012. Flexible triboelectric generator. Nano energy 1(2), 328-334. Fan, X., Chen, J., Yang, J., Bai, P., Li, Z., Wang, Z.L., 2015. Ultrathin, rollable, paper-based triboelectric nanogenerator for acoustic energy harvesting and self-powered sound recording. ACS nano 9(4), 42364243.

Fang, Q., Lee, S.-Y., Permana, H., Ghorbani, K., Cosic, I., 2011. Developing a wireless implantable body sensor network in MICS band. IEEE Transactions on Information Technology inBiomedicine 15(4), 567. Fariborzi, H., Moghavvemi, M., Mehrkanoon, S., 2007. The design of an intelligent wireless sensor network for ubiquitous healthcare. Intelligent and Advanced Systems, 2007. ICIAS 2007. International Conference on, pp. 414-417. IEEE.

Fukuda, K., Yu, K., Someya, T., 2020. The Future of Flexible Organic Solar Cells. Advanced Energy Materials, 2000765.

Gao, T., Pesto, C., Selavo, L., Chen, Y., Ko, J., Lim, J., Terzis, A., Watt, A., Jeng, J., Chen, B.-r., 2008. Wireless medical sensor networks in emergency response: Implementation and pilot results.

Technologies for Homeland Security, 2008 IEEE Conference on, pp. 187-192. IEEE.

González, A., Goikolea, E., Barrena, J.A., Mysyk, R., 2016. Review on supercapacitors: technologies and materials. Renewable and Sustainable Energy Reviews 58, 1189-1206.

Guo, H., Chen, J., Yeh, M.-H., Fan, X., Wen, Z., Li, Z., Hu, C., Wang, Z.L., 2015. An ultrarobust highperformance triboelectric nanogenerator based on charge replenishment. ACS nano 9(5), 5577-5584. Gyselinckx, B., Van Hoof, C., Ryckaert, J., Yazicioglu, R.F., Fiorini, P., Leonov, V., 2005. Human++: autonomous wireless sensors for body area networks. Proceedings of the IEEE 2005 Custom Integrated Circuits Conference, 2005., pp. 13-19. IEEE.

Halámková, L., Halámek, J., Bocharova, V., Szczupak, A., Alfonta, L., Katz, E., 2012. Implanted biofuel cell operating in a living snail. Journal of the American Chemical Society 134(11), 5040-5043.

Hamid, R., Yuce, M.R., 2017. A wearable energy harvester unit using piezoelectric-electromagnetic hybrid technique. Sensors and Actuators A: Physical 257, 198-207.

Han, Y., Yu, C., Liu, H., 2010. A microbial fuel cell as power supply for implantable medical devices. Biosensors and Bioelectronics 25(9), 2156-2160.

Hanson, M.A., Powell Jr, H.C., Barth, A.T., Ringgenberg, K., Calhoun, B.H., Aylor, J.H., Lach, J., 2009. Body area sensor networks: Challenges and opportunities. Computer 42(1). 
He, J., Wen, T., Qian, S., Zhang, Z., Tian, Z., Zhu, J., Mu, J., Hou, X., Geng, W., Cho, J., 2018. Triboelectricpiezoelectric-electromagnetic hybrid nanogenerator for high-efficient vibration energy harvesting and self-powered wireless monitoring system. Nano Energy 43, 326-339.

Heller, A., 2006. Potentially implantable miniature batteries. Analytical and Bioanalytical chemistry 385(3), 469-473.

Hoang, D.C., Tan, Y.K., Chng, H.B., Panda, S.K., 2009. Thermal energy harvesting from human warmth for wireless body area network in medical healthcare system. Power Electronics and Drive Systems, 2009. PEDS 2009. International Conference on, pp. 1277-1282. IEEE.

Holade, Y., MacVittie, K., Conlon, T., Guz, N., Servat, K., Napporn, T.W., Kokoh, K.B., Katz, E., 2015. Wireless information transmission system powered by an abiotic biofuel cell implanted in an orange. Electroanalysis 27(2), 276-280.

Hou, T.-C., Yang, Y., Zhang, H., Chen, J., Chen, L.-J., Wang, Z.L., 2013. Triboelectric nanogenerator built inside shoe insole for harvesting walking energy. Nano Energy 2(5), 856-862.

Hu, Y., Wang, Z.L., 2015. Recent progress in piezoelectric nanogenerators as a sustainable power source in self-powered systems and active sensors. Nano Energy 14, 3-14.

Hu, Y., Zhang, Y., Xu, C., Lin, L., Snyder, R.L., Wang, Z.L., 2011. Self-powered system with wireless data transmission. Nano letters 11(6), 2572-2577.

Huang, H., Li, X., Sun, Y., 2016. A triboelectric motion sensor in wearable body sensor network for human activity recognition. 2016 38th Annual International Conference of the IEEE Engineering in Medicine and Biology Society (EMBC), pp. 4889-4892. IEEE.

Huang, W., Jiang, Z., Fukuda, K., Jiao, X., McNeill, C.R., Yokota, T., Someya, T., 2020. Efficient and Mechanically Robust Ultraflexible Organic Solar Cells Based on Mixed Acceptors. Joule 4(1), 128-141.

Huang, Y., Ip, W.S., Lau, Y.Y., Sun, J., Zeng, J., Yeung, N.S.S., Ng, W.S., Li, H., Pei, Z., Xue, Q., 2017.

Weavable, conductive yarn-based $\mathrm{NiCo} / / \mathrm{Zn}$ textile battery with high energy density and rate capability. ACS nano 11(9), 8953-8961.

Hui, C.-y., Kan, C.-w., Mak, C.-I., Chau, K.-h., 2019. Flexible Energy Storage System-An Introductory Review of Textile-Based Flexible Supercapacitors. Processes 7(12), 922.

Hwang, G.T., Park, H., Lee, J.H., Oh, S., Park, K.I., Byun, M., Park, H., Ahn, G., Jeong, C.K., No, K., 2014. Self - powered cardiac pacemaker enabled by flexible single crystalline PMN - PT piezoelectric energy harvester. Advanced materials 26(28), 4880-4887.

Jin, L., Chen, J., Zhang, B., Deng, W., Zhang, L., Zhang, H., Huang, X., Zhu, M., Yang, W., Wang, Z.L., 2016. Self-powered safety helmet based on hybridized nanogenerator for emergency. ACS nano 10(8), 78747881.

Jing, Q., Zhu, G., Bai, P., Xie, Y., Chen, J., Han, R.P., Wang, Z.L., 2014. Case-encapsulated triboelectric nanogenerator for harvesting energy from reciprocating sliding motion. ACS nano 8(4), 3836-3842.

Johnson, M., Healy, M., van de Ven, P., Hayes, M.J., Nelson, J., Newe, T., Lewis, E., 2009. A comparative review of wireless sensor network mote technologies. Sensors, 2009 IEEE, pp. 1439-1442. IEEE.

Johny, B., Anpalagan, A., 2014. Body area sensor networks: Requirements, operations, and challenges. IEEE Potentials 33(2), 21-25.

Jovanov, E., Milenkovic, A., 2011. Body area networks for ubiquitous healthcare applications:

opportunities and challenges. Journal of medical systems 35(5), 1245-1254.

Justin, G.A., Zhang, Y., Sun, M., Sclabassi, R., 2004. Biofuel cells: a possible power source for implantable electronic devices. Engineering in Medicine and Biology Society, 2004. IEMBS'04. 26th Annual International Conference of the IEEE, pp. 4096-4099. IEEE.

Kanan, R., Bensalem, R., 2016. Energy harvesting for wearable wireless health care systems. Wireless Communications and Networking Conference (WCNC), 2016 IEEE, pp. 1-6. IEEE. 
Kappel, R., Auer, M., Hofer, G., Pribyl, W., Holweg, G., 2012. A low-voltage charge pump starting at $135 \mathrm{mV}$ for thermal energy harvesting in Body Area Networks. 2012 16th IEEE Mediterranean Electrotechnical Conference, pp. 618-621. IEEE.

Kappel, R., Pachler, W., Auer, M., Pribyl, W., Hofer, G., Holweg, G., 2013. Using thermoelectric energy harvesting to power a self-sustaining temperature sensor in body area networks. 2013 IEEE International Conference on Industrial Technology (ICIT), pp. 787-792. IEEE.

Kerzenmacher, S., Ducrée, J., Zengerle, R., Von Stetten, F., 2008a. An abiotically catalyzed glucose fuel cell for powering medical implants: Reconstructed manufacturing protocol and analysis of performance. Journal of Power Sources 182(1), 66-75.

Kerzenmacher, S., Ducrée, J., Zengerle, R., Von Stetten, F., 2008b. Energy harvesting by implantable abiotically catalyzed glucose fuel cells. Journal of Power Sources 182(1), 1-17.

Kerzenmacher, S., Kräling, U., Metz, T., Zengerle, R., Von Stetten, F., 2011. A potentially implantable glucose fuel cell with Raney-platinum film electrodes for improved hydrolytic and oxidative stability. Journal of Power Sources 196(3), 1264-1272.

Khan, J.Y., Yuce, M.R., Bulger, G., Harding, B., 2012. Wireless body area network (WBAN) design techniques and performance evaluation. Journal of medical systems 36(3), 1441-1457.

Kimura, H., Fukuda, K., Jinno, H., Park, S., Saito, M., Osaka, I., Takimiya, K., Umezu, S., Someya, T., 2019. High Operation Stability of Ultraflexible Organic Solar Cells with Ultraviolet - Filtering Substrates. Advanced Materials 31(19), 1808033.

Kishi, M., Nemoto, H., Hamao, T., Yamamoto, M., Sudou, S., Mandai, M., Yamamoto, S., 1999. Micro thermoelectric modules and their application to wristwatches as an energy source. Eighteenth International Conference on Thermoelectrics. Proceedings, ICT'99 (Cat. No. 99TH8407), pp. 301-307. IEEE.

Kloke, A., Biller, B., Kräling, U., Kerzenmacher, S., Zengerle, R., Von Stetten, F., 2011. A single layer glucose fuel cell intended as power supplying coating for medical implants. Fuel Cells 11(2), 316-326. Kloke, A., Köhler, C., Zengerle, R., Kerzenmacher, S., 2012. Porous platinum electrodes fabricated by cyclic electrodeposition of PtCu alloy: application to implantable glucose fuel cells. The Journal of Physical Chemistry C 116(37), 19689-19698.

Ko, J., Lu, C., Srivastava, M.B., Stankovic, J.A., Terzis, A., Welsh, M., 2010. Wireless sensor networks for healthcare. Proceedings of the IEEE 98(11), 1947-1960.

Köhler, C., Frei, M., Zengerle, R., Kerzenmacher, S., 2014. Performance Loss of a Pt - Based Implantable Glucose Fuel Cell in Simulated Tissue and Cerebrospinal Fluids. ChemElectroChem 1(11), 1895-1900. Kuang, S.Y., Chen, J., Cheng, X.B., Zhu, G., Wang, Z.L., 2015. Two-dimensional rotary triboelectric nanogenerator as a portable and wearable power source for electronics. Nano Energy 17, 10-16. Latré, B., Braem, B., Moerman, I., Blondia, C., Demeester, P., 2011. A survey on wireless body area networks. Wireless Networks 17(1), 1-18.

Lee, J.H., Lee, K.Y., Gupta, M.K., Kim, T.Y., Lee, D.Y., Oh, J., Ryu, C., Yoo, W.J., Kang, C.Y., Yoon, S.J., 2014. Highly stretchable piezoelectric - pyroelectric hybrid nanogenerator. Advanced Materials 26(5), 765-769. Lee, S., Bae, S.-H., Lin, L., Ahn, S., Park, C., Kim, S.-W., Cha, S.N., Park, Y.J., Wang, Z.L., 2013. Flexible hybrid cell for simultaneously harvesting thermal and mechanical energies. Nano Energy 2(5), 817-825. Lee, T.-S., Hong, J.-H., Cho, M.-C., 2007. Biomedical digital assistant for ubiquitous healthcare. Engineering in Medicine and Biology Society, 2007. EMBS 2007. 29th Annual International Conference of the IEEE, pp. 1790-1793. IEEE.

Lee, Y.-D., Chung, W.-Y., 2009. Wireless sensor network based wearable smart shirt for ubiquitous health and activity monitoring. Sensors and Actuators B: Chemical 140(2), 390-395.

Leijonmarck, S., Cornell, A., Lindbergh, G., Wågberg, L., 2013. Single-paper flexible Li-ion battery cells through a paper-making process based on nano-fibrillated cellulose. Journal of Materials Chemistry $A$ 1(15), 4671-4677. 
Leonov, V., Fiorini, P., Sedky, S., Torfs, T., Van Hoof, C., 2005. Thermoelectric MEMS generators as a power supply for a body area network. Solid-State Sensors, Actuators and Microsystems, 2005. Digest of Technical Papers. TRANSDUCERS'05. The 13th International Conference on, pp. 291-294. IEEE.

Leonov, V., Torfs, T., Fiorini, P., Van Hoof, C., 2007. Thermoelectric converters of human warmth for selfpowered wireless sensor nodes. IEEE Sensors Journal 7(5), 650-657.

Leonov, V., Torfs, T., Van Hoof, C., Vullers, R.J., 2009. Smart wireless sensors integrated in clothing: an electrocardiography system in a shirt powered using human body heat. Sensors \& Transducers 107(8), 165.

Li, B.-Q., Zhang, S.-Y., Wang, B., Xia, Z.-J., Tang, C., Zhang, Q., 2018a. A porphyrin covalent organic framework cathode for flexible Zn-air batteries. Energy \& Environmental Science 11(7), 1723-1729. Li, H., Han, C., Huang, Y., Huang, Y., Zhu, M., Pei, Z., Xue, Q., Wang, Z., Liu, Z., Tang, Z., 2018b. An extremely safe and wearable solid-state zinc ion battery based on a hierarchical structured polymer electrolyte. Energy \& Environmental Science 11(4), 941-951.

Li, H., Yang, Q., Mo, F., Liang, G., Liu, Z., Tang, Z., Ma, L., Liu, J., Shi, Z., Zhi, C., 2019. MoS2 nanosheets with expanded interlayer spacing for rechargeable aqueous $\mathrm{Zn}$-ion batteries. Energy Storage Materials 19, 94-101.

Li, Z., Zhu, G., Yang, R., Wang, A.C., Wang, Z.L., 2010. Muscle - driven in vivo nanogenerator. Advanced materials 22(23), 2534-2537.

Liang, K., Ju, L., Koul, S., Kushima, A., Yang, Y., 2019. Self - Supported Tin Sulfide Porous Films for Flexible Aluminum - Ion Batteries. Advanced Energy Materials 9(2), 1802543.

Liberale, A., Dallago, E., Barnabei, A.L., 2014. Energy harvesting system for wireless body sensor nodes. 2014 IEEE Biomedical Circuits and Systems Conference (BioCAS) Proceedings, pp. 416-419. IEEE.

Lin, Z., Chen, J., Li, X., Zhou, Z., Meng, K., Wei, W., Yang, J., Wang, Z.L., 2017. Triboelectric nanogenerator enabled body sensor network for self-powered human heart-rate monitoring. Acs Nano 11(9), 8830-

8837.

Lin, Z., Chen, J., Yang, J., 2016. Recent progress in triboelectric nanogenerators as a renewable and sustainable power source. Journal of Nanomaterials 2016.

Lin, Z., Yang, J., Li, X., Wu, Y., Wei, W., Liu, J., Chen, J., Yang, J., 2018. Large - scale and washable smart textiles based on triboelectric nanogenerator arrays for self - powered sleeping monitoring. Advanced Functional Materials 28(1), 1704112.

Liu, L., Yu, Y., Yan, C., Li, K., Zheng, Z., 2015. Wearable energy-dense and power-dense supercapacitor yarns enabled by scalable graphene-metallic textile composite electrodes. Nature communications 6(1), 1-9.

Liu, Q., Chang, Z., Li, Z., Zhang, X., 2018a. Flexible metal-air batteries: Progress, challenges, and perspectives. Small Methods 2(2), 1700231.

Liu, Q., Wang, Y., Dai, L., Yao, J., 2016. Scalable Fabrication of Nanoporous Carbon Fiber Films as Bifunctional Catalytic Electrodes for Flexible Zn - Air Batteries. Advanced Materials 28(15), 3000-3006. Liu, R., Kuang, X., Deng, J., Wang, Y.C., Wang, A.C., Ding, W., Lai, Y.C., Chen, J., Wang, P., Lin, Z., 2018b. Shape memory polymers for body motion energy harvesting and self - powered mechanosensing. Advanced Materials 30(8), 1705195.

Liu, W., Chen, J., Chen, Z., Liu, K., Zhou, G., Sun, Y., Song, M.S., Bao, Z., Cui, Y., 2017. Stretchable Lithium - Ion Batteries Enabled by Device - Scaled Wavy Structure and Elastic - Sticky Separator. Advanced Energy Materials 7(21), 1701076.

Liu, Z., Wang, D., Tang, Z., Liang, G., Yang, Q., Li, H., Ma, L., Mo, F., Zhi, C., 2019. A mechanically durable and device-level tough $\mathrm{Zn}-\mathrm{MnO} 2$ battery with high flexibility. Energy Storage Materials 23, 636-645. 
Liu, Z., Zhong, Z., Guo, Y.-X., 2014. High-efficiency triple-band ambient RF energy harvesting for wireless body sensor network. 2014 IEEE MTT-S International Microwave Workshop Series on RF and Wireless Technologies for Biomedical and Healthcare Applications (IMWS-Bio2014), pp. 1-3. IEEE.

Magno, M., Brunelli, D., Sigrist, L., Andri, R., Cavigelli, L., Gomez, A., Benini, L., 2016. InfiniTime: Multisensor wearable bracelet with human body harvesting. Sustainable Computing: Informatics and Systems 11, 38-49.

Maity, K., Mandal, D., 2018. All-organic high-performance piezoelectric nanogenerator with multilayer assembled electrospun nanofiber mats for self-powered multifunctional sensors. ACS applied materials \& interfaces 10(21), 18257-18269.

Mandal, S., Turicchia, L., Sarpeshkar, R., 2010. A low-power, battery-free tag for body sensor networks. IEEE Pervasive Computing 9(1).

Mano, N., Mao, F., Heller, A., 2003. Characteristics of a miniature compartment-less glucose- 02 biofuel cell and its operation in a living plant. Journal of the American Chemical Society 125(21), 6588-6594.

Meng, K., Chen, J., Li, X., Wu, Y., Fan, W., Zhou, Z., He, Q., Wang, X., Fan, X., Zhang, Y., 2019. Flexible weaving constructed self - powered pressure sensor enabling continuous diagnosis of cardiovascular disease and measurement of cuffless blood pressure. Advanced Functional Materials 29(5), 1806388. Meng, K., Zhao, S., Zhou, Y., Wu, Y., Zhang, S., He, Q., Wang, X., Zhou, Z., Fan, W., Tan, X., 2020. A Wireless Textile-Based Sensor System for Self-Powered Personalized Health Care. Matter. Mercier, P.P., Chandrakasan, A.P., 2010. A $110 \mu \mathrm{w} 10 \mathrm{mb} / \mathrm{s}$ etextiles transceiver for body area networks with remote battery power. Solid-State Circuits Conference Digest of Technical Papers (ISSCC), 2010 IEEE International, pp. 496-497. IEEE.

Miyake, T., Haneda, K., Nagai, N., Yatagawa, Y., Onami, H., Yoshino, S., Abe, T., Nishizawa, M., 2011. Enzymatic biofuel cells designed for direct power generation from biofluids in living organisms. Energy \& Environmental Science 4(12), 5008-5012.

Moon, H., Lee, H., Kwon, J., Suh, Y.D., Kim, D.K., Ha, I., Yeo, J., Hong, S., Ko, S.H., 2017.

$\mathrm{Ag} / \mathrm{Au} /$ polypyrrole core-shell nanowire network for transparent, stretchable and flexible supercapacitor in wearable energy devices. Scientific reports 7(1), 1-10.

Niitsu, K., Kobayashi, A., Ogawa, Y., Nishizawa, M., Nakazato, K., 2015. An energy-autonomous, disposable, big-data-based supply-sensing biosensor using bio fuel cell and 0.23-V 0.25- $\mu \mathrm{m}$ Zero-Vth alldigital CMOS supply-controlled ring oscillator with inductive transmitter. Biomedical Circuits and Systems Conference (BioCAS), 2015 IEEE, pp. 1-4. IEEE.

O'hayre, R., Cha, S.-W., Colella, W., Prinz, F.B., 2016. Fuel cell fundamentals. John Wiley \& Sons.

Ó Conghaile, P., Falk, M., MacAodha, D., Yakovleva, M.E., Gonaus, C., Peterbauer, C.K., Gorton, L., Shleev, S., Leech, D., 2016. Fully enzymatic membraneless glucose | oxygen fuel cell that provides $0.275 \mathrm{~mA} \mathrm{~cm}-$ 2 in $5 \mathrm{mM}$ glucose, operates in human physiological solutions, and powers transmission of sensing data. Analytical chemistry 88(4), 2156-2163.

Olivo, J., Brunelli, D., Benini, L., 2010. A kinetic energy harvester with fast start-up for wearable bodymonitoring sensors. 2010 4th International Conference on Pervasive Computing Technologies for Healthcare, pp. 1-7. IEEE.

Olivo, J., Carrara, S., De Micheli, G., 2011. Energy harvesting and remote powering for implantable biosensors. IEEE Sensors Journal 11(7), 1573-1586.

Oncescu, V., Erickson, D., 2011. A microfabricated low cost enzyme-free glucose fuel cell for powering low-power implantable devices. Journal of Power Sources 196(22), 9169-9175.

Orecchini, G., Yang, L., Tentzeris, M., Roselli, L., 2011. Wearable battery-free active paper printed RFID tag with human-energy scavenger. 2011 IEEE MTT-S International Microwave Symposium, pp. 1-4. IEEE. Otal, B., Alonso, L., Verikoukis, C., 2009. Highly reliable energy-saving MAC for wireless body sensor networks in healthcare systems. IEEE Journal on Selected Areas in Communications 27(4). 
Ouchi, K., Suzuki, T., Doi, M., 2002. Lifeminder: A wearable healthcare support system using user's context. Distributed Computing Systems Workshops, 2002. Proceedings. 22nd International Conference on, pp. 791-792. IEEE.

Oudenhoven, J., Vullers, R., Van Schaijk, R., 2012. A review of the present situation and future developments of micro - batteries for wireless autonomous sensor systems. International Journal of Energy Research 36(12), 1139-1150.

Palchoudhury, S., Ramasamy, K., Gupta, R.K., Gupta, A., 2019. Flexible supercapacitors: a materials perspective. Frontiers in Materials 5, 83.

Pan, W., Wang, Y., Zhang, Y., Kwok, H.Y.H., Wu, M., Zhao, X., Leung, D.Y., 2019. A low-cost and dendritefree rechargeable aluminium-ion battery with superior performance. Journal of Materials Chemistry $A$ 7(29), 17420-17425.

Park, J., Park, M., Nam, G., Lee, J.s., Cho, J., 2015. All - solid - state cable - type flexible zinc - air battery. Advanced Materials 27(8), 1396-1401.

Park, S., Heo, S.W., Lee, W., Inoue, D., Jiang, Z., Yu, K., Jinno, H., Hashizume, D., Sekino, M., Yokota, T., 2018. Self-powered ultra-flexible electronics via nano-grating-patterned organic photovoltaics. Nature 561(7724), 516-521.

Patel, M., Wang, J., 2010. Applications, challenges, and prospective in emerging body area networking technologies. IEEE Wireless communications 17(1).

Peng, H.-J., Huang, J.-Q., Zhang, Q., 2017. A review of flexible lithium-sulfur and analogous alkali metalchalcogen rechargeable batteries. Chemical Society Reviews 46(17), 5237-5288.

$\mathrm{Pu}, \mathrm{X}$., Li, L., Liu, M., Jiang, C., Du, C., Zhao, Z., Hu, W., Wang, Z.L., 2016. Wearable self - charging power textile based on flexible yarn supercapacitors and fabric nanogenerators. Advanced Materials 28(1), 98105.

Rapoport, B.I., Kedzierski, J.T., Sarpeshkar, R., 2012. A glucose fuel cell for implantable brain-machine interfaces. PloS one 7(6), e38436.

Rasmussen, M., Ritzmann, R.E., Lee, I., Pollack, A.J., Scherson, D., 2012. An implantable biofuel cell for a live insect. Journal of the American Chemical Society 134(3), 1458-1460.

Romero, E., Warrington, R., Neuman, M., 2009. Energy scavenging sources for biomedical sensors. Physiological measurement 30(9), R35.

Sharma, T., Hu, Y., Stoller, M., Feldman, M., Ruoff, R.S., Ferrari, M., Zhang, X., 2011. Mesoporous silica as a membrane for ultra-thin implantable direct glucose fuel cells. Lab on a Chip 11(14), 2460-2465.

Shnayder, V., Chen, B.-r., Lorincz, K., Fulford-Jones, T.R., Welsh, M., 2005. Sensor networks for medical care.

Sim, H.J., Choi, C., Lee, D.Y., Kim, H., Yun, J.-H., Kim, J.M., Kang, T.M., Ovalle, R., Baughman, R.H., Kee, C.W., 2018. Biomolecule based fiber supercapacitor for implantable device. Nano Energy 47, 385-392. $\mathrm{Sim}$, W.Y., Kim, G.Y., Yang, S.S., 2001. Fabrication of micro power source (mps) using a micro direct methanol fuel cell (/spl mu/dmfc) for the medical application. Micro Electro Mechanical Systems, 2001. MEMS 2001. The 14th IEEE International Conference on, pp. 341-344. IEEE.

Song, J., Yang, B., Zeng, W., Peng, Z., Lin, S., Li, J., Tao, X., 2018. Highly flexible, large - area, and facile textile - based hybrid nanogenerator with cascaded piezoelectric and triboelectric units for mechanical energy harvesting. Advanced Materials Technologies 3(6), 1800016.

Southcott, M., MacVittie, K., Halámek, J., Halámková, L., Jemison, W.D., Lobel, R., Katz, E., 2013. A pacemaker powered by an implantable biofuel cell operating under conditions mimicking the human blood circulatory system-battery not included. Physical chemistry chemical physics 15(17), 6278-6283. Stetten, F., Kerzenmacher, S., Lorenz, A., Chokkalingam, V., Miyakawa, N., Zengerle, R., Ducrée, J., 2006. A one-compartment, direct glucose fuel cell for powering long-term medical implants. Micro Electro 
Mechanical Systems, 2006. MEMS 2006 Istanbul. 19th IEEE International Conference on, pp. 934-937. IEEE.

Su, H., Zhang, X., 2009. Battery-dynamics driven TDMA MAC protocols for wireless body-area monitoring networks in healthcare applications. IEEE Journal on selected areas in communications 27(4).

Su, S., Xu, Y., Wang, Y., Wang, X., Shi, L., Wu, D., Zou, P., Nairan, A., Lin, Z., Kang, F., 2019. Holey nickel nanotube reticular network scaffold for high-performance flexible rechargeable $\mathrm{Zn} / \mathrm{MnO} 2$ batteries. Chemical Engineering Journal 370, 330-336.

Su, Y., Chen, J., Wu, Z., Jiang, Y., 2015. Low temperature dependence of triboelectric effect for energy harvesting and self-powered active sensing. Applied Physics Letters 106(1), 013114.

Su, Y., Zhu, G., Yang, W., Yang, J., Chen, J., Jing, Q., Wu, Z., Jiang, Y., Wang, Z.L., 2014. Triboelectric sensor for self-powered tracking of object motion inside tubing. ACS nano 8(4), 3843-3850.

Sun, H., Zhang, Y., Zhang, J., Sun, X., Peng, H., 2017. Energy harvesting and storage in 1D devices. Nature Reviews Materials 2(6), 1-12.

Sun, J.-G., Yang, T.-N., Wang, C.-Y., Chen, L.-J., 2018. A flexible transparent one-structure tribo-piezopyroelectric hybrid energy generator based on bio-inspired silver nanowires network for biomechanical energy harvesting and physiological monitoring. Nano Energy 48, 383-390.

Tan, P., Chen, B., Xu, H., Zhang, H., Cai, W., Ni, M., Liu, M., Shao, Z., 2017. Flexible Zn-and Li-air batteries: recent advances, challenges, and future perspectives. Energy \& Environmental Science 10(10), 20562080.

Tang, Q., Yeh, M.-H., Liu, G., Li, S., Chen, J., Bai, Y., Feng, L., Lai, M., Ho, K.-C., Guo, H., 2018. Whirligiginspired triboelectric nanogenerator with ultrahigh specific output as reliable portable instant power supply for personal health monitoring devices. Nano Energy 47, 74-80.

Tao, T., Lu, S., Chen, Y., 2018. A Review of Advanced Flexible Lithium - Ion Batteries. Advanced Materials Technologies 3(9), 1700375.

Toh, W.Y., Tan, Y.K., Koh, W.S., Siek, L., 2014. Autonomous wearable sensor nodes with flexible energy harvesting. IEEE sensors journal 14(7), 2299-2306.

Torfs, T., Leonov, V., Van Hoof, C., Gyselinckx, B., 2006. Body-heat powered autonomous pulse oximeter. SENSORS, 2006 IEEE, pp. 427-430. IEEE.

Tran, T., Chung, W.-Y., 2016. High-efficient energy harvester with flexible solar panel for a wearable sensor device. IEEE Sensors Journal, vol. PP(99), 1-1.

Ullah, S., Higgins, H., Braem, B., Latre, B., Blondia, C., Moerman, I., Saleem, S., Rahman, Z., Kwak, K.S., 2012. A comprehensive survey of wireless body area networks. Journal of medical systems 36(3), 10651094.

Vieira, M.A.M., Coelho, C.N., Da Silva, D., da Mata, J.M., 2003. Survey on wireless sensor network devices. EFTA 2003. 2003 IEEE Conference on Emerging Technologies and Factory Automation. Proceedings (Cat. No. 03TH8696), pp. 537-544. IEEE.

Voss, T.J., Subbian, V., Beyette, F.R., 2014. Feasibility of energy harvesting techniques for wearable medical devices. 2014 36th Annual International Conference of the IEEE Engineering in Medicine and Biology Society, pp. 626-629. IEEE.

Vullers, R., van Schaijk, R., Doms, I., Van Hoof, C., Mertens, R., 2009. Micropower energy harvesting. Solid-State Electronics 53(7), 684-693.

Wang, M., Li, Y., Fang, J., Villa, C.J., Xu, Y., Hao, S., Li, J., Liu, Y., Wolverton, C., Chen, X., 2020. Superior Oxygen Reduction Reaction on Phosphorus - Doped Carbon Dot/Graphene Aerogel for All - Solid State Flexible Al - Air Batteries. Advanced Energy Materials 10(3), 1902736.

Wang, S.-W., Im, J.-P., Cho, G.-H., 2011. Dual-input dual-output energy harvesting DC-DC boost converter for wireless body area network. 2011 IEEE Biomedical Circuits and Systems Conference (BioCAS), pp. 217-220. IEEE. 
Wang, S., Wang, Z.L., Yang, Y., 2016a. A one - structure - based hybridized nanogenerator for scavenging mechanical and thermal energies by triboelectric - piezoelectric - pyroelectric effects. Advanced Materials 28(15), 2881-2887.

Wang, Y., Chen, C., Xie, H., Gao, T., Yao, Y., Pastel, G., Han, X., Li, Y., Zhao, J., Fu, K., 2017a. 3D - Printed All - Fiber Li - Ion Battery toward Wearable Energy Storage. Advanced Functional Materials 27(43), 1703140.

Wang, Y., Kwok, H.Y., Pan, W., Zhang, Y., Zhang, H., Lu, X., Leung, D.Y., 2019a. Combining Al-air battery with paper-making industry, a novel type of flexible primary battery technology. Electrochimica Acta 319, 947-957.

Wang, Y., Kwok, H.Y., Zhang, Y., Pan, W., Zhang, H., Lu, X., Leung, D.Y., 2019b. A flexible paper-based hydrogen fuel cell for small power applications. International Journal of Hydrogen Energy 44(56), 2968029691.

Wang, Y., Leung, D.Y., Xuan, J., Wang, H., 2016b. A review on unitized regenerative fuel cell technologies, part-A: Unitized regenerative proton exchange membrane fuel cells. Renewable and Sustainable Energy Reviews 65, 961-977.

Wang, Y., Leung, D.Y., Xuan, J., Wang, H., 2017b. A review on unitized regenerative fuel cell technologies, part B: Unitized regenerative alkaline fuel cell, solid oxide fuel cell, and microfluidic fuel cell. Renewable and Sustainable Energy Reviews 75, 775-795.

Wang, Y., Pan, W., Kwok, H.Y., Zhang, H., Lu, X., Leung, D.Y., 2019c. Liquid-free Al-air batteries with paper-based gel electrolyte: A green energy technology for portable electronics. Journal of Power Sources 437, 226896.

Wang, Z., Leonov, V., Fiorini, P., Van Hoof, C., 2007. Micromachined thermopiles for energy scavenging on human body. TRANSDUCERS 2007-2007 International Solid-State Sensors, Actuators and Microsystems Conference, pp. 911-914. IEEE.

Wang, Z., Leonov, V., Fiorini, P., Van Hoof, C., 2009. Realization of a wearable miniaturized thermoelectric generator for human body applications. Sensors and Actuators A: Physical 156(1), 95-102. Wang, Z., Mo, F., Ma, L., Yang, Q., Liang, G., Liu, Z., Li, H., Li, N., Zhang, H., Zhi, C., 2018. Highly Compressible Cross-Linked Polyacrylamide Hydrogel-Enabled Compressible Zn-MnO2 Battery and a Flexible Battery-Sensor System. ACS applied materials \& interfaces 10(51), 44527-44534.

Wang, Z.L., Chen, J., Lin, L., 2015. Progress in triboelectric nanogenerators as a new energy technology and self-powered sensors. Energy \& Environmental Science 8(8), 2250-2282.

Wang, Z.L., Song, J., 2006. Piezoelectric nanogenerators based on zinc oxide nanowire arrays. Science 312(5771), 242-246.

Wei, X., Liu, J., 2008. Power sources and electrical recharging strategies for implantable medical devices. Frontiers of Energy and Power Engineering in China 2(1), 1-13.

Weidlich, E., Richter, G., Von Sturm, F., Rao, J., Thoren, A., Lagergren, H., 1976. Animal experiments with biogalvanic and biofuel cells. Biomaterials, medical devices, and artificial organs 4(3-4), 277-306.

Wen, Z., Yeh, M.-H., Guo, H., Wang, J., Zi, Y., Xu, W., Deng, J., Zhu, L., Wang, X., Hu, C., 2016. Selfpowered textile for wearable electronics by hybridizing fiber-shaped nanogenerators, solar cells, and supercapacitors. Science advances 2(10), e1600097.

Wu, N., Cheng, X., Zhong, Q., Zhong, J., Li, W., Wang, B., Hu, B., Zhou, J., 2015a. Cellular polypropylene piezoelectret for human body energy harvesting and health monitoring. Advanced Functional Materials 25(30), 4788-4794.

Wu, T., Wu, F., Redouté, J.-M., Yuce, M.R., 2017. An autonomous wireless body area network implementation towards IoT connected healthcare applications. IEEE Access 5, 11413-11422. 
Wu, Y., Jing, Q., Chen, J., Bai, P., Bai, J., Zhu, G., Su, Y., Wang, Z.L., 2015b. A self - powered angle measurement sensor based on triboelectric nanogenerator. Advanced Functional Materials 25(14), 2166-2174.

Xia, K., Zhu, Z., Zhang, H., Xu, Z., 2018. A triboelectric nanogenerator as self-powered temperature sensor based on PVDF and PTFE. Applied Physics A 124(8), 520.

Xia, L., Cheng, J., Glover, N.E., Chiang, P., 2014. 0.56 V,-20 dBm RF-powered, multi-node wireless body area network system-on-a-chip with harvesting-efficiency tracking loop. IEEE Journal of Solid-State Circuits 49(6), 1345-1355.

Xing, J., Zhu, Y., 2009. A survey on body area network. Wireless Communications, Networking and Mobile Computing, 2009. WiCom'09. 5th International Conference on, pp. 1-4. IEEE.

Xu, Y., Zhang, Y., Guo, Z., Ren, J., Wang, Y., Peng, H., 2015. Flexible, Stretchable, and Rechargeable Fiber - Shaped Zinc - Air Battery Based on Cross - Stacked Carbon Nanotube Sheets. Angewandte Chemie International Edition 54(51), 15390-15394.

Xu, Y., Zhao, Y., Ren, J., Zhang, Y., Peng, H., 2016. An all - solid - state fiber - shaped aluminum - air battery with flexibility, stretchability, and high electrochemical performance. Angewandte Chemie International Edition 55(28), 7979-7982.

Xue, H., Yang, Q., Wang, D., Luo, W., Wang, W., Lin, M., Liang, D., Luo, Q., 2017. A wearable pyroelectric nanogenerator and self-powered breathing sensor. Nano Energy 38, 147-154.

Yamada, T., Uezono, T., Sugawara, H., Okada, K., Masu, K., Oki, A., Horiike, Y., 2004. Battery-less wireless communication system through human body for in-vivo healthcare chip. Silicon Monolithic Integrated Circuits in RF Systems, 2004. Digest of Papers. 2004 Topical Meeting on, pp. 322-325. IEEE.

Yan, C., Deng, W., Jin, L., Yang, T., Wang, Z., Chu, X., Su, H., Chen, J., Yang, W., 2018. Epidermis-inspired ultrathin 3D cellular sensor array for self-powered biomedical monitoring. ACS applied materials \& interfaces 10(48), 41070-41075.

Yan, C., Gao, Y., Zhao, S., Zhang, S., Zhou, Y., Deng, W., Li, Z., Jiang, G., Jin, L., Tian, G., 2020. A linear-torotary hybrid nanogenerator for high-performance wearable biomechanical energy harvesting. Nano Energy 67, 104235.

Yan, L., Yoo, J., Kim, B., Yoo, H.-J., 2010. A 0.5- $\mu$ Vrms 12- $\mu$ W Wirelessly Powered Patch-Type Healthcare Sensor for Wearable Body Sensor Network. IEEE Journal of Solid-State Circuits 45(11), 2356-2365. Yang, G.-Z., Yang, G., 2006. Body sensor networks. Springer.

Yang, J., Chen, J., Liu, Y., Yang, W., Su, Y., Wang, Z.L., 2014a. Triboelectrification-based organic film nanogenerator for acoustic energy harvesting and self-powered active acoustic sensing. ACS nano 8(3), 2649-2657.

Yang, J., Chen, J., Su, Y., Jing, Q., Li, Z., Yi, F., Wen, X., Wang, Z., Wang, Z.L., 2015. Eardrum - Inspired active sensors for self - powered cardiovascular system characterization and throat - attached anti Interference voice recognition. Advanced Materials 27(8), 1316-1326.

Yang, J., Chen, J., Yang, Y., Zhang, H., Yang, W., Bai, P., Su, Y., Wang, Z.L., 2014b. Broadband vibrational energy harvesting based on a triboelectric nanogenerator. Advanced Energy Materials 4(6), 1301322.

Yang, L., Zhou, Y.J., Zhang, C., Yang, X.M., Yang, X.-X., Tan, C., 2018. Compact multiband wireless energy harvesting based battery-free body area networks sensor for mobile healthcare. IEEE Journal of Electromagnetics, RF and Microwaves in Medicine and Biology 2(2), 109-115.

Yang, W., Chen, J., Jing, Q., Yang, J., Wen, X., Su, Y., Zhu, G., Bai, P., Wang, Z.L., 2014c. 3D stack integrated triboelectric nanogenerator for harvesting vibration energy. Advanced Functional Materials 24(26), 4090-4096.

Yang, W., Chen, J., Wen, X., Jing, Q., Yang, J., Su, Y., Zhu, G., Wu, W., Wang, Z.L., 2014d. Triboelectrification based motion sensor for human-machine interfacing. ACS applied materials \& interfaces 6(10), 7479-7484. 
Yang, W., Chen, J., Zhu, G., Wen, X., Bai, P., Su, Y., Lin, Y., Wang, Z., 2013a. Harvesting vibration energy by a triple-cantilever based triboelectric nanogenerator. Nano Research 6(12), 880-886.

Yang, W., Chen, J., Zhu, G., Yang, J., Bai, P., Su, Y., Jing, Q., Cao, X., Wang, Z.L., 2013b. Harvesting energy from the natural vibration of human walking. ACS nano 7(12), 11317-11324.

Yang, Y., Guo, W., Pradel, K.C., Zhu, G., Zhou, Y., Zhang, Y., Hu, Y., Lin, L., Wang, Z.L., 2012a. Pyroelectric nanogenerators for harvesting thermoelectric energy. Nano letters 12(6), 2833-2838.

Yang, Y., Wang, S., Zhang, Y., Wang, Z.L., 2012b. Pyroelectric nanogenerators for driving wireless sensors. Nano letters 12(12), 6408-6413.

Yang, Y., Wei, X.-J., Liu, J., 2007. Suitability of a thermoelectric power generator for implantable medical electronic devices. Journal of Physics D: Applied Physics 40(18), 5790.

Yang, Y., Zhang, H., Chen, J., Lee, S., Hou, T.-C., Wang, Z.L., 2013c. Simultaneously harvesting mechanical and chemical energies by a hybrid cell for self-powered biosensors and personal electronics. Energy \& Environmental Science 6(6), 1744-1749.

Yang, Y., Zhang, H., Lin, Z.-H., Liu, Y., Chen, J., Lin, Z., Zhou, Y.S., Wong, C.P., Wang, Z.L., 2013d. A hybrid energy cell for self-powered water splitting. Energy \& Environmental Science 6(8), 2429-2434.

Yang, Y., Zhang, H., Lin, Z.-H., Zhou, Y.S., Jing, Q., Su, Y., Yang, J., Chen, J., Hu, C., Wang, Z.L., $2013 e$. Human skin based triboelectric nanogenerators for harvesting biomechanical energy and as selfpowered active tactile sensor system. ACS nano 7(10), 9213-9222.

Yang, Y., Zhou, Y., Wu, J.M., Wang, Z.L., 2012c. Single micro/nanowire pyroelectric nanogenerators as self-powered temperature sensors. ACS nano 6(9), 8456-8461.

Yao, S.-C., Tang, X., Hsieh, C.-C., Alyousef, Y., Vladimer, M., Fedder, G.K., Amon, C.H., 2006. Microelectro-mechanical systems (MEMS)-based micro-scale direct methanol fuel cell development. Energy 31(5), 636-649.

Yoon, G.C., Shin, K.-S., Gupta, M.K., Lee, K.Y., Lee, J.-H., Wang, Z.L., Kim, S.-W., 2015. High-performance hybrid cell based on an organic photovoltaic device and a direct current piezoelectric nanogenerator. Nano Energy 12, 547-555.

Yu, D., Qian, Q., Wei, L., Jiang, W., Goh, K., Wei, J., Zhang, J., Chen, Y., 2015. Emergence of fiber supercapacitors. Chemical Society Reviews 44(3), 647-662.

Yu, K., Rich, S., Lee, S., Fukuda, K., Yokota, T., Someya, T., 2019a. Organic photovoltaics: Toward selfpowered wearable electronics. Proceedings of the IEEE 107(10), 2137-2154.

Yu, P., Zeng, Y., Zhang, H., Yu, M., Tong, Y., Lu, X., 2019b. Flexible Zn - Ion Batteries: Recent Progresses and Challenges. Small 15(7), 1804760.

Yu, X., Fu, Y., Cai, X., Kafafy, H., Wu, H., Peng, M., Hou, S., Lv, Z., Ye, S., Zou, D., 2013. Flexible fiber-type zinc-carbon battery based on carbon fiber electrodes. Nano Energy 2(6), 1242-1248.

Yu, Z., Jiao, S., Li, S., Chen, X., Song, W.L., Teng, T., Tu, J., Chen, H.S., Zhang, G., Fang, D.N., 2019c. Flexible Stable Solid - State Al - Ion Batteries. Advanced Functional Materials 29(1), 1806799.

Yuce, M.R., Ng, S.W., Myo, N.L., Khan, J.Y., Liu, W., 2007. Wireless body sensor network using medical implant band. Journal of Medical Systems 31(6), 467-474.

Zaghib, K., Dontigny, M., Guerfi, A., Charest, P., Rodrigues, I., Mauger, A., Julien, C.M., 2011. Safe and fast-charging Li-ion battery with long shelf life for power applications. Journal of Power Sources 196(8), 3949-3954.

Zeng, Y., Zhang, X., Qin, R., Liu, X., Fang, P., Zheng, D., Tong, Y., Lu, X., 2019. Dendrite - Free Zinc Deposition Induced by Multifunctional CNT Frameworks for Stable Flexible Zn - Ion Batteries. Advanced Materials 31(36), 1903675.

Zhai, S., Karahan, H.E., Wei, L., Qian, Q., Harris, A.T., Minett, A.I., Ramakrishna, S., Ng, A.K., Chen, Y., 2016. Textile energy storage: structural design concepts, material selection and future perspectives. Energy Storage Materials 3, 123-139. 
Zhang, B., Chen, J., Jin, L., Deng, W., Zhang, L., Zhang, H., Zhu, M., Yang, W., Wang, Z.L., 2016a. Rotatingdisk-based hybridized electromagnetic-triboelectric nanogenerator for sustainably powering wireless traffic volume sensors. ACS nano 10(6), 6241-6247.

Zhang, H., Yang, Y., Su, Y., Chen, J., Adams, K., Lee, S., Hu, C., Wang, Z.L., 2014a. Triboelectric nanogenerator for harvesting vibration energy in full space and as self - powered acceleration sensor. Advanced Functional Materials 24(10), 1401-1407.

Zhang, L., Zhang, B., Chen, J., Jin, L., Deng, W., Tang, J., Zhang, H., Pan, H., Zhu, M., Yang, W., $2016 b$. Lawn structured triboelectric nanogenerators for scavenging sweeping wind energy on rooftops. Advanced Materials 28(8), 1650-1656.

Zhang, M., Gao, T., Wang, J., Liao, J., Qiu, Y., Yang, Q., Xue, H., Shi, Z., Zhao, Y., Xiong, Z., 2015. A hybrid fibers based wearable fabric piezoelectric nanogenerator for energy harvesting application. Nano Energy 13, 298-305.

Zhang, N., Chen, J., Huang, Y., Guo, W., Yang, J., Du, J., Fan, X., Tao, C., 2016c. A wearable all - solid photovoltaic textile. Advanced Materials 28(2), 263-269.

Zhang, N., Huang, F., Zhao, S., Lv, X., Zhou, Y., Xiang, S., Xu, S., Li, Y., Chen, G., Tao, C., 2020. PhotoRechargeable Fabrics as Sustainable and Robust Power Sources for Wearable Bioelectronics. Matter. Zhang, N., Tao, C., Fan, X., Chen, J., 2017. Progress in triboelectric nanogenerators as self-powered smart sensors. Journal of Materials Research 32(9), 1628-1646.

Zhang, T., Lu, J., Hu, F., Hao, Q., 2014b. Bluetooth low energy for wearable sensor-based healthcare systems. Healthcare Innovation Conference (HIC), 2014 IEEE, pp. 251-254. IEEE.

Zhang, X., Jiang, H., Zhang, L., Zhang, C., Wang, Z., Chen, X., 2010. An energy-efficient ASIC for wireless body sensor networks in medical applications. IEEE transactions on biomedical circuits and systems 4(1), 11-18.

Zhang, Y., Wang, L., Guo, Z., Xu, Y., Wang, Y., Peng, H., 2016d. High - performance lithium - air battery with a coaxial - fiber architecture. Angewandte Chemie International Edition 55(14), 4487-4491.

Zhang, Y., Zhang, F., Shakhsheer, Y., Silver, J.D., Klinefelter, A., Nagaraju, M., Boley, J., Pandey, J., Shrivastava, A., Carlson, E.J., 2013. A Batteryless 19\$mu \$ W MICS/ISM-Band Energy Harvesting Body Sensor Node SoC for ExG Applications. IEEE Journal of Solid-State Circuits 48(1), 199-213.

Zhang, Y., Zhao, Y., Ren, J., Weng, W., Peng, H., 2016e. Advances in Wearable Fiber - Shaped Lithium Ion Batteries. Advanced Materials 28(22), 4524-4531.

Zheng, L., Cheng, G., Chen, J., Lin, L., Wang, J., Liu, Y., Li, H., Wang, Z.L., 2015. A hybridized power panel to simultaneously generate electricity from sunlight, raindrops, and wind around the clock. Advanced Energy Materials 5(21), 1501152.

Zheng, Q., Shi, B., Fan, F., Wang, X., Yan, L., Yuan, W., Wang, S., Liu, H., Li, Z., Wang, Z.L., 2014. In vivo powering of pacemaker by breathing - driven implanted triboelectric nanogenerator. Advanced materials 26(33), 5851-5856.

Zhou, T., Zhang, C., Han, C.B., Fan, F.R., Tang, W., Wang, Z.L., 2014. Woven structured triboelectric nanogenerator for wearable devices. ACS applied materials \& interfaces 6(16), 14695-14701.

Zhou, Z., Padgett, S., Cai, Z., Conta, G., Wu, Y., He, Q., Zhang, S., Sun, C., Liu, J., Fan, E., 2020. Singlelayered ultra-soft washable smart textiles for all-around ballistocardiograph, respiration, and posture monitoring during sleep. Biosensors and Bioelectronics 155, 112064.

Zhu, G., Bai, P., Chen, J., Wang, Z.L., 2013a. Power-generating shoe insole based on triboelectric nanogenerators for self-powered consumer electronics. Nano Energy 2(5), 688-692.

Zhu, G., Chen, J., Liu, Y., Bai, P., Zhou, Y.S., Jing, Q., Pan, C., Wang, Z.L., 2013b. Linear-grating triboelectric generator based on sliding electrification. Nano letters 13(5), 2282-2289.

Zhu, G., Chen, J., Zhang, T., Jing, Q., Wang, Z.L., 2014a. Radial-arrayed rotary electrification for high performance triboelectric generator. Nature communications 5, 3426. 
Zhu, G., Peng, B., Chen, J., Jing, Q., Wang, Z.L., 2015. Triboelectric nanogenerators as a new energy technology: from fundamentals, devices, to applications. Nano Energy 14, 126-138.

Zhu, G., Zhou, Y.S., Bai, P., Meng, X.S., Jing, Q., Chen, J., Wang, Z.L., 2014b. A shape - adaptive thin - film - based approach for $50 \%$ high - efficiency energy generation through micro - grating sliding electrification. Advanced materials 26(23), 3788-3796.

Zi, Y., Lin, L., Wang, J., Wang, S., Chen, J., Fan, X., Yang, P.K., Yi, F., Wang, Z.L., 2015. Triboelectric pyroelectric - piezoelectric hybrid cell for high - efficiency energy - harvesting and self - powered sensing. Advanced materials 27(14), 2340-2347. 